\title{
SISTEMA INFORMATIZADO PARA PROJETO DE ESTRUTURAS INDUSTRIALIZADAS DE MADEIRA PARA TELHADOS
}

\section{HENRIQUE PARTEL}

Dissertação apresentada à Escola de Engenharia de São Carlos da Universidade de São Paulo, como parte dos requisitos para obtenção do título de Mestre em Engenharia de Estruturas.

ORIENTADOR: Prof. Dr. Antonio Alves Dias 
Giase. TESE-EEX
Tombo $\frac{1227}{039 / 01}$

Ficha catalográfica preparada pela Seção de Tratamento da Informação do Serviço de Biblioteca - EESC/USP

\begin{tabular}{|c|c|}
\hline \multirow[t]{3}{*}{ P273s } & $\begin{array}{l}\text { Partel, Henrique } \\
\quad \text { Sistema informatizado para projeto de estruturas } \\
\text { industrializadas de madeira para telhados / Henrique } \\
\text { Partel. -- São Carlos, } 2000 .\end{array}$ \\
\hline & $\begin{array}{l}\text { Dissertação (Mestrado) -- Escola de Engenharia de } \\
\text { São Carlos-Universidade de São Paulo, } 2000 . \\
\text { Área: Engenharia de Estruturas. } \\
\text { Orientador: Prof. Dr. Antonio Alves Dias. }\end{array}$ \\
\hline & $\begin{array}{l}\text { 1. Estruturas de madeira. 2. Treliças. } \\
\text { 3. Industrialização. 4. Software. I. Título. }\end{array}$ \\
\hline
\end{tabular}




\section{FOLHA DE APROVACÃO}

Candidato: Engenheiro HENRIQUE PARTEL

Dissertação defendida e aprovada em 20-10-2000 pela Comissão Julgadora:

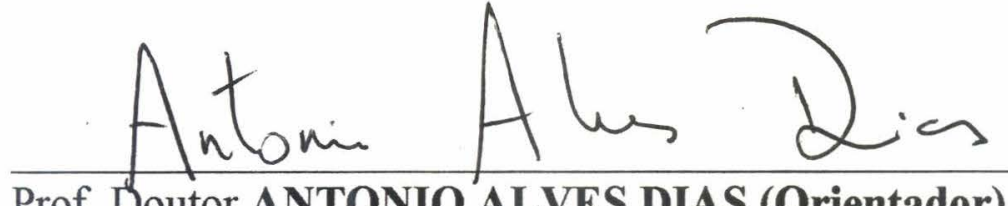

(Escola de Engenharia de São Carlos - Universidade de São Paulo)

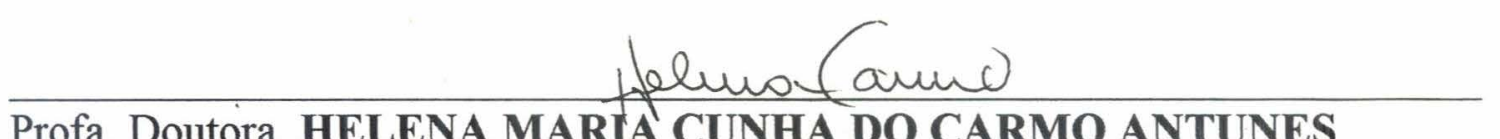

Profa. Doutora HELENA MARIA CUNHA DO CARMO ANTUNES

(Escola de Engenharia de São Carlos - Universidade de São Paulo)

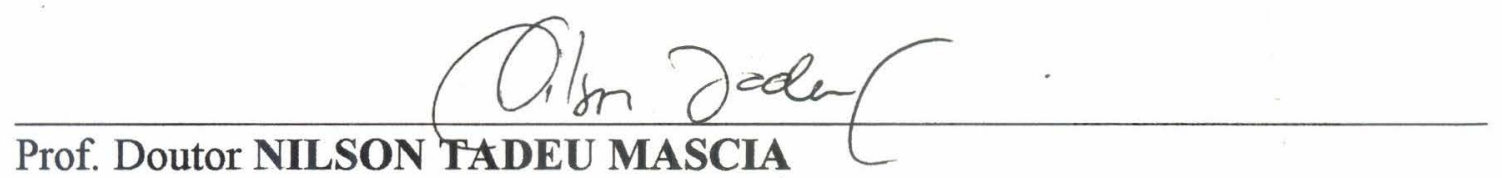

(Universidade Estadual de Campinas - UNICAMP)
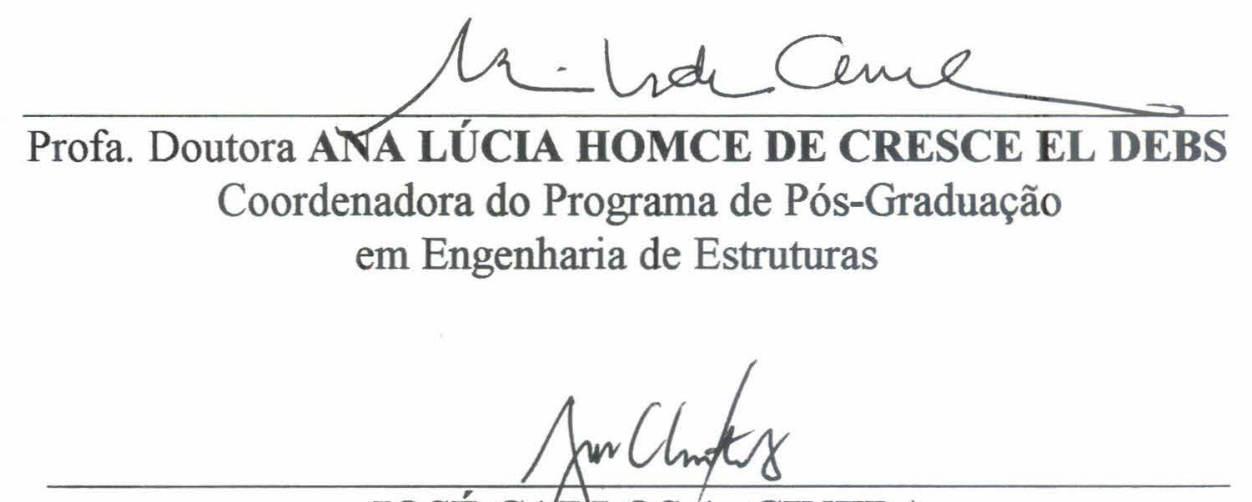

JOSÉ CARLOS A. CINTRA

Presidente da Comissão de Pós-Graduação da EESC 
Aos meus pais, Walter e Berenice,

à minha esposa Virginia,

e aos meus filhos Victor, Vinícius e Guilherme. 


\section{AGRADECIMENTOS}

Ao meu orientador, Antonio, pelo apoio, orientação segura e, sobretudo, pela amizade.

À CAPES, pelo apoio financeiro.

A todos os funcionários e professores do LaMEM, pela permanente disposição em ajudar, e pelos momentos de descontração.

Ao amigo Ricardo Montanha de Oliveira, pela imensa colaboração no trabalho.

Aos meus amigos e familiares, por estarem ao meu lado e tornarem possível este trabalho. 


\section{LISTA DE FIGURAS}

FIGURA 1 - Elementos da estrutura de cobertura $\quad 07$

FIGURA 2 - Elementos da geometria da cobertura 09

FIGURA 3 - Estrutura de cobertura no sistema convencional 10

FIGURA 4 - Estrutura de cobertura no sistema pré-fabricado 11

FIGURA 5 - Estrutura de cobertura no sistema intermediário 12

FIGURA 6 - Geometria de tesoura típica de cobertura industrializada 13

$\begin{array}{ll}\text { FIGURA } 7 \text { - Geometria de tesoura definida por dados numéricos } & 14\end{array}$

$\begin{array}{ll}\text { FIGURA } 8 \text { - Coordenadas globais } & 17\end{array}$

FIGURA 9 - Coordenadas locais segundo sistema de referência global 18

FIGURA 10 - Coordenadas locais segundo sistema de referência local 18

FIGURA 11 - Flexão Oblíqua em viga biapoiada $\quad 21$

FIGURA 12 - Flexo compressão em viga biapoiada $\quad 21$

FIGURA 13 - Redução da área líquida de conectores $\quad 42$

FIGURA 14 - Diagrama de contexto $\quad 44$

FIGURA 15 - Diagrama de fluxo de dados - Visão global do sistema 45

FIGURA 16 - Diagrama de fluxo de dados - Módulo $1 \quad 46$

FIGURA 17 - Diagrama de fluxo de dados - Módulo $2 \quad 47$

FIGURA 18 - Diagrama de fluxo de dados - Módulo $3 \quad 48$

FIGURA 19 - Diagrama de fluxo de dados - Módulo $4 \quad 50$

FIGURA 20 - Esforços de momento e cortante nas extremidades de uma barra 51

FIGURA 21 - Diagrama de fluxo de dados - Módulo 5

FIGURA 22 - Diagrama de fluxo de dados - Módulo 5.1

FIGURA 23 - Diagrama de fluxo de dados - Módulo $5.2 \quad 55$

FIGURA 24 - Diagrama de fluxo de dados - Módulo $5.3 \quad 57$

FIGURA 25 - Diagrama de fluxo de dados - Módulo 5.4

FIGURA 26 - Tela de apresentação do software 63

FIGURA 27 - Geometria da estrutura $\quad 64$ 
FIGURA 28 - Seções transversais dos elementos da estrutura $\quad 64$

FIGURA 29 - Condição de apoio das tesouras $\quad 65$

FIGURA 30 - Características de materiais para a estrutura $\quad 65$

FIGURA 31 - Ações permanentes nas tesouras $\quad 66$

FIGURA 32 - Ações de vento de sobrepressão nas tesouras $\quad 66$

FIGURA 33 - Ações de vento de sucção nas tesouras $\quad 67$

FIGURA 34 - Ações acidentais nas tesouras $\quad 67$

FIGURA 35 - Ações em terças e caibros da estrutura $\quad 68$

FIGURA 36 - Impressão de relatório $\quad 68$ 
LISTA DE TABELAS

TABELA 1 - Classes de resistência das coníferas $\quad 26$

TABELA 2 - Classes de resistência das dicotiledôneas $\quad 26$

$\begin{array}{ll}\text { TABELA } 3 \text { - Classes de umidade } & 28\end{array}$ 
LISTA DE ABREVIATURAS E SIGLAS

ABNT - Associação Brasileira de Normas Técnicas
NBR - Norma Brasileira Registrada
ABCI - Associação Brasileira de Construções Industrializadas 


\section{LISTA DE SÍMBOLOS}

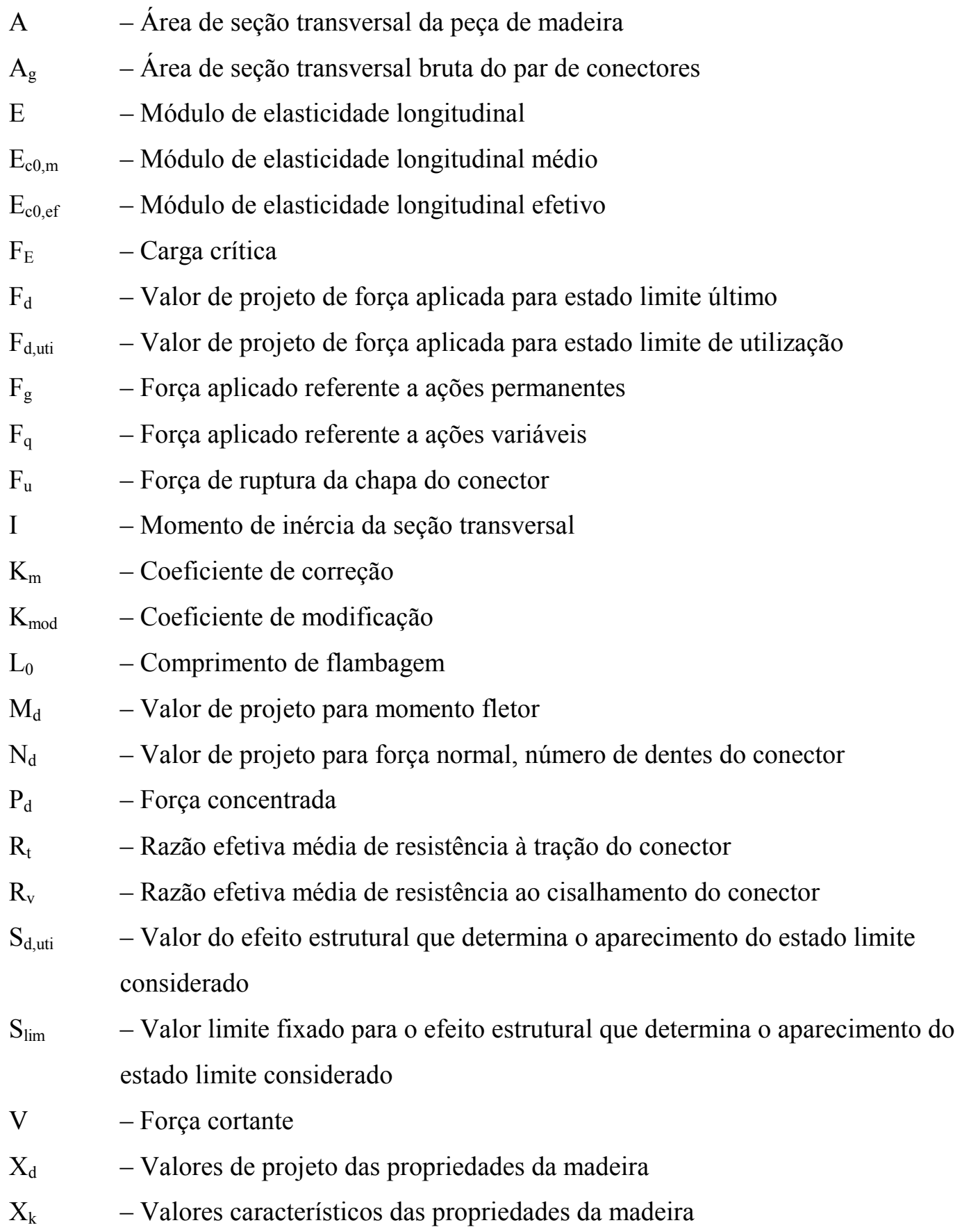


b $\quad$ - Largura da seção transversal

$\mathrm{e}_{\mathrm{a}} \quad-$ Excentricidade acidental

$\mathrm{e}_{\mathrm{c}}-$ Excentricidade suplementar de $1^{\mathrm{a}}$ ordem para fluência da madeira

$\mathrm{e}_{\mathrm{d}} \quad-$ Excentricidade de cálculo

$\mathrm{e}_{\mathrm{i}}-$ Excentricidade de $1^{\mathrm{a}}$ ordem decorrente da situação de projeto

$\mathrm{e}_{1}-$ Excentricidade de $1^{\mathrm{a}}$ ordem

$\mathrm{f}_{\mathrm{ad}} \quad-$ Resistência de cálculo para arrancamento de conectores

$\mathrm{f}_{\mathrm{c} 0, \mathrm{~d}} \quad-$ Resistência de cálculo à compressão paralela

$\mathrm{f}_{\mathrm{st}} \quad-$ Tensão máxima de serviço para a chapa

$\mathrm{f}_{\mathrm{td}} \quad-$ Resistência de cálculo para tração de conectores

$\mathrm{f}_{\mathrm{t} 0, \mathrm{~d}} \quad-$ Resistência de cálculo à tração paralela

$\mathrm{f}_{\mathrm{tu}}-$ Resistência à tração última do conector

$\mathrm{f}_{\text {tub }}-$ Resistência à tração última do metal base

$\mathrm{f}_{\mathrm{v} 0, \mathrm{~d}} \quad-$ Resistência de cálculo ao cisalhamento

$\mathrm{f}_{\mathrm{vd}} \quad-$ Resistência de cálculo para cisalhamento de conectores

$\mathrm{f}_{\mathrm{vub}} \quad-$ Resistência ao cisalhamento última do metal base

$\mathrm{f}_{\mathrm{y}} \quad-$ Resistência característica da chapa

$\mathrm{f}_{\mathrm{wd}}-$ Resistência de cálculo à tração ou compressão, conforme a borda verificada

h $\quad-$ Altura da seção transversal

$\mathrm{i}_{\min } \quad-$ Raio de giração mínimo

$\mathrm{p}_{\mathrm{d}} \quad-$ Força distribuída

$\mathrm{t}_{1}-$ Espessura efetiva do conector

$\mathrm{v}_{\mathrm{d}} \quad-$ Flecha na peça de madeira devido a carga distribuída

$\mathrm{v}_{\mathrm{c}} \quad-$ Flecha na peça de madeira devido a carga concentrada

x $\quad-$ Coordenada

y $\quad-$ Coordenada

$\psi_{0} \quad$-Fator de combinação para ações variáveis secundárias

$\psi_{1}, \psi_{2} \quad$ - Fator de utilização para as combinações de ações em ELUti

$\phi \quad-$ Coeficiente de fluência

$\gamma_{\mathrm{g}} \quad-$ Coeficiente de ponderação para ações permanentes

$\gamma_{\mathrm{q}} \quad$ - Coeficiente de ponderação para ações variáveis

$\gamma_{\mathrm{w}}-$ Coeficiente de minoração da resistência da madeira

$\lambda \quad-$ Índice de esbeltez

$\pi \quad-$ constante $=3,14159$ 
$\sigma_{\mathrm{c} 0, \mathrm{~d}} \quad-$ Valor de cálculo para tensão de compressão paralela

$\sigma_{\mathrm{cl} 1, \mathrm{~d}} \quad-$ Valor de cálculo para tensão na borda mais comprimida da seção transversal

$\sigma_{\mathrm{Mx}, \mathrm{d}}, \quad-$ Valor de cálculo para tensões devidas à flexão segundo às direções principais

$\sigma_{\mathrm{My}, \mathrm{d}}$

$\sigma_{\mathrm{Nd}}-$ Valor de cálculo para tensão de compressão devido a força normal de compressão

$\sigma_{\mathrm{t} 0, \mathrm{~d}} \quad-$ Valor de cálculo para tensão de tração paralela

$\sigma_{\mathrm{t} 2, \mathrm{~d}}-$ Valor de cálculo para tensão na borda mais tracionada da seção transversal

$\sigma_{\mathrm{Md}} \quad-$ Valor de cálculo para tensão de compressão devido ao momento fletor

$\tau_{\mathrm{d}} \quad-$ Valor de projeto para tensão tangencial 


\section{RESUMO}

A norma brasileira para projeto de estruturas de madeira foi revisada recentemente para considerar critérios de dimensionamento baseados no método dos estados limites. Com isto ocorreu uma alteração fundamental no processo de dimensionamento de elementos estruturais de madeira.

O objetivo deste trabalho é identificar os aspectos pertinentes do processo de dimensionamento de estruturas treliçadas industrializadas de madeira para telhados, e desenvolver um software para determinar as solicitações de cálculo e verificação dos estados limites últimos e de utilização de elementos estruturais (barras de tesouras, ligações entre barras de tesouras por conectores metálicos com dentes estampados (CDE), terças e caibros) baseadas na norma NBR 7190 - Projeto de Estruturas de Madeira da Associação Brasileira de Normas Técnicas (1997).

Palavras chave: estruturas de madeira, treliças, industrialização, software. 


\begin{abstract}
The brazilian code for design of timber structures were recently revised to consider the concepts of limit states design. There was a fundamental alteration in the process for design of wooden structures.

The aim of this study is the identification of the pertinent aspects of the design process for industrialized trussed timber structures for roofing, and the development of a software for structural analysis and design of structural members (truss members, metal plate connected joints, purlins and rafters) based on the standard NBR 7190 - Projeto de Estruturas de Madeira - Associação Brasileira de Normas Técnicas (1997).
\end{abstract}

Keywords: wood structures, trusses, industrialization, software. 


\section{SUMÁRIO}

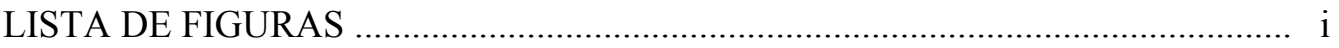

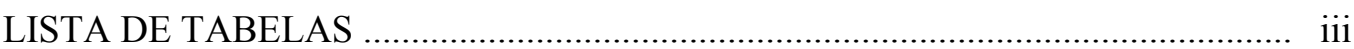

LISTA DE ABREVIATURAS E SIGLAS ………........................................... iv

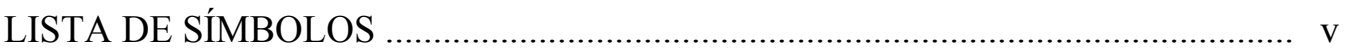

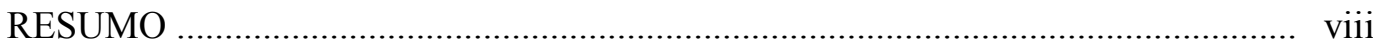

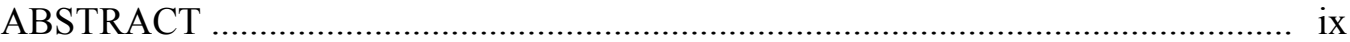

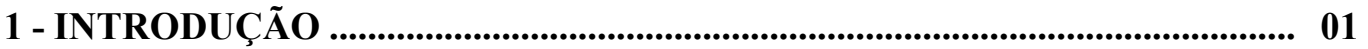

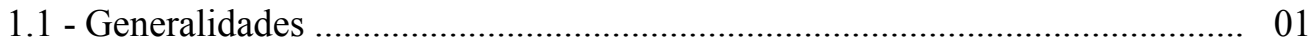

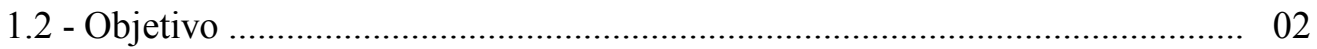

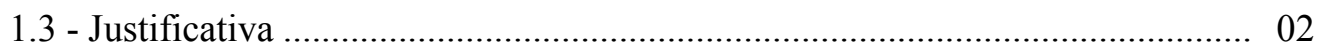

2 - REVISÃO BIBLIOGRÁFICA _...................................................................... 04

2.1 - Aspectos referentes à industrialização das construções ................................... 04

2.2 - Aspectos referentes a estruturas treliçadas de cobertura ................................ 07

2.2.1 - Elementos componentes da estrutura de cobertura .............................. 07

2.2.2 - Elementos da geometria da cobertura .................................................. 09

2.2.3 - Alternativas estruturais .................................................................. 10

2.2.3.1 - Sistema estrutural convencional ................................................... 10

2.2.3.2 - Sistema estrutural pré-fabricado..................................................... 11

2.2.3.3 - Sistema estrutural intermediário...................................................... 12

2.3 - Aspectos referentes ao modelo de cálculo de esforços nos elementos de estruturas de cobertura 
2.3.1 - Cálculo dos esforços nos elementos de tesouras

2.3.1.1 - Determinação da geometria das tesouras

2.3.1.2 - Modelo de cálculo dos esforços solicitantes e deslocamentos dos elementos da tesoura

2.3.1.3 - Método de cálculo dos esforços solicitantes e deslocamentos dos elementos da tesoura

2.3.2 - Cálculo dos esforços em terças ............................................................... 21

2.3.3 - Cálculo dos esforços em caibros ............................................................ 21

2.3.4 - Cálculo de esforços em ligações entre elementos da estrutura principal 22

2.4 - Aspectos referentes ao dimensionamento dos elementos de estruturas de cobertura

2.4.1 - Ações em estruturas de cobertura ......................................................... 23

2.4 .2 - Propriedades da madeira .................................................................... 26

2.4.3 - Critérios de dimensionamento de peças de madeira .............................. 29

2.4.3.1 - Estados limites últimos ............................................................. 28

2.4.3.1.1 - Compressão paralela às fibras .............................................. 29

2.4.3.1.2 - Tração paralela ..................................................................... 32

2.4.3.1.3 - Cisalhamento .................................................................... 33

2.4.3.1.4 - Flexão simples reta …………………………………........ 33

2.4.3.1.5 - Flexão composta ................................................................... 34

2.4.3.1.6 - Flexão oblíqua .................................................................. 36

2.4.3.2 - Estados limites de utilização ....................................................... 36

2.4.4 - Critérios de dimensionamento de ligações entre peças de madeira ........ 38

3 - DESENVOLVIMENTO DO SOFTWARE …..................................................4 43

3.1 - Ambiente de operação do sistema ................................................................. 43

3.2 - Desenvolvimento do algoritmo ............................................................. 43

3.2.1 - Definição da geometria da estrutura (módulo 1) ..................................... 45

3.2.2 - Definiçãa de materiais (módulo 2) …………………………………...... 46

3.2.3 - Definiçãa de ações na estrutura (módulo 3) ............................................ 47

3.2.4 - Esforços / Deslocamentos nos elementos da estrutura (módulo 4) ........ 49

3.2.5 - Verificação dimensional dos elementos da estrutura (módulo 5) ........... 52

3.2.5.1 - Verificação de barras de tesouras (módulo 5.1) ......................... 53

3.2.5.2 - Verificação de ligações entre barras de tesouras (módulo 5.3) . 55 
3.2.5.3 - Verificação de terças da estrutura (módulo 5.3) 56

3.2.5.4 - Verificação de caibros da estrutura (módulo 5.4) 58

3.2.6 - Arquivos de dados 60

3.2.7 - Relatório 60

4 - PROJETO EXEMPLO ................................................................................................. 61

4.1 - Dados básicos do projeto .................................................................... 61

4.2 - Entrada de dados pelo Software ……….................................................. 62

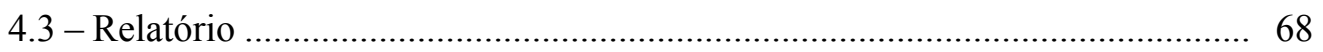

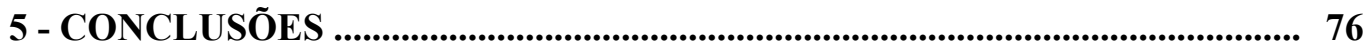

ANEXO A - MANUAL BÁSICO DE OPERAÇÃO .............................................. 77

ANEXO B - CÓDIGOS FONTE ........................................................................... 101

ANEXO C - SOFTWARE "MADEPRO" INSTALÁVEL ....................................... 102

REFERÊNCIAS BIBLIOGRÁFICAS _......................................................... 103 


\section{1 - INTRODUÇÃO}

\section{1 - GENERALIDADES}

Estruturas de coberturas de pequenos e médios vãos, principalmente as estruturas residenciais, são responsáveis por uma parcela significativa do consumo de madeira como elemento estrutural no Brasil. Em contrapartida, tais estruturas são executadas tradicionalmente por pessoal não especializado, ou seja, convencionou-se deixar a execução e até o dimensionamento empírico destas estruturas a critério dos carpinteiros.

Tal fato pode ser atribuído a alguns fatores básicos. O principal é o histórico do emprego da madeira para estruturas de cobertura, que ocorreu em larga escala numa época de abundância desta matéria prima, além da proximidade entre os grandes centros consumidores e os locais de extração, aliados ao baixo custo da mesma e da mão de obra envolvida. Estas condições deram origem à falta de conscientização de proprietários e construtores de obras que não valorizam projetos de quaisquer tipos, preferindo contratar apenas a mão de obra mais barata e com alguma experiência prática, porém sem conhecimentos técnicos. Paralelamente, deparamo-nos com o número reduzido de profissionais (arquitetos e engenheiros) interessados em calcular estruturas de madeira.

O conjunto dos fatores citados, que formaram o ambiente da utilização da madeira como elemento estrutural no Brasil, gerou um grande desperdício de madeira e, com o passar do tempo, as florestas nativas economicamente acessíveis se reduzem drasticamente. $\mathrm{O}$ aumento das distâncias das florestas remanescentes e a crescente escassez das chamadas madeiras de lei provocaram o aumento acentuado do custos destas madeiras e, consequentemente, o aumento da utilização de espécies pouco conhecidas comercialmente.

Diante da realidade de mercado com que hoje nos deparamos, e sabendo que a madeira é um material construtivo de inúmeros aspectos positivos, é evidente que os esforços que se iniciaram no sentido da industrialização da produção da madeira, com a extração programada em áreas de reflorestamento, bem como a industrialização da produção de estruturas de madeira com projetos racionalizados devem ser incentivados, tanto no 
âmbito político e social como no âmbito tecnológico, desenvolvendo-se mecanismos e ferramentas técnicas necessários ao incremento da utilização de estruturas de madeira no Brasil.

Neste contexto se insere este trabalho, buscando desenvolver ferramenta técnica para cálculo e dimensionamento de estruturas de cobertura em madeira, visando o incentivo ao crescente uso da madeira como material construtivo no Brasil.

O resultado final deste trabalho é um software de domínio público para projeto e dimensionamento de estruturas treliçadas em madeira para telhados, que servirá como ferramenta adicional ao uso de estruturas em madeira na construção civil, principalmente no ambiente de industrialização de estruturas de madeira. As recomendações para utilização, bem como as instruções para operação e considerações adotadas no desenvolvimento deste software são apresentadas em forma de anexo e devem ser parte integrante do software quando da utilização deste.

\section{2 - OBJETIVO}

O objetivo básico deste trabalho é identificar os aspectos pertinentes do processo de dimensionamento de estruturas treliçadas de madeira para telhados, e desenvolver rotinas informatizadas para determinar as solicitações de cálculo e verificar os estados limites últimos e de utilização de elementos estruturais (barras de tesouras, terças, caibros e ligações), tendo como premissa os preceitos da NBR 7190 - Projeto de Estruturas de Madeira, da Associação Brasileira de Normas Técnicas (1997). O conjunto de rotinas desenvolvidas compõe um software para projeto de estruturas industrializadas em madeira para coberturas.

\section{3 - JUSTIFICATIVA}

O primeiro texto normativo brasileiro referente ao cálculo e execução de estruturas de madeira foi homologado pela Associação Brasileira de Normas Técnicas (ABNT) em 1951, sendo reeditada em 1982, tendo a denominação de NBR 7190/82 - Cálculo e Execução de Estruturas de Madeira. Ambos tinham como base os princípios do método das tensões admissíveis. 
Em 1997 foi concluída a elaboração do novo documento normativo, denominado NBR 7190/97 - Projeto de Estruturas de Madeira, agora baseado no método dos estados limites.

Novos conceitos foram introduzidos pela NBR 7190/97, tais como as ligações através de conectores metálicos com dentes estampados, amplamente utilizados em estruturas industrializadas de telhados, excentricidades iniciais e acidentais em peças comprimidas, entre outros. A definição da espécie de madeira pelas classes de resistência, também um novo conceito introduzido pela NBR 7190/97, favorece o uso de espécies de madeira pouco conhecidas comercialmente, mas que podem ser largamente utilizadas no processo de industrialização de estruturas de madeira.

Em obras de estruturas industrializadas de madeira para telhados, nota-se o uso crescente de madeiras de reflorestamento com dimensões de seção transversal limitadas, e geometria da estrutura simplificada, em sua maior parte composta de tesouras de duas águas e tesouras de banzos paralelos. O cálculo estrutural para dimensionamento de estruturas de madeira, em especial em estruturas treliçadas, se utiliza de grande quantidade de rotinas de cálculo numérico, quer para determinação de esforços solicitantes e deslocamentos de elementos estruturais através de análise matricial, quer para dimensionamento da seção transversal e ligações de elementos de uma estrutura típica.

Observa-se, entretanto, que a pouca quantidade de sistemas computacionais relativos ao dimensionamento de estruturas de madeira existentes nesta área baseiam-se nas diretrizes ditadas pela antiga norma NBR 7190/82 - Cálculo e Execução de Estruturas de Madeira da Associação Brasileira de Normas Técnicas (1982). Além disso, o contínuo desenvolvimento da informática nos fornece recursos atuais de programação de grande potencial.

A utilização do sistema desenvolvido neste trabalho concorrerá para significativa redução do tempo despendido na elaboração de projetos de estruturas de madeira industrializadas desenvolvidos segundo a norma NBR 7190/97, minimização dos riscos de erros na execução de rotinas repetitivas, e melhoria da qualidade da apresentação final do projeto.

Além disso, a ocorrência de elementos estruturais que obedecem a uma seqüência repetitiva de características geométricas torna automática a definição geométrica da estrutura em questão através de arquivos numéricos que posteriormente podem ser compartilhados por rotinas gráficas em sistemas $\mathrm{CAD}$ para detalhamento de projetos estruturais. 


\section{2 - REVISÃO BIBLIOGRÁFICA}

\section{1 - ASPECTOS REFERENTES À INDUSTRIALIZAÇÃO DAS CONSTRUÇÕES}

Não é objetivo principal deste trabalho um estudo aprofundado da teoria da industrialização das construções, porém alguns conceitos são importantes para situar esta proposta do trabalho no contexto do emprego das estruturas de madeira no país.

Segundo BISHOP apud BARROS (1991) ${ }^{1}$, um sistema industrializado de construções abrange a organização do trabalho, programação, projeto e execução, assim como a produção industrial de edifícios completos, e de componentes para construções, onde, nesses casos, nenhum estágio pode ser considerado isoladamente, já que o mercado consumidor, o produtor, o processo de produção industrial, a mão de obra especializada existente e as relações industriais constituem fatores inter-relacionados pelos problemas de custo.

Ainda de acordo com BISHOP apud BARROS (1991), a construção industrializada aumenta a proporção dos custos indiretos, tais como administrativos, técnicos, de fiscalização, etc., tornando-se vulnerável. Esses aumentos devem ser compensados através da redução dos custos diretos, principalmente pelo aumento da produtividade.

BARROS (1991) cita outros fatores, além do custo, que ganham importância no desempenho de um sistema, tais como a habilidade nos cumprimentos de prazos e a necessidade de redução de mão de obra, principalmente a especializada.

Já TERNER \& TURNER apud BARROS $(1991)^{2}$ citam a necessidade de se desenvolverem tecnologias de pré-fabricação intermediárias, ou seja, de componentes de edificações caracterizadas pela maior liberdade e autonomia de produção em função das

\footnotetext{
${ }^{1}$ BISHOP.D.(1966) - Custos da Construção Tradicional - Objetivos da Construção Industrializada. Revista "The National Builder" apud BARROS, O.J.(1991) - Algumas Considerações Sobre a PréFabricação de Estruturas de Madeira para Coberturas. São Carlos, USP - EESC - SET - LaMEM.

${ }^{2}$ TERNER, I.D. \& TURNER, J.F.C. (1972) - Vivienda Industrializada. Intercâmbio de Ideias e Métodos apud BARROS, O.J.(1991) - Algumas Considerações Sobre a Pré-Fabricação de Estruturas de Madeira para Coberturas. São Carlos, USP - EESC - SET - LaMEM
} 
necessidades e prioridades habitacionais, respeitando-se o inter-relacionamento entre alguns conceitos básicos. A sistematização é direcionada a componentes normalizados e a coordenação modular é a extensão da normalização, permitindo uma maior integração dos componentes.

Seguindo os conceitos de BISHOP (1966) e TERNER \& TURNER (1972), BARROS (1991) considera que os três requisitos básicos para a industrialização total são a normalização, a concentração e a mecanização, sendo também a especificação da mão de obra comum a ela. Um sistema de construção totalmente industrializado combina os principais elementos descritos. Portanto, uma série sistemática ou racionalizada de componentes normalizados se produz pela mão de obra especializada, concentrada e mecanizada.

Ainda segundo BARROS (1991), quando é introduzida a coordenação modular, os sistemas industrializados tornam-se mais abertos, ou seja, seus componentes são mais compatíveis com os componentes de outros sistemas, permitindo uma maior flexibilidade aos usuários, e oferecendo um maior número de opções aos mesmos. O autor conclui que as perspectivas dos sistemas industrializados no setor habitacional são muito promissoras, porém dependem dos custos técnicos e suporte tecnológico disponível que, embora não sendo as únicas variáveis envolvidas, são a de maior importância.

Sob o ponto de vista da construção industrializada no campo habitacional, pode-se destacar como fatores e características principais os relativos aos seguintes aspectos (ABCI 1986) :

Aspectos Macroeconômicos: são os caracterizados principalmente pela natureza da economia na construção e vice-versa, pela participação da indústria da construção na economia, pela caracterização das demandas potencial e efetiva, pela explicação da demanda através dos clientes, usuários e intermediários, pelos insumos e componentes de custo, pelo sub-setor da indústria de materiais de componentes para construção, pelas condições de equilíbrio do mercado no setor da construção, pela definição de preços e da política de oferta, e finalmente pela política de emprego;

Aspectos Microeconômicos: são os caracterizados pelos custos de produção, de transportes e de montagem das unidades produzidas pelos custos de insumos (diretos e indiretos), pela duração do ciclo da construção, pela velocidade de execução, raio de ação, localização, capital fixo, rotatividade de capital, flexibilidade de utilização do ativo fixo, durabilidade e amortização de equipamentos, infra-estruturas e outras instalações, pelos custos atualizados dos processos produtos, pelos custos de manutenção, conservação, operação e valores residuais das unidades produzidas; tais fatores são característicos de cada 
sistema construtivo escolhido, porém alguns se preocupam com itens isolados do custo global das obras, e assim sendo, surgem alguns obstáculos tais como a necessidade de integração projeto / obra / fábrica, investimentos altos, alto capital de giro, e necessidade de retaguardas administrativa, técnica e operacional;

Aspectos Sociais: são os caracterizados pela capacidade de resposta e adaptação às mudanças de exigências dos usuários, pela capacidade de atendimento às necessidades de ampliação ou modificação dos produtos das unidades, pela estabilidade, segurança e salário da mão-de-obra, além da necessidade da regionalização de materiais, técnicas construtivas e projetos, todos peculiares a cada região, evitando-se assim a importação e exportação desses insumos básicos que encarecem sobremaneira as obras;

Aspectos Técnicos: são os caracterizados pela natureza das necessidades dos usuários e requisitos das unidades, pelas características de oferta, pela capacidade e produtividade das indústrias envolvidas, pela normalização dos produtos de mercado através da coordenação modular, pelas tecnologias de produção, transporte e montagem, pelo desempenho dos sistemas em relação às exigências de habitabilidade, pelos detalhes construtivos, insumos básicos e característicos; os obstáculos mais freqüentes são os altos investimentos em pesquisas que garantam um desempenho mínimo de habitabilidade às edificações, o aperfeiçoamento da mão-de-obra, se não a níveis de especialização, mas até a obtenção de um grau mínimo de qualificação que garanta o equilíbrio do mercado de trabalho, a criação e obrigatoriedade de aplicação de normas técnicas adequadas à perfeita integração das necessidades da habitação com a devida coordenação modular entre todos os materiais de construção à disposição do mercado, e finalmente, a aplicação de controle de qualidade em todas as fases da construção para se garantir execução e utilização das habitações compatíveis com as necessidades básicas dos usuários. 


\section{2 - ASPECTOS REFERENTES A ESTRUTURAS TRELIÇADAS DE COBERTURA}

O telhado destina-se a proteger o edifício contra a ação das intempéries, tais como chuva, vento, raios solares, neve e também impedir a penetração de poeiras e ruídos no seu interior. Como função secundária, porém não menos importante, o telhado contribui para o aspecto estético da edificação, proporcionando aos arquitetos grande liberdade de opção de formas, inclinações, tipos de telhamento, etc...

Os telhados podem ser definidos como uma composição de duas partes básicas descritas por MOLITERNO (1981).

Estrutura de cobertura - Corresponde ao conjunto de elementos estruturais para sustentação da cobertura, como tesouras, terças, caibros, ripas, etc...

Cobertura ou telhamento - Podendo ser de materiais diversos, desde que impermeáveis às águas pluviais e resistentes a ação do vento e intempéries. As coberturas mais comuns podem ser de telhas cerâmicas, telhas de concreto, telhas de fibro-cimento, telhas de madeira e telhas asfálticas tipo shingle.

\subsection{1 - ELEMENTOS COMPONENTES DA ESTRUTURA DE COBERTURA}

A terminologia dos elementos de madeira da estrutura de um telhado é muito diversa nas várias regiões do Brasil, isto provavelmente por herança dos primeiros carpinteiros oriundos de vários pontos de Portugal e outros países da Europa Central. MOLITERNO (1981) apresenta os elementos da estrutura de cobertura com a terminologia adotada neste trabalho (em letras maiúsculas), bem como a terminologia correspondente encontrada nas diversas regiões do Brasil. 


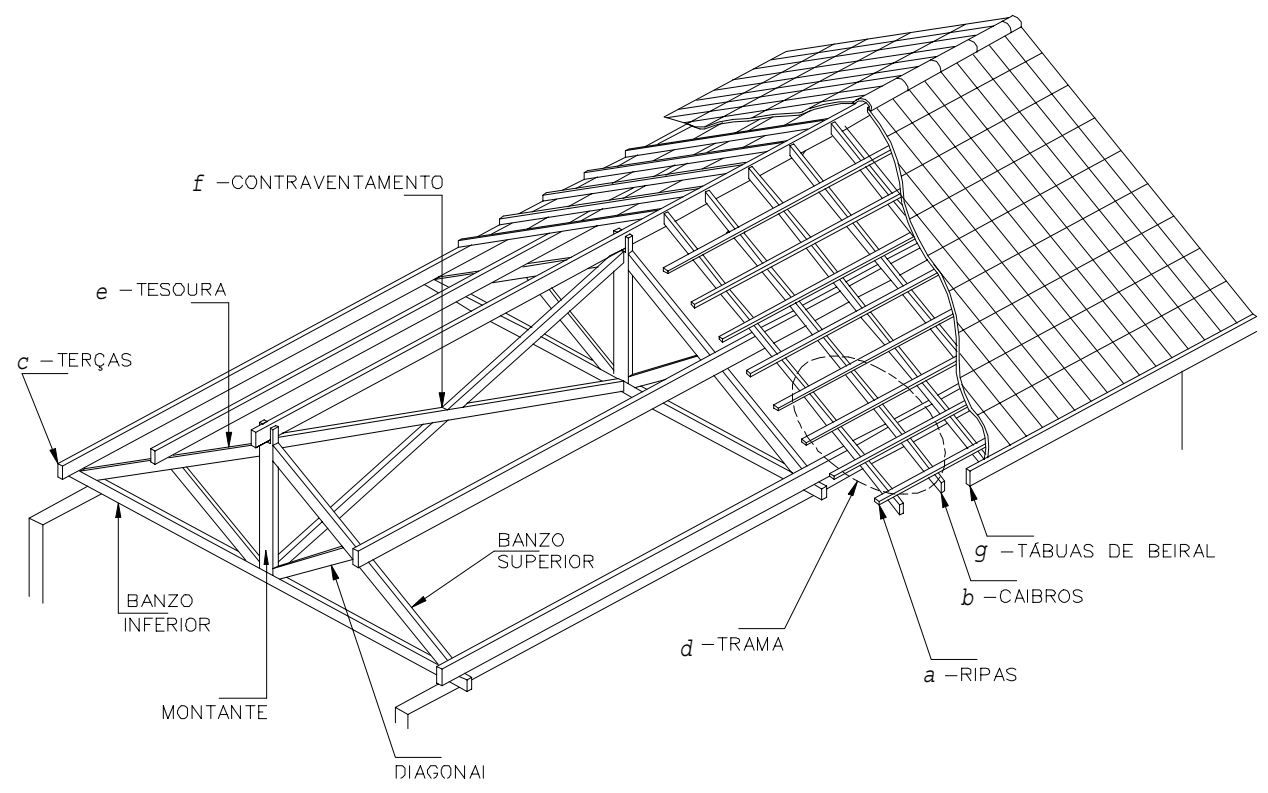

FIGURA 1 - Elementos da estrutura de cobertura

$a$ - RIPAS - Peças de madeira de pequena dimensão pregadas sobre os caibros, para sustentação das telhas;

b - CAIBROS - Peças de madeira apoiadas sobre as terças para sustentação das ripas; $c$ - TERÇAS - Vigas de madeira apoiada sobre as tesouras e pontaletes ou sobre paredes, para sustentação dos caibros;

$d$ - TRAMA - é o conjunto formado pelas ripas, caibros e terças, que servem de lastro ao material da cobertura;

$e$ - TESOURA - Viga em treliça plana vertical, formada de barras dispostas de maneira a compor uma rede de triângulos, tornando o sistema estrutural indeslocável. Os elementos componentes da treliça tem a seguinte denominação:

BANZO SUPERIOR - Também chamado de asna, perna, empena ou membrura superior;

BANZO INFERIOR - Também chamado de linha, rochante, tirante, tensor, ou membrura inferior;

MONTANTE - Também chamado de pontalete, suspensório ou pendural;

DIAGONAL - Também chamado de escora;

$f$ - CONTRAVENTAMENTO - Estrutura formada por barras cruzadas dispostas de maneira a servir de sustentação para a ação das forças que atuam na estrutura, travando as tesouras e impedindo sua rotação e deslocamento, principalmente contra a ação do vento. Serve também como elemento de vinculação de peças comprimidas contra a flambagem lateral;

g - TÁBUAS DE BEIRAL - Também chamado de testeira, tabeira ou aba. 


\subsection{2 - ELEMENTOS DA GEOMETRIA DA COBERTURA}

MOLITERNO (1981) descreve a superfície do telhado como o conjunto de um ou mais planos (uma água, duas águas, quatro águas ou múltiplas águas) ou por uma ou mais superfície curvas (arco, cúpula ou arcos múltiplos). O conjunto das diversas águas da cobertura define os seguintes elementos do telhado:

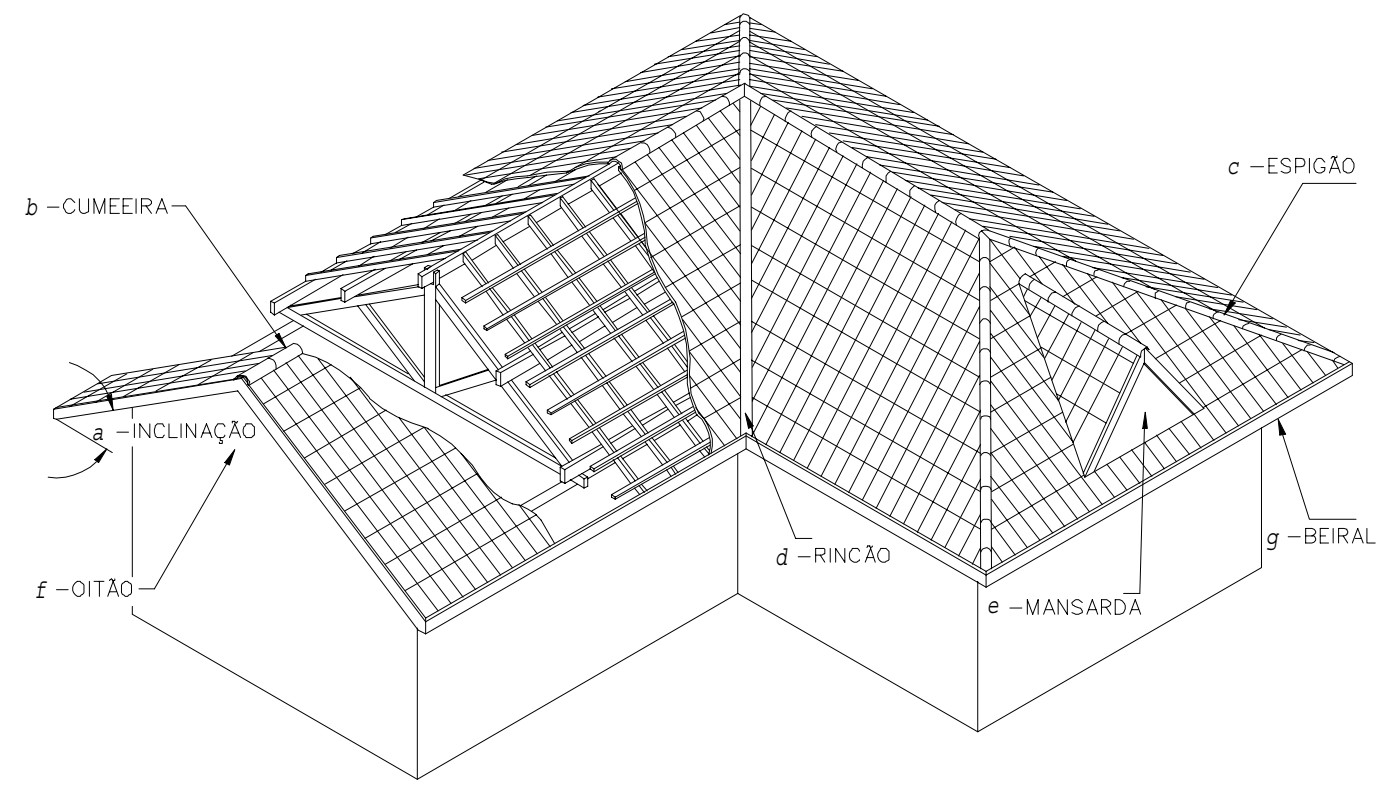

FIGURA 2 - Elementos da geometria da cobertura

$a$ - INCLINAÇÃO - É a relação entre a superfície de uma água e a linha horizontal; $b$ - CUMEEIRA - É formada pelo encontro entre as duas águas principais do telhado, e geralmente corresponde à linha média da área coberta;

$c$ - ESPIGÃO - Aresta saliente formada pelo encontro de duas águas;

$d$ - RINCÃO - Aresta no sentido contrário ao espigão, formada pelo encontro de duas águas. A incidência de rincão exige a colocação de calha para escoamento de água de chuva;

$e$ - MANSARDA - Tipo de cobertura secundária que aproveita a inclinação do telhado, constituindo um cômodo denominado sótão;

$f$ - OITÃO - Paredes extremas paralelas às tesouras, que muitas vezes servem de apoio para terças;

g - BEIRAL - Prolongamento da cobertura, fora do alinhamento da parede; 


\subsection{3 - ALTERNATIVAS ESTRUTURAIS}

BARROS (1991) descreve algumas alternativas estruturais para telhados segundo a seguinte classificação :

\subsubsection{1 - SISTEMA ESTRUTURAL CONVENCIONAL}

Estruturas do sistema convencional são aquelas em que os elementos da estrutura principal (tesouras) bem como os componentes chamados auxiliares (terças, caibros, ripas e contraventamentos) são montados no próprio local da obra, utilizando ligações com entalhes em barras comprimidas e ligações com elementos convencionais prescritos em norma, ou sejam pinos metálicos, cavilhas de madeira e anéis metálicos, em barras tracionadas.

A característica principal de estruturas do sistema convencional, além dos elementos de ligação, são as barras diagonais (em treliças tipo Pratt) ou montantes (em treliças tipo Howe) submetidas a esforços de tração situadas em planos diferentes do plano das demais barras, a fim de otimizar as ligações entre barras através dos elementos convencionais de ligação já citados.

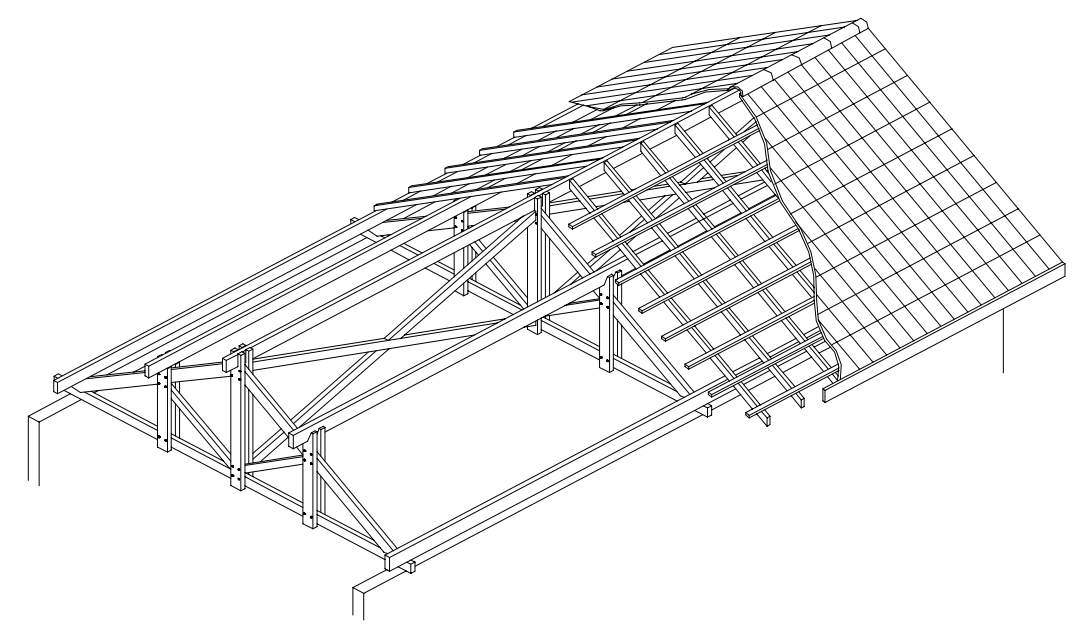

FIGURA 3 - Estrutura de cobertura no sistema convencional. 


\subsubsection{2 - SISTEMA ESTRUTURAL PRÉ-FABRICADO}

A principal característica das estruturas pré-fabricadas é o uso de conectores metálicos com dentes estampados, conhecidos como conectores "GANG-NAIL", nas ligações entre barras de tesoura. A utilização deste tipo de conectores exige que todas as barras da estrutura, tracionadas ou comprimidas, tenham a mesma espessura e se situem no mesmo plano de montagem, ao contrário das estruturas do sistema convencional.

No sistema pré-fabricado, o princípio básico é o da substituição das peças secundárias (terças, e caibros) por tesouras pré-fabricadas. O sistema pré-fabricado segue algumas diretrizes básicas, como descrito :

Os espaçamentos entre tesouras no sistema convencional variam, em função das particularidades de cada projeto, de 2,0 a 3,0 metros para coberturas com telhas cerâmicas, e de 3,0 a 4,5 metros para coberturas com telhas onduladas de fibrocimento, metálicas, etc... No sistema pré-fabricado, o espaçamento entre tesouras é reduzido para faixas de 0,8 a 1,0 metro para os casos com telhas cerâmicas, e para 1,5 a 2,0 metros para as demais. As estruturas principais pré-fabricadas são bem mais esbeltas e leves, em função, é claro, das cargas de projeto e da menor área de influência.

Substitui-se todo o madeiramento complementar somente por sarrafos que cumprem a função das ripas, no caso de telhas cerâmicas, ou das terças, no caso de telhas de fibrocimento ou metálica.

O aumento da quantidade de tesouras é compensado pela possível redução do volume de madeira empregado nas mesmas, já considerada também a substituição das espécies de madeira, bem como a eliminação da totalidade da trama da cobertura (terças e caibros).

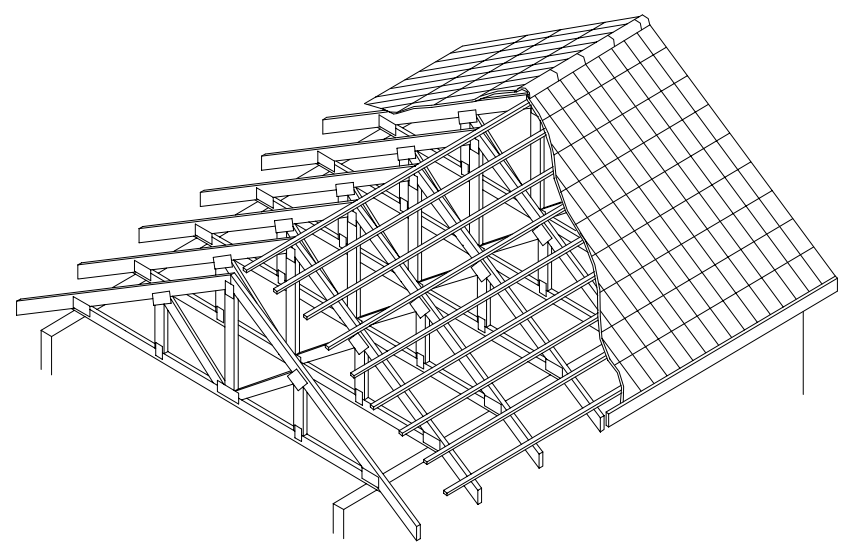

FIGURA 4 - Estrutura de cobertura no sistema pré-fabricado. 


\subsubsection{3 - SISTEMA ESTRUTURAL INTERMEDIÁRIO}

O sistema intermediáro é caracterizado pela simples substituição da estrutura principal convencional pela estrutura principal pré-fabricada (tesouras pré-fabricadas), com a manutenção de todas as demais particularidades do sistema convencional, tais como espaçamento entre tesouras e componentes secundários.

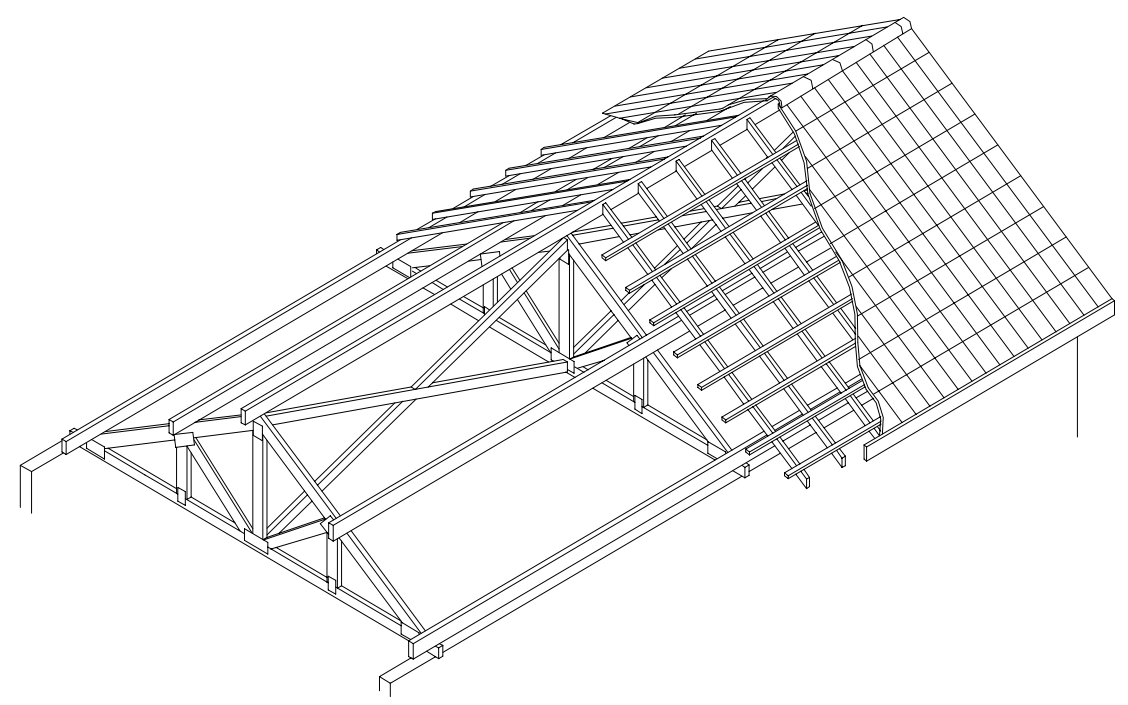

FIGURA 5 - Estrutura de cobertura no sistema intermediário. 


\section{3 - ASPECTOS REFERENTES AO MODELO DE CÁLCULO DE ESFORÇOS NOS ELEMENTOS DE ESTRUTURAS DE COBERTURA}

A análise das alternativas de cálculo descritas conduz a modelos de cálculo desenvolvidos segundo uma abordagem racionalizada dos elementos de projeto, da qual podemos destacar os procedimentos seguintes :

\subsection{1 - CÁLCULO DOS ESFORÇOS NOS ELEMENTOS DE TESOURAS}

\subsubsection{1 - DETERMINAÇÃO DA GEOMETRIA DAS TESOURAS}

Conforme descrito por PARTEL (1988), os elementos componentes de tesouras devem ser considerados numericamente de acordo com dados que possibilitem definir cada elemento em separado, bem como a inter-relação dos elementos estruturais entre si ( ver figuras 6 e 7) e em relação às condições de contorno (restrições de apoios).

Para tanto, são necessários os dados seguintes:

- Coordenadas dos nós de tesouras em relação à origem de um sistema de eixos cartesianos;

- Definição da incidência de barras de tesouras em relação aos nós previamente definidos (nó inicial e nó final de cada barra);

- Vinculação de nós de tesouras.

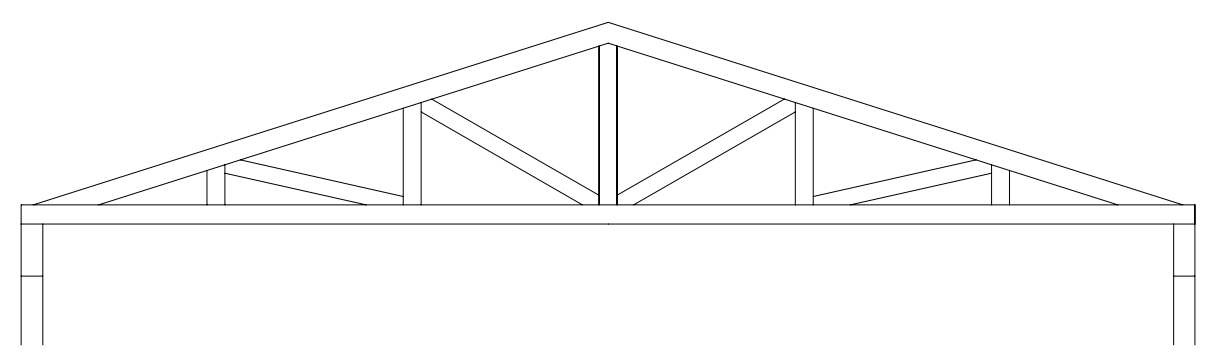

FIGURA 6 - Geometria de tesoura típica de cobertura industrializada. 


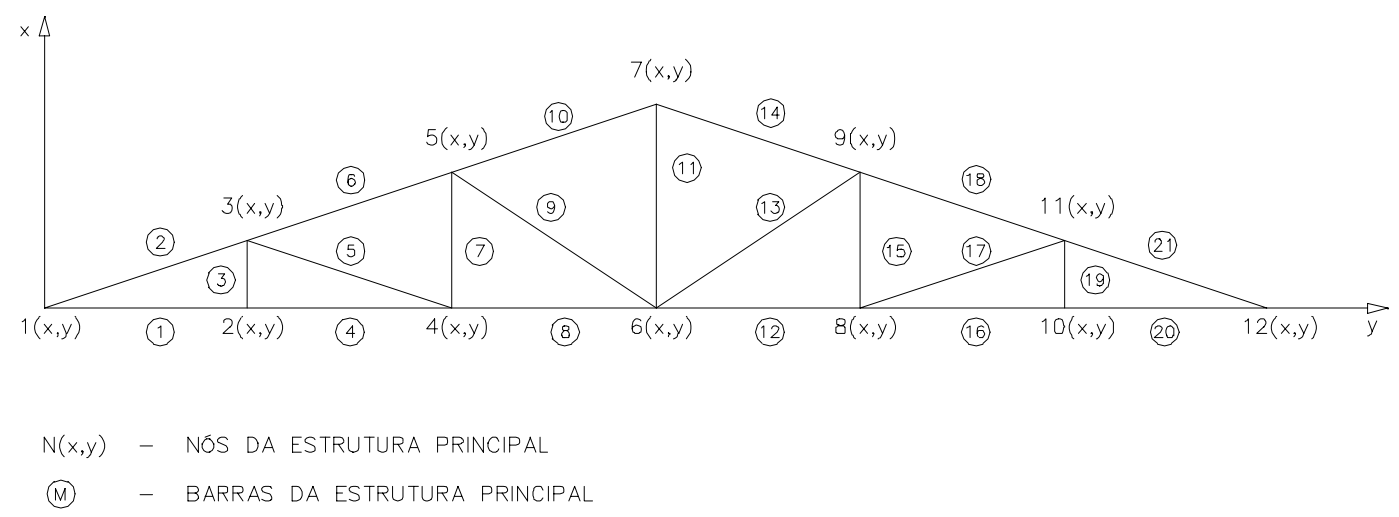

FIGURA 7 - Geometria de tesoura (correspondente a Figura 6) definida por dados numéricos.

Em particular, para tipos usuais de tesouras, a definição da geometria pode ser facilitada em função da simetria e regularidade da disposição entre elementos. Para tanto o sistema deve considerar os dados de projeto seguintes:

- Tipo de tesoura;

- Vão livre de tesoura;

- Espaçamento entre tesouras;

- Inclinação da cobertura;

- Tipo de telha a utilizar.

\subsubsection{2 - MODELO DE CÁLCULO DOS ESFORÇOS SOLICITANTES E DESLOCAMENTOS DOS ELEMENTOS DA TESOURA}

Definida a geometria da tesoura, esta deve ser submetida às diversas composições de carregamentos consideradas no projeto, resultando nos valores de esforços solicitantes em cada barra da estrutura, bem como deslocamentos nodais e reações de apoio.

O cálculo de estruturas do tipo treliçado segue padrões consagrados ao longo dos anos. As técnicas e simplificações desenvolvidas são extremamente louváveis e inteligentes. No entanto, GESUALDO e GRECO (1997) destacam a disponibilidade de poderosos recursos computacionais atuais que permitem modelar as estruturas de forma a se obter respostas mais próximas do fenômeno real, gerando maior precisão e confiabilidade ao projeto.

Alguns autores, tais como WANG (1953), PARCEL (1955) e TIMOSHENKO (1957) citam o efeito de flexão em estruturas do tipo treliçado, observando que as tensões de 
flexão em barras de tesoura podem ter a mesma intensidade que as tensões geradas pelas forças axiais.

GESUALDO e GRECO (1997) avaliaram dois modelos de estrutura, sendo uma tesoura em balanço e uma tesoura duas águas, comparando o dimensionamento das estruturas considerando-as como tesouras de nós articulados e como pórticos com articulações somente nas extremidades de barras com ligações não rígidas. Notar que os banzos destas estruturas são praticamente contínuos, sendo as emendas destes elementos localizadas fora dos nós da estrutura, em pontos de momentos fletores próximos de zero.

As estruturas analisadas por GESUALDO e GRECO (1997) foram consideradas com os banzos contínuos, com articulações nos encontros de banzos e nos pontos de mudança de inclinação. Os montantes ou as diagonais foram consideradas com extremidades perfeitamente articuladas, nos pontos onde as ligações foram consideradas por entalhes, para o caso de barras comprimidas. Nas ligações de barras tracionadas, os autores consideram as ligações por pinos como perfeitamente articuladas.

As tesouras analisadas foram submetidas a carregamentos de peso próprio, sobrecarga e vento de sucção aplicados aos nós do banzo superior. O cálculo dos esforços foi feito através de programas computacionais baseado no métodos dos deslocamentos.

Foram comparados os casos de estruturas calculadas com todas as extremidades articuladas - modelo da treliça convencional - e a estrutura com articulações apenas nos pontos anteriormente citados, sendo as barras dimensionadas segundo prescrições da NBR 7190/97. As seções transversais comerciais resultantes para as barras, em ambos os casos foram as mesmas, já que as seções transversais comerciais disponíveis conduzem ao dimensionamento com uma determinada reserva de material.

Dos resultados do experimento, GESUALDO e GRECO (1997) concluem ser adequada a utilização dos modelos de cálculo que contemplam a continuidade das barras dos banzos de tesouras. Poderão existir casos onde o efeito da flexão poderá ser significativo. Caso este efeito seja pequeno, o procedimento sugerido não trará nenhum prejuízo, sendo o cálculo de esforços considerado mais seguro e próximo do real. 


\subsubsection{3 - MÉTODO DE CÁLCULO DOS ESFORÇOS SOLICITANTES E DESLOCAMENTOS DOS ELEMENTOS DA TESOURA}

O método para cálculo dos esforços solicitantes e deslocamentos dos elementos de tesouras para considerar a continuidade dos banzos da tesoura é similar ao algoritmo para cálculo de pórticos planos, assumindo um único tipo básico de elemento (barras) na composição da estrutura e assumindo deslocamentos nulos segundo as coordenadas globais em nós que definem as vinculações de apoio da estrutura.

SOUZA \& ANTUNES (1995) fornecem os conceitos teóricos necessários ao desenvolvimento de um algoritmo elementar de cálculo de pórticos planos pelo processo dos deslocamentos, considerando apenas efeitos estáticos, com a teoria da elasticidade linear de primeira ordem. Segundo os autores, o desenvolvimento deste algoritmo se faz pelos passos seguintes :

\section{- PREMISSAS BÁSICAS :}

Para a definição do algoritmo, algumas premissas básicas são consideradas :

- A estrutura pode ser definida como um conjunto de elementos unidos entre si;

- Os pontos do elemento susceptíveis de se unirem a outros elementos são chamados extremidades do elemento;

- Os pontos de união dos elementos são chamados nós da estrutura;

- A união de elementos é feita de forma a satisfazer as condições de equilíbrio e compatibilidade da estrutura.

A geometria da estrutura se define, inicialmente, pela posição dos nós através de coordenadas segundo o sistema global de referência. Por sistema global de referência adotamos um sistema Oxyz dextrorso, em relação ao qual se definem as posições dos nós, bem como as direções das coordenadas globais.

A definição da geometria da estrutura se completa pela existência de barras associadas aos nós que elas interligam. As barras da estrutura devem ter definida uma orientação em relação ao nó inicial e nó final de suas extremidades, e devem estar associadas a um sistema local de referência, segundo o qual se definem as características das barras, as 
cargas nas barras e as direções das coordenadas locais para entrada e saída de resultados destas barras. $\mathrm{O}$ eixo $\mathrm{x}$ deste sistema local de referência, também dextrorso, deve ter a direção coincidente com a de uma orientação a ser definida para a barra, e o eixo z será coincidente com o eixo $\mathrm{z}$ do sistema global de referência.

Definida a geometria da estrutura, definem-se os carregamentos atuantes. $\mathrm{O}$ algoritmo considera 2 tipos de carregamentos possíveis :

- Ações aplicadas diretamente aos nós da estrutura, compostas de forças horizontais e verticais, introduzidas segundo o sistema de coordenadas globais;

- Forças verticais uniformemente distribuídas aplicadas aos elementos segundo o sistema de coordenadas locais;

Finalmente, a estrutura têm definidas as condições de contorno pela imposição de deslocamentos nodais nulos nas direções com restrições de apoio segundo às coordenadas globais.

\section{- SISTEMA DE COORDENADAS GLOBAIS}

Cada nó da estrutura terá 3 coordenadas, permitindo, assim, a consideração de 3 deslocamentos independentes possíveis e a aplicação de 3 esforços independentes. As coordenadas globais da estrutura são definidas de acordo com o esquema da figura 8:

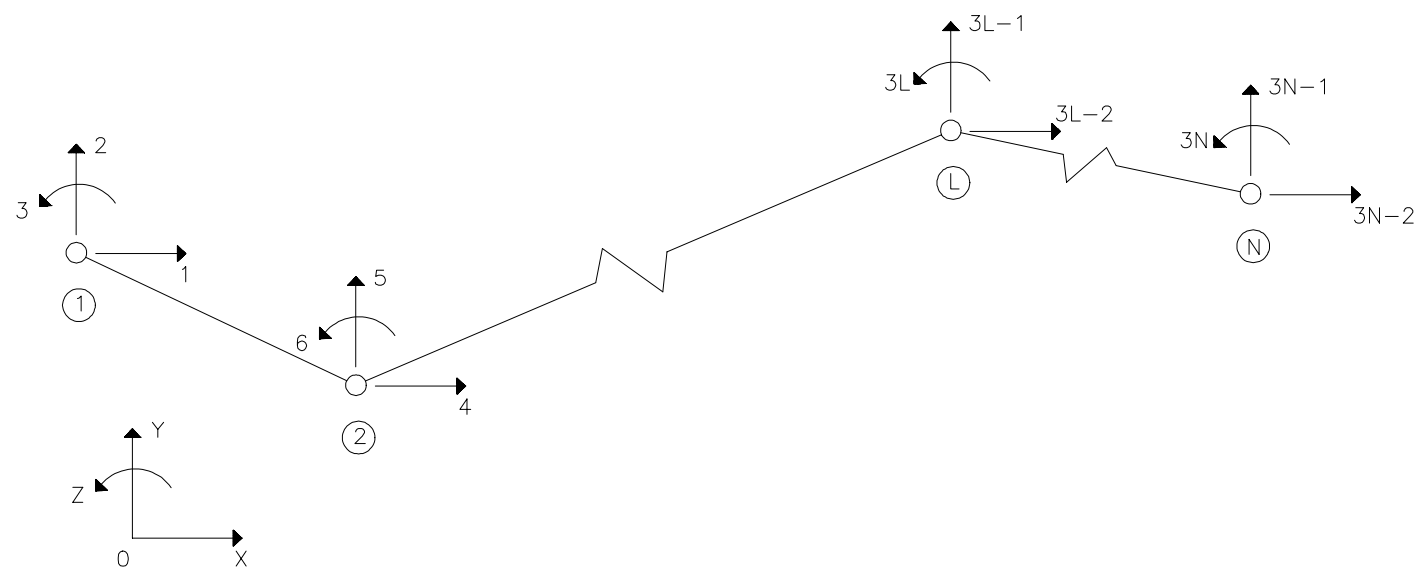

FIGURA 8 - Coordenadas globais. 


\section{- SISTEMA DE COORDENADAS LOCAIS}

Cada barra da estrutura definida por um nó inicial $\mathrm{J}$ e um nó final $\mathrm{K}$ contará com 3 coordenadas por extremidade, permitindo a consideração de 3 deslocamentos e 3 esforços independentes em cada extremidade.

Vale lembrar que neste algoritmo as barras de montantes e diagonais da estrutura treliçada serão tratadas apenas segundo as coordenadas locais em $x$ e $y$, e consideradas pela simulação como tendo momento de inércia nulo. Ainda, algumas barras apresentam condições de vinculação diferentes do convencional, ou seja, uma extremidade contínua e outra articulada, caso dos banzos associados aos nós de apoio

$\mathrm{O}$ tratamento das matrizes de incidência cinemática torna-se bastante simplificado quando consideramos o sistema de coordenadas locais com eixos relacionados seqüencialmente com o sistema global de referência, conforme figura 9 :

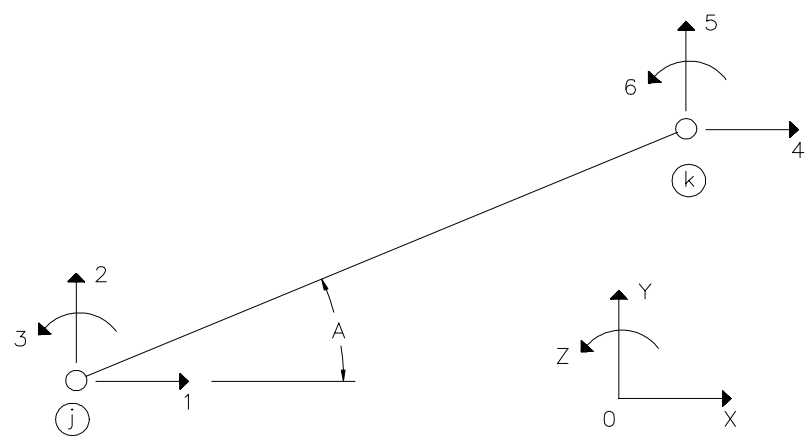

FIGURA 9 - Coordenadas locais segundo sistema de referência global.

Se, entretanto, considerarmos o sistema local de coordenadas relacionados sequencialmente ao sistema local de referência associado ao elemento conforme figura 10, os resultados dos elementos seriam facilmente manipulados. Adotaremos, portanto, os dois sistemas locais de coordenadas que são facilmente relacionados entre si por matriz de transformação de coordenadas.

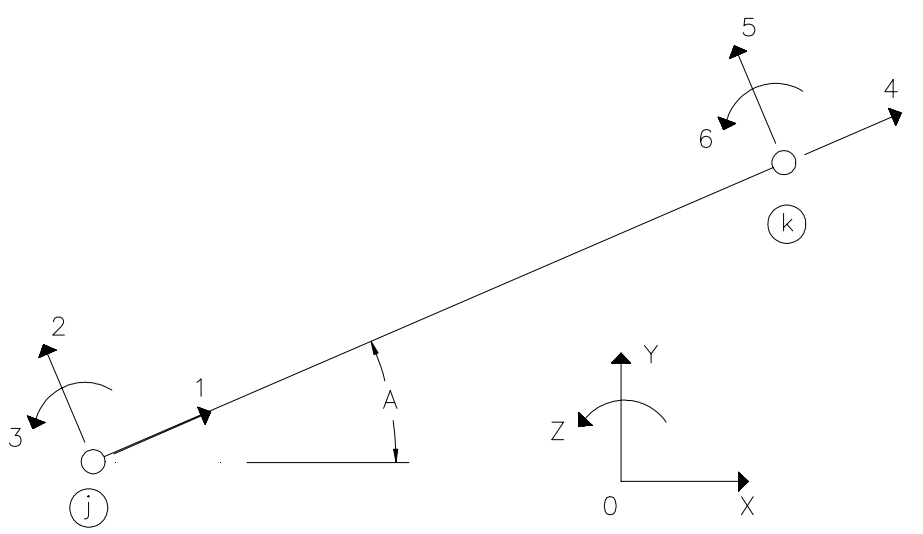

FIGURA 10 - Coordenadas locais segundo sistema de referência local. 
- DETERMINAÇÃO DA MATRIZ DE RIGIDEZ [R]

$\left[r_{g}\right]_{i}=\left[\beta_{e}\right]_{i}^{t} \cdot\left[r_{e}\right]_{i} \cdot\left[\beta_{e}\right]_{i}$

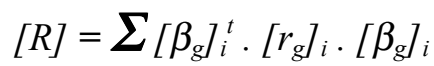

Onde :

$\left[\boldsymbol{\beta}_{\mathrm{e}}\right]_{\mathrm{i}}$ - Matriz de Incidência cinemática;

$\left[\boldsymbol{\beta}_{\mathrm{g}}\right]_{\mathrm{i}}$ - Matriz de Incidência cinemática;

$\left[\mathbf{r}_{\mathrm{e}}\right]_{\mathbf{i}}$ - Matriz de Rigidez do elemento nas coordenadas locais associados ao elemento;

$\left[\mathbf{r}_{\mathbf{g}}\right]_{\mathbf{i}}$ - Matriz de Rigidez do elemento nas coordenadas locais associados ao sistema global de referência;

- DETERMINAÇÃO DAS FORÇAS NODAIS EQUIVALENTES ÀS AÇÕES APLICADAS NAS BARRAS $\left\{\mathrm{F}_{\mathrm{eq}}\right\}$

$\left\{P_{0 g}\right\}_{i}=\left[\beta_{e}\right]_{i}^{t} \cdot\left\{P_{0 e}\right\}_{i}$

$\left\{F_{e q}\right\}=-\Sigma\left[\beta_{g}\right]_{i}^{t} \cdot\left\{P_{0 g}\right\}_{i}$

Onde :

$\left\{\mathbf{P}_{\mathbf{0}}\right\}_{\mathrm{i}}$ - Forças nodais equivalentes nas coordenadas locais associadas ao elemento, devidas às ações no elemento;

$\left\{\mathbf{P}_{\mathbf{0 g}}\right\}_{\mathrm{i}}$ - Forças nodais equivalentes associadas ao sistema global de referência, devidas às ações no elemento;

$\left[\boldsymbol{\beta}_{\mathrm{e}}\right]_{\mathrm{i}}$ - Matriz de Incidência cinemática;

$\left[\boldsymbol{\beta}_{\mathrm{g}}\right]_{\mathrm{i}}$ - Matriz de Incidência cinemática.

- DETERMINAÇÃO DOS DESLOCAMENTOS NODAIS $\{\mathrm{U}\}$

$\{F\}+\left\{F_{e q}\right\}=[R] \cdot\{u\}$

Onde :

$\{$ F $\}$ - Forças aplicadas aos nós associadas ao sistema global de coordenadas;

$\left\{\mathbf{F}_{\text {eq }}\right\}$ - Forças nodais equivalentes associadas ao sistema global de referência, devidas às ações nos elementos;

[R] - Matriz de Rigidez da estrutura. 
- DETERMINAÇÃO DOS DESLOCAMENTOS NAS EXTREMIDADES DOS ELEMENTOS $\left\{\delta_{\mathrm{E}}\right\}$.

$\left\{\delta_{g}\right\}_{i}=\left[\beta_{g}\right]_{i} \cdot\{u\}$

$\left\{\delta_{e}\right\}_{i}=\left[\beta_{e}\right]_{i} \cdot\left\{\delta_{g\}_{i}}\right.$

Onde :

$\left\{\boldsymbol{\delta}_{\mathrm{g}}\right\}_{\mathrm{i}}$ - Deslocamentos nas coordenadas locais associadas ao sistema global de referência;

$\{\mathbf{u}\}$ - Deslocamentos nodais;

$\left[\boldsymbol{\beta}_{\mathrm{e}}\right]_{\mathrm{i}}$ - Matriz de Incidência cinemática;

$\left[\beta_{\mathrm{g}}\right]_{\mathrm{i}}$ - Matriz de Incidência cinemática.

- DETERMINAÇÃO DAS AÇÕES NAS EXTREMIDADES DOS ELEMENTOS $\left\{\mathrm{P}_{\mathrm{E}}\right\}$.

$\left\{P_{e}\right\}_{i}=\left\{P_{0 e}\right\}_{i}+\left[r_{e}\right]_{i} \cdot\left\{\delta_{e}\right\}_{i}$

Onde :

$\left\{\mathbf{P}_{\mathbf{0}}\right\}_{\mathbf{i}}$ - Forças nodais equivalentes nas coordenadas locais associadas ao elemento, devidas às ações no elemento;

$\left[\mathbf{r}_{\mathrm{e}}\right]_{\mathbf{i}}$ - Matriz de Rigidez de um elemento segundo as coordenadas locais.

$\left\{\boldsymbol{\delta}_{\mathrm{e}}\right\}_{\mathrm{i}}$ - Deslocamentos nas coordenadas locais associadas ao elemento;

- DETERMINAÇÃO DAS REAÇÕES $\left\{\mathrm{F}_{\mathrm{R}}\right\}$.

$\left\{P_{g}\right\}_{i}=\left[\beta_{e}\right]_{i}^{t} \cdot\left\{P_{e}\right\}_{i}$

$\left\{F_{r}\right\}=-\{F\}+\Sigma\left(\left[\beta_{g}\right]_{i}^{t} \cdot\left\{P_{g}\right\}_{i}\right)$

Onde :

$\left\{\mathbf{P}_{\mathbf{e}}\right\}_{\mathrm{i}}$ - Forças nas coordenadas locais associadas ao elemento;

$\left\{\mathbf{P}_{\mathrm{g}}\right\}_{\mathrm{i}}$ - Forças nas coordenadas locais associadas ao sistema global de referência;

$\{\mathbf{F}\}$ - Forças aplicadas aos nós associadas ao sistema global de coordenadas;

$\left[\boldsymbol{\beta}_{\mathrm{e}}\right]_{\mathbf{i}}$ - Matriz de Incidência cinemática;

$\left[\boldsymbol{\beta}_{\mathrm{g}}\right]_{\mathrm{i}}$ - Matriz de Incidência cinemática; 


\subsection{2 - CÁLCULO DOS ESFORÇOS EM TERÇAS}

Conforme descrito por MOLITERNO (1981), as terças da estrutura de cobertura estão submetidas a esforços de flexão simples oblíqua, em função do apoio das terças sobre as tesouras. Tais esforços são quantificados em função das composições de carregamentos aplicados à estrutura e do vão livre entre apoios da terça, ou seja, o espaçamento entre tesouras da estrutura do telhado.
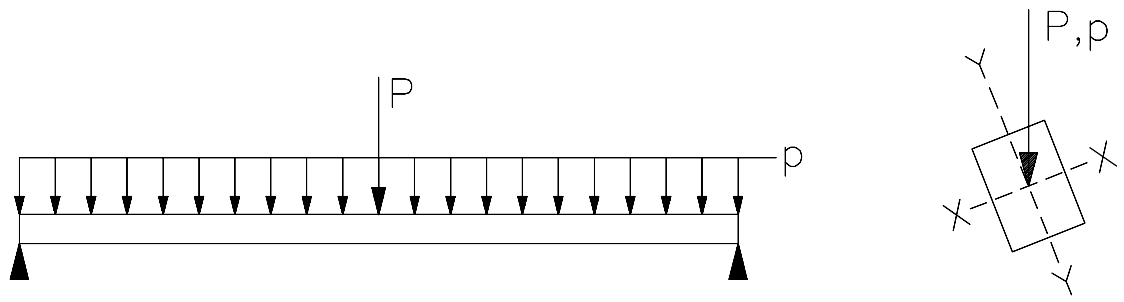

FIGURA 11 - Flexão oblíqua em viga biapoiada.

\subsection{3 - CÁLCULO DOS ESFORÇOS EM CAIBROS.}

Conforme descrito por MOLITERNO (1981), os caibros da estrutura de cobertura estão submetidas a esforços de flexo-compressão devidos à inclinação das forças atuantes em relação ao eixo longitudinal das peças. Tais esforços são quantificados em função das composições de carregamentos aplicados à estrutura e do vão livre entre apoios do caibro, ou seja, o espaçamento entre terças da estrutura do telhado.
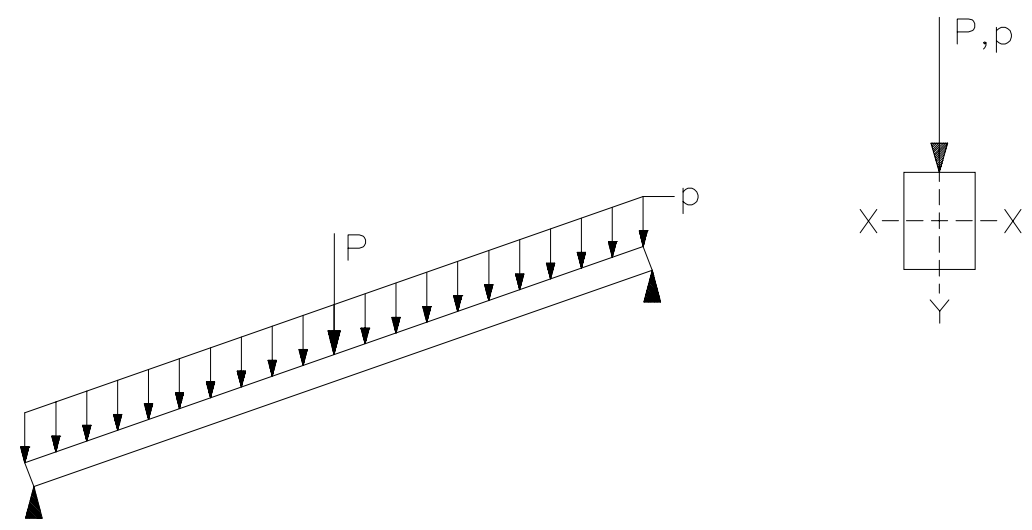

FIGURA 12 - Flexo-compressão em em viga biapoiada. 


\subsection{4 - CÁLCULO DE ESFORÇOS EM LIGAÇÕES ENTRE ELEMENTOS DE}

\section{TESOURAS}

A NBR 7190/97 prevê ligações mecânicas das peças de madeira por meio dos seguintes elementos:

- Pinos Metálicos ( pregos e parafusos );

- Cavilhas (pinos de madeira torneados );

- Conectores (anéis metálicos e chapas metálicas com dentes estampados).

Os esforços nas ligações entre elementos de tesouras são resultado dos esforços axiais das barras que convergem a um determinado nó, considerados segundo o ângulo de incidência das barras. Os critérios de dimensionamento de ligações mecânicas de peças de madeira por pinos metálicos, cavilhas e anéis metálicos são fornecidos pela NBR 7190/97, enquanto os valores de resistência de cálculo que podem ser atribuídos às chapas de dentes estampados, correspondentes a uma única seção de corte, devem ser garantidos pelo respectivo fabricante, de acordo com a legislação brasileira. 


\section{4 - ASPECTOS REFERENTES AO DIMENSIONAMENTO DOS ELEMENTOS DE ESTRUTURAS DE COBERTURA}

\subsection{1 - AÇÕES EM ESTRUTURAS DE COBERTURA}

A NBR 8691/84 (Ações e Segurança nas Estruturas), da Associação Brasileira de Normas Técnicas, define ações como causas que provocam esforços ou deformações nas estruturas.

Segundo a NBR 7190/97 as ações aplicadas a estruturas típicas de cobertura especificamente são combinadas e ponderadas conforme as considerações seguintes :

- Classe de Carregamento : A ação variável principal aplicada a estruturas de cobertura típica define a classe de carregamento como de longa duração;

- Carregamento : O carregamento imposto a uma estrutura típica de cobertura é normal, incluindo apenas as ações decorrentes do uso previsto para a construção;

- Situação de Projeto : A situação de projeto de uma estrutura de cobertura é considerada como duradoura, sendo, portanto, verificados os estados limites últimos e estados limites de utilização. Para estado limite último, consideram-se as combinações normais de carregamento, enquanto para os estados limites de utilização devem ser verificadas as combinações de longa duração;

- Combinações últimas normais de ações : Para verificação dos estados limites últimos.

$$
F_{d}=\sum_{i=1}^{m} \gamma_{g i} F_{g i, k}+\gamma_{Q}\left(F_{Q 1, k}+\sum_{j=2}^{n} \psi_{0 j} F_{Q j, k}\right)
$$

- Combinações de longa duração : Para verificação dos estados limites de utilização.

$$
F_{d, u t i}=\sum_{i=1}^{m} F_{g i, k}+\sum_{j=1}^{n} \psi_{2 j} F_{Q j, k}
$$


- Coeficientes de ponderação para as combinações de ações em estados limites últimos :

$$
\begin{aligned}
& \gamma_{\mathrm{g}}=\text { coeficiente para as ações permanentes } \\
& \gamma_{\mathrm{Q}}=\text { coeficiente de majoração para as ações variáveis } \\
& \psi_{0}=\text { fator de combinação para as ações variáveis secundárias }
\end{aligned}
$$

De acordo com as situações de projeto, estes coeficientes assumem os valores seguintes para combinações últimas normais em estruturas típicas de cobertura:

a) Coeficiente de ponderação para as ações permanentes $\left(\gamma_{\mathrm{g}}\right)$ :

Ações permanentes de pequena variabilidade : A norma brasileira considera como de pequena variabilidade o peso da madeira classificada estruturalmente cuja densidade tenha coeficiente de variação não superior a $10 \%$, e especifica para este caso os seguintes valores de $\gamma_{\mathrm{g}}$ para combinações últimas normais :

$$
\begin{aligned}
& \gamma_{\mathrm{g}}=1,3 \text { - para efeitos desfavoráveis } \\
& \gamma_{\mathrm{g}}=1,0 \text { - para efeitos favoráveis }
\end{aligned}
$$

Ações permanentes de grande variabilidade : Quando o peso próprio da estrutura não supera $75 \%$ da totalidade dos pesos permanentes, a norma brasileira considera as ações permanentes como de grande variabilidade e especifica os valores de $\gamma_{\mathrm{g}}$ para combinações últimas normais :

$$
\begin{aligned}
& \gamma_{\mathrm{g}}=1,4-\text { para efeitos desfavoráveis } \\
& \gamma_{\mathrm{g}}=0,9 \text { - para efeitos favoráveis }
\end{aligned}
$$

Neste trabalho, as ações permanentes foram consideradas como sendo de grande variabilidade. 
b) Coeficiente de ponderação para as ações variáveis $\left(\gamma_{q}\right)$ :

A norma brasileira especifica em análise de combinações últimas normais :

$\gamma_{\mathrm{q}}=1,4$ - para ações variáveis em geral

c) Fator de combinação para as ações variáveis secundárias $\left(\psi_{0}\right)$ :

Este coeficiente varia de acordo com a ação considerada, e em estruturas típicas de cobertura podem ser definidos como:

$\psi_{0}=0,5$ - para pressão dinâmica do vento

$\psi_{0}=0,4$ - para cargas acidentais em edifícios em locais em que não há predominância de peso de equipamentos fixos

- Fatores de Utilização para as combinações de ações em estados limites de utilização :

$\psi_{1}=$ fator de utilização para valores frequentes

$\psi_{2}=$ fator de utilização para valores quase permanentes

De acordo com as situações de projeto, estes coeficientes assumem os valores seguintes para combinações de longa duração para estado limite de utilização em estruturas típicas de cobertura:

$\psi_{1}=0,2$ - para pressão dinâmica do vento

$\psi_{1}=0,3$ - para cargas acidentais em edifícios em locais em que não há predominância de peso de equipamentos fixos

$\psi_{2}=0$ - para pressão dinâmica do vento

$\psi_{2}=0,2$ - para cargas acidentais em edifícios em locais em que não há predominância de peso de equipamentos fixos 


\subsection{2 - PROPRIEDADES DA MADEIRA}

Segundo CALIL et al (1998), são quatro as propriedades da madeira a serem consideradas no dimensionamento de elementos estruturais : densidade, resistência, rigidez e umidade.

Visando a padronização das propriedades da madeira a NBR-7190/97 adota o conceito de classes de resistência, propiciando, assim, a possibilidade de utilização de várias espécies com propriedades similares em um projeto.

Os valores característicos das propriedades da madeira consideradas neste trabalho serão definidas através do conceito de classes de resistência da NBR-7190/97, cuja classificação é apresentada nas tabelas 1 e 2.

TABELA 1 - Classes de resistência das coníferas (Fonte NBR 7190/1996)

\section{Coníferas}

(Valores na condição padrão de referência $U=12 \%$ )

\begin{tabular}{|c|c|c|c|c|c|}
\hline Classe & $\begin{array}{c}\mathrm{f}_{\mathrm{cok}} \\
(\mathrm{MPa})\end{array}$ & $\begin{array}{c}\mathrm{f}_{\mathrm{Vk}} \\
(\mathrm{MPa})\end{array}$ & $\begin{array}{c}\mathrm{E}_{\mathrm{co}, \mathrm{m}} \\
(\mathrm{MPa})\end{array}$ & $\begin{array}{c}\rho_{\text {bas }, \mathrm{m}} \\
\left(\mathrm{kg} / \mathrm{m}^{3}\right)\end{array}$ & $\begin{array}{c}\rho_{\text {aparente }} \\
\left(\mathrm{kg} / \mathrm{m}^{3}\right)\end{array}$ \\
\hline C 20 & 20 & 4 & 3500 & 400 & 500 \\
C 25 & 25 & 5 & 8500 & 450 & 550 \\
C 30 & 30 & 6 & 14.500 & 500 & 600 \\
\hline
\end{tabular}

TABELA 2 - Classes de resistência das dicotiledôneas (Fonte NBR 7190/97)

\begin{tabular}{|c|c|c|c|c|c|}
\hline \multicolumn{7}{|c|}{ Dicotiledôneas } \\
\hline Classe & $\begin{array}{c}\mathrm{f}_{\mathrm{cok}} \\
(\mathrm{MPa})\end{array}$ & $\begin{array}{c}\mathrm{f}_{\mathrm{vk}} \\
(\mathrm{MPa})\end{array}$ & $\begin{array}{c}\mathrm{E}_{\mathrm{co}, \mathrm{m}} \\
(\mathrm{MPa})\end{array}$ & $\begin{array}{c}\rho_{\mathrm{bas}, \mathrm{m}} \\
\left(\mathrm{kg} / \mathrm{m}^{3}\right)\end{array}$ & $\begin{array}{c}\rho_{\text {aparente }} \\
\left(\mathrm{kg} / \mathrm{m}^{3}\right)\end{array}$ \\
\hline C 20 & 20 & 4 & 9500 & 500 & 650 \\
C 30 & 30 & 5 & 14.500 & 650 & 800 \\
C 40 & 40 & 6 & 19.500 & 750 & 950 \\
C 60 & 60 & 8 & 24.500 & 800 & 1000 \\
\hline
\end{tabular}


Definidos os valores característicos das propriedades da madeira $\left(\mathrm{X}_{\mathrm{k}}\right)$, pode-se obter os valores de projeto $\left(\mathrm{X}_{\mathrm{d}}\right)$ pela expressão seguinte :

$$
X_{d}=K_{\bmod } \frac{X_{k}}{\gamma_{w}}
$$

para:

$-\gamma_{\mathrm{w}}=$ coeficiente de minoração da resistência da madeira

- $\mathrm{K}_{\bmod }=$ coeficiente de modificação

Os coeficientes de modificação $\mathrm{K}_{\text {mod }}$ afetam os valores de cálculo de propriedades da madeira em função da classe de carregamento da estrutura, da classe de umidade e da qualidade da madeira utilizada.

Conforme descrito por CALIL et al (1998), a NBR 7190/97 especifica o coeficiente de modificação determinado pela expressão a seguir:

$$
\mathrm{K}_{\text {mod }}=\mathrm{K}_{\text {mod, } 1} \cdot \mathrm{K}_{\text {mod,2 }} \cdot \mathrm{K}_{\text {mod,3 }}
$$

O coeficiente de modificação $K_{\text {mod,1 }}$ leva em conta a classe de carregamento e o tipo de material empregado, e segundo as considerações adotadas nos itens anteriores para estruturas típicas de cobertura ( carregamento de longa duração e madeira serrada ), assume o valor :

$$
\mathrm{K}_{\text {mod1 }}=0,70
$$

O coeficiente de modificação $\mathrm{K}_{\mathrm{mod}, 2}$ leva em conta a classe de umidade e o tipo de material empregado, e para uso de madeira serrada assume os valores seguintes :

$$
\begin{aligned}
& \mathrm{K}_{\text {mod2 }}=1,0(\text { classe de umidade (1) e (2)) } \\
& \mathrm{K}_{\text {mod2 }}=0,8(\text { classe de umidade (3) e (4)) }
\end{aligned}
$$

onde as classes de umidade são definidas pela tabela 3 . 
TABELA 3 - Classes de umidade (Fonte: NBR 7190/97)

\begin{tabular}{|c|c|c|}
\hline Classes de umidade & $\begin{array}{c}\text { Umidade relativa do ambiente } \\
\mathrm{U}_{\mathrm{amb}}\end{array}$ & $\begin{array}{c}\text { Umidade de equilíbrio da } \\
\text { madeira } \mathrm{U}_{\mathrm{eq}}\end{array}$ \\
\hline 1 & $\leq 65 \%$ & $12 \%$ \\
\hline 2 & $65 \%<\mathrm{U}_{\mathrm{amb}} \leq 75 \%$ & $15 \%$ \\
\hline 3 & $75 \%<\mathrm{U}_{\mathrm{amb}} \leq 85 \%$ & $18 \%$ \\
\hline 4 & $\mathrm{U}_{\mathrm{amb}}>85 \%$ & $\geq 25 \%$ \\
\hline
\end{tabular}

O coeficiente de modificação $\mathrm{K}_{\bmod , 3}$ leva em conta a categoria da madeira utilizada. Para madeira de primeira categoria, ou seja, aquela que passou por classificação visual para garantir a isenção de defeitos e, por classificação mecânica para garantir a homogeneidade da rigidez, o valor de $\mathrm{K}_{\text {mod,3 }}$ é 1,0. Caso contrário a madeira é classificada como de segunda categoria e o valor de $\mathrm{K}_{\text {mod,3 }}$ é 0,8 .

Para o caso particular das coníferas, deve-se adotar o valor de 0,8 sempre, para levar em conta a presença de nós não detectáveis pela inspeção visual.

Nas verificações de segurança que dependem da rigidez da madeira, o módulo de elasticidade na direção paralela às fibras deve ser tomado como:

$$
\mathrm{E}_{\mathrm{co}, \mathrm{ef}}=\mathrm{K}_{\mathrm{mod}, 1} \cdot \mathrm{K}_{\mathrm{mod}, 2} \cdot \mathrm{K}_{\mathrm{mod}, 3} \cdot \mathrm{E}_{\mathrm{c} 0, \mathrm{~m}}
$$

Para estados limites últimos, a NBR 7190/97 especifica os valores dos coeficientes de ponderação da resistência da madeira $\left(\gamma_{\mathrm{w}}\right)$, de acordo com a solicitação :

- Compressão paralela às fibras: $\gamma_{\mathrm{wc}}=1,4$

- Tração paralela às fibras: $\gamma_{\mathrm{wt}}=1,8$

- Cisalhamento paralelo às fibras: $\gamma_{\mathrm{wv}}=1,8$

Para estados limites de utilização, adota-se o valor básico de $\gamma_{\mathrm{w}}=1,0$. 


\subsection{3 - CRITÉRIOS DE DIMENSIONAMENTO DE PEÇAS DE MADEIRA}

CALIL et al (1998) apresenta os aspectos da NBR 7190/97 que devem necessariamente ser considerados na análise dos elementos de uma estrutura de cobertura típica, como segue :

\subsubsection{1 - ESTADOS LIMITES ÚLTIMOS}

\subsubsection{1 - COMPRESSÃO PARALELA ÀS FIBRAS}

Em estruturas típicas de cobertura, compressão paralela às fibras da madeira ocorre em barras de tesouras ou em barras de contraventamento.

$\mathrm{O}$ critério de dimensionamento de peças estruturais de madeira solicitadas à compressão paralela às fibras depende diretamente do índice de esbeltez $(\lambda)$, calculado pela expressão :

$$
\lambda=\frac{L_{0}}{i_{\text {min }}} \quad \text { onde } \quad i_{\text {min }}=\sqrt{\frac{I_{\text {min }}}{A}}
$$

Sendo $i_{\min } \mathrm{o}$ raio de giração mínimo da seção transversal do elemento estrutural, Imin o momento de Inércia no plano de menor rigidez, $A$ a área da seção transversal e $L_{0} \mathrm{o}$ comprimento de flambagem do elemento.

Em função índice de esbeltez $(\lambda)$, as peças de madeira solicitadas por compressão paralela são classificadas como :

\section{- PEÇAS CURTAS $(\lambda \leq 40)$ :}

A condição de segurança de elementos estruturais comprimidos axialmente é verificada pela expressão :

$$
\sigma_{c 0, d} \leq f_{c 0, d}
$$

Onde :

$\sigma_{\mathrm{c} 0, \mathrm{~d}}=$ tensão de compressão atuante (valor de cálculo);

$\mathrm{f}_{\mathrm{c} 0, \mathrm{~d}}=$ resistência de cálculo à compressão. 


\section{PEÇAS MEDIANAMENTE ESBELTAS $(40<\lambda \leq 80)$}

Peças medianamente esbeltas comprimidas axialmente devem ter garantida segurança em relação ao estado limite último de instabilidade. Esta condição é verificada, no ponto mais comprimido da seção transversal, se for respeitada a seguinte condição:

$$
\frac{\sigma_{N d}}{f_{c 0, d}}+\frac{\sigma_{M d}}{f_{c 0, d}} \leq 1
$$

Onde :

$\sigma_{\mathrm{Nd}}=$ Valor de cálculo da tensão de compressão devida à força normal de compressão;

$\sigma_{\mathrm{Md}}=$ Valor de cálculo da tensão de compressão devida ao momento fletor $\mathrm{M}_{\mathrm{d}}$, calculado pela expressão

$$
M_{d}=N_{d} \cdot e_{d}
$$

Onde a excentricidade de cálculo $\left(e_{d}\right)$ é obtida pela expressão :

$$
e_{d}=e_{1}\left(\frac{F_{E}}{F_{E}-N_{d}}\right)
$$

Onde a excentricidade de primeira ordem $\left(e_{l}\right)$ é obtida por :

$$
\begin{aligned}
& e_{1}=e_{i}+e_{a} \\
& e_{i}=\frac{M_{1 d}}{N_{d}}
\end{aligned}
$$

Onde $e_{i}$ é decorrente dos valores de cálculo $\mathrm{M}_{1 \mathrm{~d}}$ e $\mathrm{N}_{\mathrm{d}}$ na situação de projeto, não se tomando para $e_{i}$ valor inferior a $\mathrm{h} / 30$, sendo h a altura da seção transversal referente ao plano de verificação, e $e_{a}$, excentricidade acidental dada por:

$$
e_{a}=\frac{L_{0}}{300}
$$

e

$$
F_{E}=\frac{\pi^{2} E_{c 0, e f} I}{L_{0}^{2}}
$$


Onde I é o momento de inércia da seção transversal da peça relativo ao plano de flexão em que se está verificando a condição de segurança, e $\mathrm{E}_{\mathrm{c} 0 \text {,ef }}$ é o módulo de elasticidade efetivo.

Nesta situação a NBR 7190/97 não considera, para peças medianamente esbeltas, a verificação de compressão simples, sendo necessária a verificação da flexo-compressão no elemento estrutural em razão de possíveis excentricidades. Esta verificação é feita isoladamente para os planos de rigidez mínima e de rigidez máxima do elemento estrutural.

\section{- PEÇAS ESBELTAS $(80<\lambda \leq 140)$}

Neste caso adota-se a mesma verificação para peças medianamente esbeltas, pela expressão:

$$
\frac{\sigma_{N d}}{f_{c 0, d}}+\frac{\sigma_{M d}}{f_{c 0, d}} \leq 1
$$

Com:

$$
M_{d}=N_{d} \cdot e_{1, e f}\left(\frac{F_{E}}{F_{E}-N_{d}}\right)
$$

Sendo o valor de $\mathrm{F}_{\mathrm{E}}$ igual ao calculado para peças medianamente esbeltas e a excentricidade efetiva de $1^{\underline{a}}$ ordem, $e_{1, e f}$, dada por:

$$
e_{1, e f}=e_{1}+e_{c}=e_{i}+e_{a}+e_{c}
$$

Onde:

$e_{i}=$ excentricidade de $1^{\mathrm{a}}$ ordem decorrente da situação de projeto;

$e_{a}=$ excentricidade acidental;

$e_{c}=$ excentricidade suplementar de $1^{\underline{a}}$ ordem que representa a fluência da madeira.

Estas excentricidades são calculadas por:

$$
e_{i}=\frac{M_{1 d}}{N_{d}}=\frac{M_{1 g d}+M_{1 q d}}{N_{d}} \quad \text { não se tomando valor inferior a } \mathrm{h} / 30 \text {. }
$$

Com $\mathrm{M}_{1 \mathrm{gd}}$ e $\mathrm{M}_{1 \mathrm{qd}}$, os valores de cálculo, na situação de projeto, dos momentos devidos às cargas permanentes e às cargas variáveis, respectivamente; 


$$
\begin{aligned}
& e_{a}=\frac{L_{0}}{300} \\
& e_{c}=\left(e_{i g}+e_{a}\right)\left\{\exp ^{\left.\left\{\frac{\phi\left[N_{g k}+\left(\psi_{1}+\psi_{2}\right) N_{q k}\right]}{F_{E}-\left[N_{g k}+\left(\psi_{1}+\psi_{2}\right) N_{q k}\right.}\right\}\right]}-1\right\}
\end{aligned}
$$

$\operatorname{com} \psi_{1}+\psi_{2} \leq 1$.

Os valores de $\mathrm{N}_{\mathrm{gk}}$ e $\mathrm{N}_{\mathrm{qk}}$, são os característicos da força normal devidos às cargas permanentes e variáveis, respectivamente, $\psi_{1}$ e $\psi_{2}$ assumem valores determinados em 2.4.1, e a excentricidade $\mathrm{e}_{\mathrm{ig}}$ calculada como segue:

$$
e_{i g}=\frac{M_{1 g, d}}{N_{g d}}
$$

Onde $\mathrm{M}_{1 \mathrm{g,d}}$ é o valor de cálculo do momento fletor devido apenas às ações permanentes.

O coeficiente de fluência $(\phi)$ para classes de carregamento de longa duração, assume os valores :

$$
\begin{aligned}
& \phi=0,8 \text { ( classe de umidade (1) e (2)) } \\
& \phi=2,0 \text { ( classe de umidade (3) e (4)) }
\end{aligned}
$$

\subsubsection{2 - TRAÇÃO PARALELA}

Em estruturas típicas de cobertura, tração paralela às fibras da madeira ocorre em barras de tesouras ou em barras de contraventamento.

A condição de segurança de elementos estruturais tracionados axialmente é verificada pela expressão :

$$
\sigma_{t 0, d} \leq f_{t 0, d}
$$

Onde :

$\sigma_{\mathrm{t} 0 \mathrm{~d}}=$ tensão de tração atuante (valor de cálculo);

$\mathrm{f}_{\mathrm{t} 0 \mathrm{~d}}=$ resistência de cálculo à tração. 


\subsubsection{3 - CISALHAMENTO}

Tensões de cisalhamento ocorrem em elementos estruturais submetidos a flexão: Nestas situações a seguinte verificação deve ser feita:

$$
\tau_{d} \leq f_{v 0, d}
$$

Onde :

$\tau_{\mathrm{d}}=$ tensão de cisalhamento atuante (valor de cálculo);

$\mathrm{f}_{\mathrm{v} 0, \mathrm{~d}}=$ resistência de cálculo ao cisalhamento.

\subsubsection{4 - FLEX AOO SIMPLES RETA}

Esforços de flexão simples reta ocorrem em terças com seção transversal não inclinada, e devem ter verificadas as condições de segurança para as tensões normais e tangenciais :

\section{- VERIFICAÇÃO DA SEGURANÇA PARA TENSÕES NORMAIS}

Elementos estruturais submetidos a momento fletor, cujo plano de ação contém um eixo central de inércia da seção transversal resistente, devem ter verificadas as relações seguintes :

$$
\begin{aligned}
& \sigma_{c 1, d} \leq f_{c 0, d} \\
& \sigma_{t 2, d} \leq f_{t 0, d}
\end{aligned}
$$

Onde:

$\mathrm{f}_{\mathrm{cd}}$ e $\mathrm{f}_{\mathrm{td}}$ são as resistências à compressão paralela e à tração paralela, respectivamente; $\sigma_{\mathrm{c} 1, \mathrm{~d}}$ e $\sigma_{\mathrm{t} 2, \mathrm{~d}}$ são respectivamente as tensões atuantes de cálculo nas bordas mais comprimida e mais tracionada da seção transversal considerada.

Os valores das tensões normais são determinados de acordo com os conceitos da resistência dos materiais, que especifica a tensão normal como sendo:

$$
\sigma=\frac{M}{I} y
$$


Onde:

$\mathrm{M}=$ momento fletor na seção considerada;

I = momento de inércia da seção transversal no plano de verificação;

y = distância da borda considerada em relação ao centro de gravidade da seção transversal.

- VERIFICAÇÃO DA SEGURANÇA PARA TENSÕES TANGENCIAIS

Neste caso, as tensões de cisalhamento devem se verificadas através da expressão apresentada no item 2.4.3.1.3, sendo $\tau_{\mathrm{d}}$ a máxima tensão de cisalhamento atuante na peça, determinada de acordo com os conceitos da resistência dos materiais, como:

$$
\tau_{d}=\frac{V \cdot A}{b \cdot I}
$$

Para vigas de seção transversal retangular, de largura b e altura $h$, tem-se:

$$
\tau_{d}=\frac{3 \cdot V}{2 \cdot b \cdot h}
$$

Onde:

$\mathrm{V}=$ força cortante na seção considerada;

$\mathrm{b}=$ largura da seção transversal considerada;

$\mathrm{h}=$ altura da seção transversal considerada;

\subsubsection{5 - FLEX ÃO COMPOSTA}

Em estruturas típicas de cobertura, ocorrem situações de flexão composta nos banzos superiores e inferiores de tesouras e em caibros, devido à inclinação do telhado.

Dois tipos de flexão composta podem ocorrer : a flexo-tração e a flexo-compressão.

\section{- FLEXO-TRAÇÃO}

A NBR 7190/97 determina que em barras submentidas a flexo-tração, a condição de segurança para forças normais é expressa pela mais rigorosa das duas expressões seguintes, aplicadas ao ponto mais solicitado da borda mais tracionada, considerando-se uma função linear para a influência das tensões devidas a força normal de tração : 


$$
\begin{aligned}
& \frac{\sigma_{N t, d}}{f_{t 0, d}}+\frac{\sigma_{M x, d}}{f_{t 0, d}}+k_{M} \frac{\sigma_{M y, d}}{f_{t 0, d}} \leq 1 \\
& \frac{\sigma_{N t, d}}{f_{t 0, d}}+k_{M} \frac{\sigma_{M x, d}}{f_{t 0, d}}+\frac{\sigma_{M y, d}}{f_{t 0, d}} \leq 1
\end{aligned}
$$

Onde :

$\sigma_{\mathrm{N} t \mathrm{~d}} \mathrm{e}$ o valor de cálculo da parcela de tensão normal atuante em virtude apenas da força normal de tração.

O coeficiente $\mathrm{k}_{\mathrm{M}}$ de correção é tomado como:

- $\quad \mathrm{k}_{\mathrm{M}}=0,5$ para seção retangular

\section{- FLEXO-COMPRESSÃO}

Para as solicitações de flexo-compressão devem ser verificadas duas situações de segurança: de estabilidade para tensões normais, a ser feita de acordo com os critérios apresentados para o dimensionamento de peças solicitadas à compressão; e a verificação de acordo com a mais rigorosa das duas expressões a seguir, aplicados ao ponto mais solicitado da borda mais comprimida, levando-se em conta a resistência do elemento estrutural em função dos carregamentos:

$$
\begin{gathered}
\left(\frac{\sigma_{N c, d}}{f_{c 0, d}}\right)^{2}+\frac{\sigma_{M x, d}}{f_{c 0, d}}+k_{M} \frac{\sigma_{M y, d}}{f_{c 0, d}} \leq 1 \\
\left(\frac{\sigma_{N c, d}}{f_{c 0, d}}\right)^{2}+k_{M} \frac{\sigma_{M x, d}}{f_{c 0, d}}+\frac{\sigma_{M y, d}}{f_{c 0, d}} \leq 1
\end{gathered}
$$

Onde :

$\sigma_{\mathrm{Nc}, \mathrm{d} \text { é }} \mathrm{O}$ valor de cálculo da parcela de tensão normal atuante em virtude apenas da força normal de compressão.

$\mathrm{O}$ coeficiente $\mathrm{k}_{\mathrm{M}}$ de correção é tomado como:

- $\quad \mathrm{k}_{\mathrm{M}}=0,5$ para seção retangular 


\subsubsection{6 - FLEXÃO OBLÍQUA}

$\mathrm{Na}$ prática, em estruturas de cobertura, solicitações de flexão-oblíqua ocorrem basicamente nas terças e ripas.

Para elementos estruturais submetidos a flexão oblíqua, a NBR 7190/97 especifica a verificação da segurança para tensões normais pela mais rigorosa das duas condições seguintes, tanto em relação às tensões de tração quanto às de compressão paralela:

$$
\begin{aligned}
& \frac{\sigma_{M x, d}}{f_{w d}}+k_{M} \frac{\sigma_{M y, d}}{f_{w d}} \leq 1 \\
& k_{M} \frac{\sigma_{M x, d}}{f_{w d}}+\frac{\sigma_{M y, d}}{f_{w d}} \leq 1
\end{aligned}
$$

Onde :

$\sigma_{\mathrm{Mx}, \mathrm{d}} \mathrm{e} \sigma_{\mathrm{My}, \mathrm{d}}$ são as tensões máximas devidas às componentes de flexão atuantes segundo as direções principais

$\mathrm{f}_{\mathrm{wd}}$ é a respectiva resistência de cálculo, de tração ou de compressão conforme a borda verificada

O coeficiente $\mathrm{k}_{\mathrm{M}}$ de correção é tomado como:

- $\quad \mathrm{k}_{\mathrm{M}}=0,5$ para seção retangular

\subsubsection{2 - ESTADOS LIMITES DE UTILIZAÇÃO}

A NBR 7190/97 determina a verificação do estado limite de utilização em estruturas de madeira basicamente pela consideração de limites de deslocamento que possam ocasionar desconforto aos usuários, danos a materiais não estruturais da construção, ou que provoquem vibração excessiva.

A condição para verificação da segurança é dada pela seguinte situação:

$$
S_{d, u t i} \leq S_{\text {lim }}
$$


Onde:

$\mathrm{S}_{\mathrm{lim}}$ é o valor limite fixado para o efeito estrutural que determina o aparecimento do estado limite considerado;

$\mathrm{S}_{\mathrm{d} \text {,uti }}$ são os valores desses mesmos efeitos, decorrentes da aplicação das ações estabelecidas para a verificação, calculados com a hipótese de comportamento elástico linear da estrutura.

De acordo com as hipóteses adotadas para estruturas correntes, são consideradas apenas as combinações de ações de longa duração, levando-se em conta o valor efetivo do módulo de elasticidade especificado no item 2.4.2.

Os limites de deslocamentos permitidos pela NBR 7190/97 são:

L/200 dos vãos;
L/100 do comprimento dos balanços

Para a verificação de casos de flexão oblíqua, os limites anteriores de flechas podem ser verificados isoladamente para cada um dos planos principais de flexão. 


\subsection{4 - CRITÉRIOS DE DIMENSIONAMENTO DE LIGAÇÕES ENTRE PEÇAS DE MADEIRA}

Conforme descrito por CALIL et al (1998), o estado limite último de uma ligação é atingido por deficiência de resistência da madeira e/ou do elemento de ligação. A NBR 7190/97 fornece critérios de dimensionamento em função dos elementos de ligações (pinos metálicos, cavilhas e anéis metálicos) e das peças de madeira que compõe a ligação.

Entretanto, a NBR 7190/97 não fornece critérios explícitos de dimensionamento de ligações de peças de madeira por conectores metálicos com dentes estampados, objetos deste trabalho, recomendando que os valores da resistência de cálculo que podem ser atribuídos a estes conectores, correspondentes a uma seção de corte, devem ser garantidos pelo respectivo fabricante, de acordo com a legislação brasileira.

Alguns estudos descrevem critérios de dimensionamento, como o apresentado por BARALDI (1998), que propõe três verificações básicas para a ligação de peças de madeira com conectores de dentes estampados :

- Tração da chapa

- Cisalhamento da chapa

- Arrancamento do conector

BARALDI (1998) propõe a verificação dos elementos da ligação como descrito :

\section{Ligações solicitadas a tração :}

A resistência do conector à tração é obtida a partir dos ensaios do conector em corpos de prova de acordo com a NBR 7190/97 e de ensaios em corpos de prova de aço utilizado na fabricação dos conectores.

A partir das tensões de escoamento dos ensaios, as resistências de cálculo das ligações solicitadas à tração podem ser determinadas pelo procedimento abaixo :

a) Determinação da resistência à tração última do conector :

$$
f_{t u}=\frac{F_{u}}{A_{g}}
$$


Sendo :

$F_{u}=$ Força de ruptura da chapa em ensaio de C.P.'s padronizados;

$\mathrm{A}_{\mathrm{g}}=$ Área de seção transversal bruta do par de conectores $\left(\mathrm{A}_{\mathrm{g}}=\mathrm{L}^{*} \mathrm{e}\right)$;

$\mathrm{L}=$ Dimensão bruta da chapa considerada;

e = Espessura mínima especificada para o conector.

b) Determinação da resistência à tração última do metal base :

$$
f_{t u, b}=\frac{F_{u, b}}{A_{g, b}}
$$

Sendo :

$\mathrm{F}_{\mathrm{u}, \mathrm{b}}=$ Força de tração de ruptura do aço C.P.'s padronizados;

$\mathrm{A}_{\mathrm{g}, \mathrm{b}}=$ Área de aço na seção transversal de maior solicitação dos C.P.'s.

c) Determinação da razão efetiva média de resistência à tração :

$$
R_{t}=\frac{f_{t u}}{f_{t u, b}}
$$

A razão $R_{t}$ deve ser determinada para cada ângulo de inclinação da chapa $\left(\alpha_{c h}\right)$.

d) Determinação da tensão máxima de serviço para a chapa :

$$
f_{s t}=0,9 . f_{y}
$$

e) Determinação da resistência de cálculo para a tração:

$$
f_{t d}=R_{t} \cdot f_{s t} \cdot t_{1}
$$

Sendo :

$\mathrm{t}_{1}=$ espessura efetiva.

$\mathrm{O}$ valor $\mathrm{f}_{\mathrm{t}, \mathrm{d}}$ é expresso por força de unidade de largura transversal à direção de solicitação da chapa submetida a tração. Para o dimensionamento das ligações deve ser utilizado o seguinte critério :

$$
L=\frac{F_{d}}{f_{t d}}
$$

Sendo :

$\mathrm{L}=\mathrm{a}$ dimensão necessária à chapa para resistir à solicitação, levando em conta $\mathrm{o}$ ângulo da chapa $\left(\alpha_{\mathrm{ch}}\right)$;

$\mathrm{F}_{\mathrm{d}}=$ Força atuante de cálculo. 
No caso de ligações comprimidas, deve-se dimensionar a chapa para que resista a pelo menos $50 \%$ da força de compressão.

Ligações solicitadas ao cisalhamento :

A resistência do conector ao cisalhamento é obtida a partir dos ensaios do conector em corpos de prova de acordo com a NBR 7190/97. A resistência do aço ao cisalhamento pode ser admita como sendo uma parcela da tensão de escoamento do aço $\left(f_{v}=0,6 . f_{y}\right)$.

A partir das tensões de cisalhamento obtidas dos ensaios, as resistências de cálculo das ligações solicitadas ao cisalhamento podem ser determinadas pelo procedimento seguinte:

a) Determinação da resistência ao cisalhamento última do conector :

$$
f_{v u}=\frac{F_{u}}{A_{g}}
$$

Sendo :

$\mathrm{F}_{\mathrm{u}}=$ Força de ruptura da chapa em ensaio de C.P.'s padronizados;

$\mathrm{A}_{\mathrm{g}}=$ Área de seção transversal bruta do par de conectores $\left(\mathrm{A}_{\mathrm{g}}=\mathrm{L} * \mathrm{e}\right)$;

$\mathrm{L}=$ Dimensão bruta da chapa considerada;

e = Espessura mínima especificada para o conector.

b) Determinação da resistência à tração última do metal base :

$$
f_{t u, b}=\frac{F_{u, b}}{A_{g, b}}
$$

Sendo :

$\mathrm{F}_{\mathrm{u}, \mathrm{b}}=$ Força de tração de ruptura do aço C.P.'s padronizados;

$\mathrm{A}_{\mathrm{g}, \mathrm{b}}=$ Área de aço na seção transversal de maior solicitação dos C.P.'s.

c) Determinação da razão efetiva média de resistência ao cisalhamento :

$$
R_{v}=\frac{f_{v u}}{0,6 \cdot f_{t u, b}}
$$

A razão $R_{v}$ deve ser determinado para cada posição da chapa $\left(\alpha_{c h}\right)$. 
d) Determinação da tensão máxima de serviço para a chapa :

$$
f_{v}=0,6 . f_{y}
$$

e) Determinação da resistência de cálculo para o cisalhamento :

$$
f_{v d}=R_{v} \cdot f_{v} \cdot t_{1}
$$

\section{Sendo :}

$t_{1}=$ espessura efetiva.

$\mathrm{O}$ valor $\mathrm{f}_{\mathrm{v}, \mathrm{d}}$ é expresso por força de unidade de largura transversal à direção de solicitação da chapa submetida a tração. Para o dimensionamento das ligações deve ser utilizado o seguinte critério :

$$
L=\frac{F_{d}}{f_{v d}}
$$

\section{Sendo :}

$\mathrm{L}=\mathrm{a}$ dimensão necessária à chapa para resistir à solicitação, levando em conta $\mathrm{o}$ ângulo da chapa $\left(\alpha_{\mathrm{ch}}\right)$;

$\mathrm{F}_{\mathrm{d}}=$ Força atuante de cálculo.

OBS : Em treliças é muito comum nós onde o conector é solicitado tanto por tração como por cisalhamento. Nestes casos, no dimensionamento da ligação, deve-se determinar as dimensões necessárias da chapa tanto à tração quanto ao cisalhamento, adotando a maior dimensão.

\section{Verificação do arrancamento da chapa na ligação :}

A resistência ao arrancamento é função da densidade da madeira e da área de chapa que atua resistindo aos esforços. Além disso, a resistência ao arrancamento deve ser verificada de acordo com o ângulo da força em relação às fibras da madeira.

A partir da resistência ao arrancamento por dente do conector obtido em ensaios de C.P.'s padronizados, o dimensionamento das ligações é feito pela expressão :

$$
N_{d}=\frac{F_{d}}{f_{a d}}
$$


Sendo :

$\mathrm{N}_{\mathrm{d}}=$ Número mínimo de dentes necessários à ligação;

$\mathrm{F}_{\mathrm{d}}=$ Força axial atuante no elemento de madeira;

$\mathrm{f}_{\mathrm{ad}}=$ Valor de cálculo da resistência ao arrancamento por dente do conector;

Os valores de resistência ao arrancamento característico devem ser expressos para cada classe de resistência apresentada pela norma brasileira. Para a prevenção de danos devidos à manipulação, transporte ou montagem, deve-se dimensionar a ligação para um esforço mínimo de $1,75 \mathrm{KN}$.

OBS :

Os valores de resistência ao arrancamento em ligações de nós de apoio de tesouras, para prever efeitos de momento na ligação, devem ser reduzidos pelo fator FR, calculado pela expressão :

$$
F R=0,85-0,05 \cdot(12 \cdot \operatorname{tg} \theta-2)
$$

Para $0,65<\mathrm{FR}<0,85$

Onde $\theta$ é o ângulo entre o banzo inferior e o banzo superior da treliça.

Para membros de madeira solicitados à compressão, o conector deve ser dimensionado para resistir a $50 \%$ do esforço atuante.

Para todas as ligações devem ser feitas reduções na área líquida da chapa com redução nas dimensões, sendo de $12,7 \mathrm{~mm}$ nas extremidades e de $6,4 \mathrm{~mm}$ nas bordas das peças de madeira, conforme figura 17.
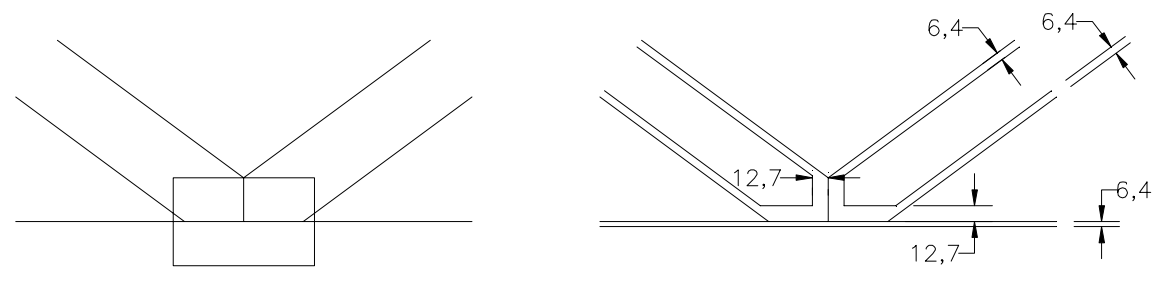

FIGURA 13 - Redução na área líquida de conectores 


\section{3 - DESENVOLVIMENTO DO SOFTWARE}

\section{1 - AMBIENTE DE OPERAÇÃO DO SISTEMA}

O sistema é desenvolvido através do Software Borland - Delphi for Windows, visto que esta ferramenta de desenvolvimento de sistemas em ambiente Windows para processadores padrão Pentium $P C$ vem sendo largamente utilizada na área técnica e comercial, substituindo linguagens como o Clipper e outras que operam em plataforma DOS.

\section{2 - DESENVOLVIMENTO DO ALGORITMO}

A partir do estudo bibliográfico foi montado o modelo matemático do sistema proposto segundo os procedimentos de análise estruturada de sistemas descrito por GANE (1983) e YOURDON (1989) de modo a possibilitar a automatização das etapas de análise estrutural, dimensionamento e verificações dos elementos estruturais.

O modelo matemático do sistema é resultado de uma abordagem racionalizada dos elementos de projeto cuja inter-relação entre dados, procedimentos e ambiente externo é representada pelos diagramas de fluxo de dados (DFD) apresentados nas figuras 18 e 19.

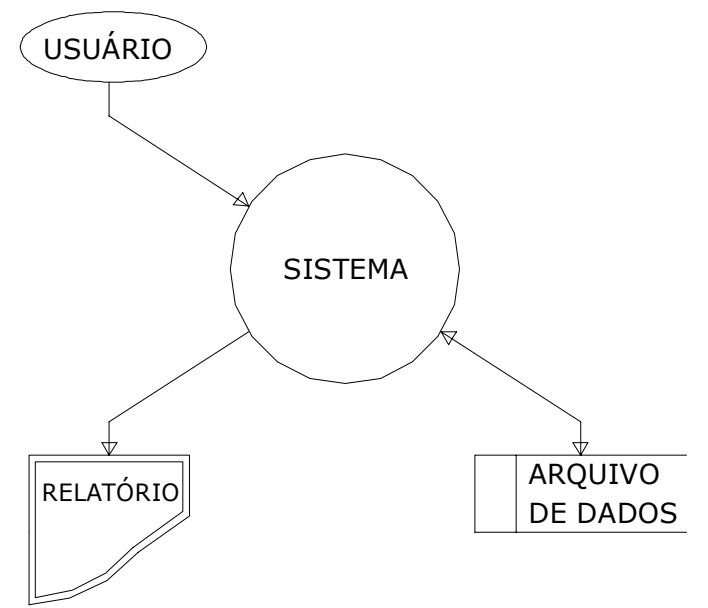

FIGURA 14 - Diagrama de Contexto - Visão do Sistema interagindo com o ambiente externo. 


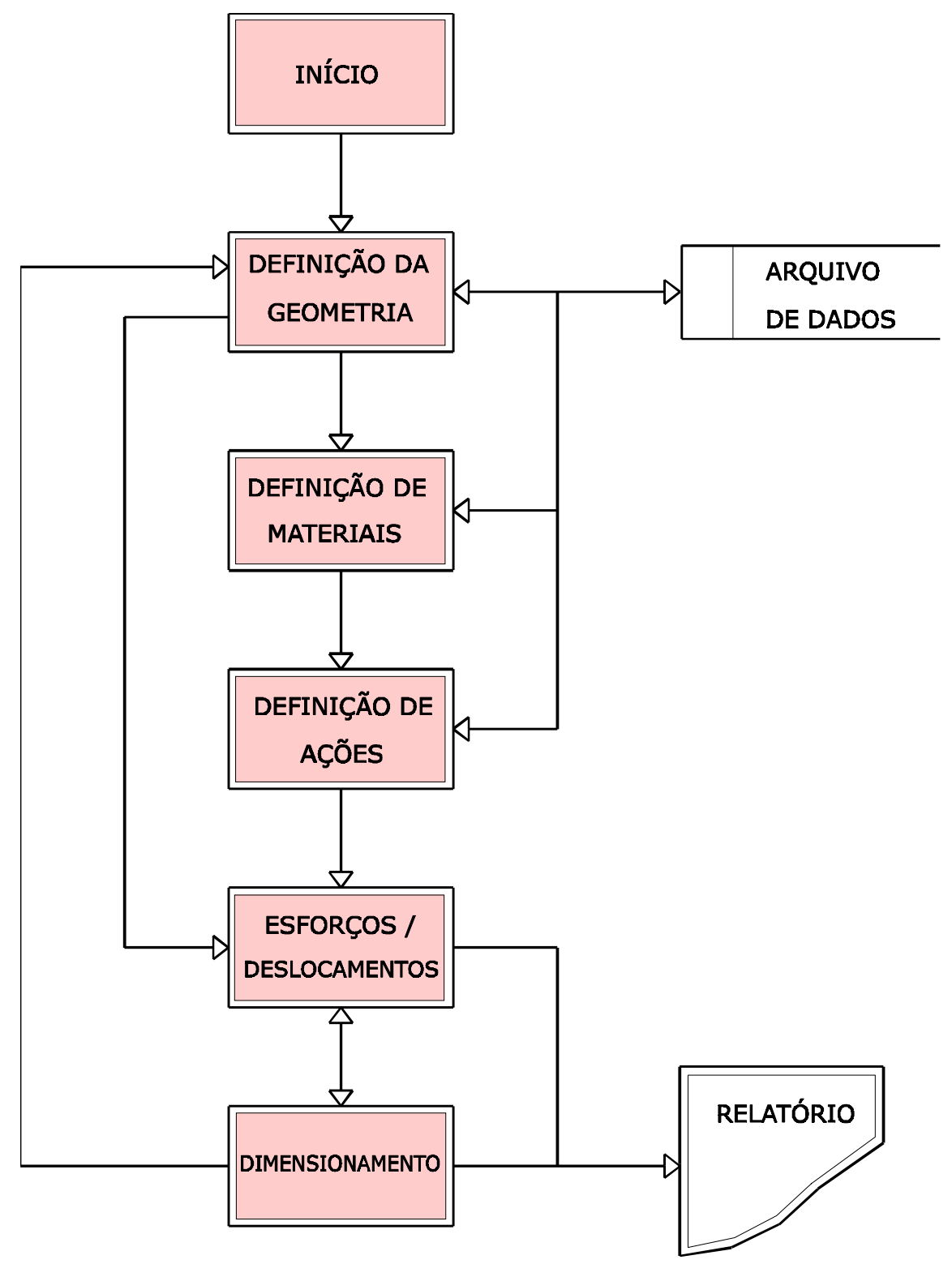

FIGURA 15 - Diagrama de Fluxo de Dados - Visão Global do Sistema.

Os módulos de operação do diagrama da figura 15 ( módulos de 1 a 5) são apresentados e descritos de forma mais detalhada nos itens subsequentes : 


\subsection{1 - DEFINIÇÃO DA GEOMETRIA DA ESTRUTURA (MÓDULO 1)}

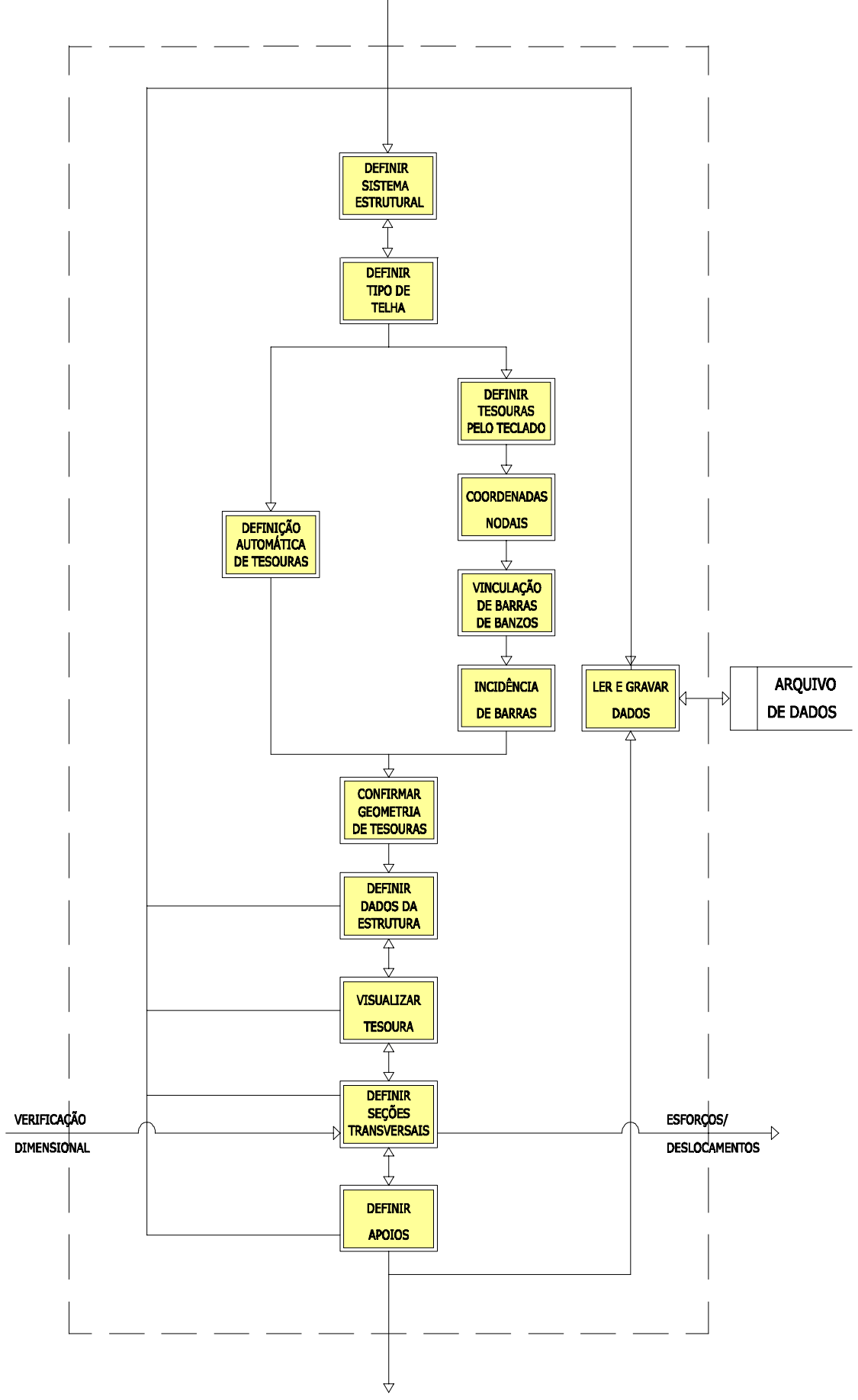

FIGURA.16 - Diagrama de Fluxo de Dados - Módulo 1.

A geometria da estrutura é definida pelos elementos da tesoura, como descrito no item 2.3.1.1, bem como disposição e espaçamentos entre tesouras, terças e caibros. O sistema considera os sistemas estruturais intermediário e pré-fabricado, apresentadas nos itens 2.2.3.2 e 2.2.3.3. Como descrito, nestas configurações estruturais, são utilizadas barras de 
tesouras de seção retangular simples e de mesma espessura para toda a estrutura principal, devido ao tipo de ligação utilizado.

Dados para a definição geométrica da estrutura podem ser introduzidos explicitamente pela entrada direta de todos os dados que definem geometricamente a estrutura, ou gerados a partir de relações geométricas inerentes a alternativas estruturais específicas. O sistema permite, ainda, que a geração de dados geométricos seja facilitada quando o projeto considera o uso de estruturas principais de tipos consagrados, como tesouras tipo HOWE, PRATT, FINK e tesouras de banzos paralelos.

\subsection{2 - DEFINIÇÃO DE MATERIAIS (MÓDULO 2)}

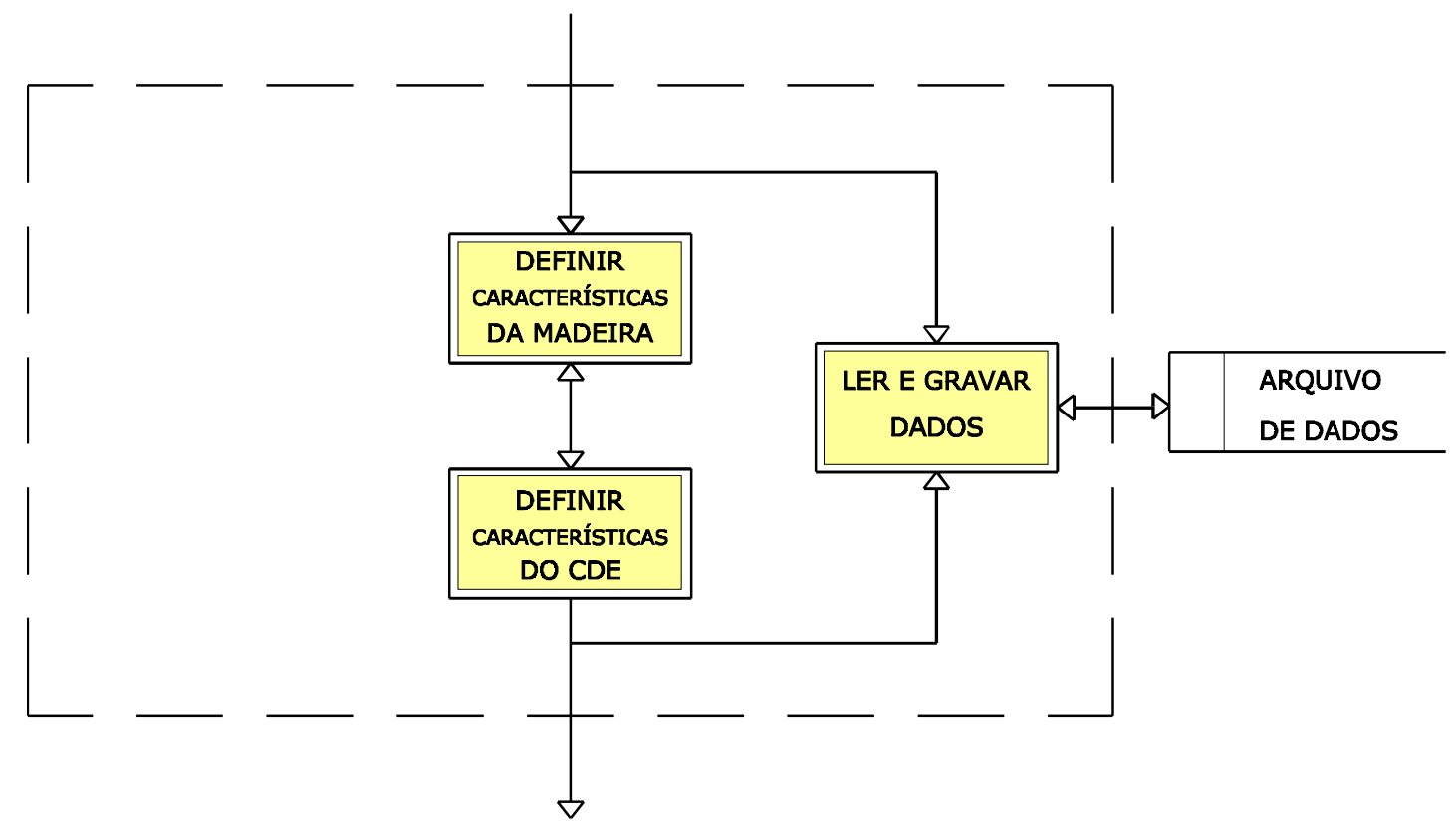

FIGURA 17 - Diagrama de Fluxo de Dados - Módulo 2.

A definição de materiais corresponde às características de materiais utilizados na estrutura e condições de uso que afetam o seu comportamento, tais como classe de resistência, classe de umidade, e categoria da madeira. Os valores de resistência de conectores CDE devem ser fornecidos e garantidos pelo fabricante, de acordo com a recomendação da NBR 7190/97. 


\subsection{3 - DEFINIÇÃO DE AÇÕES (MÓDULO 3)}

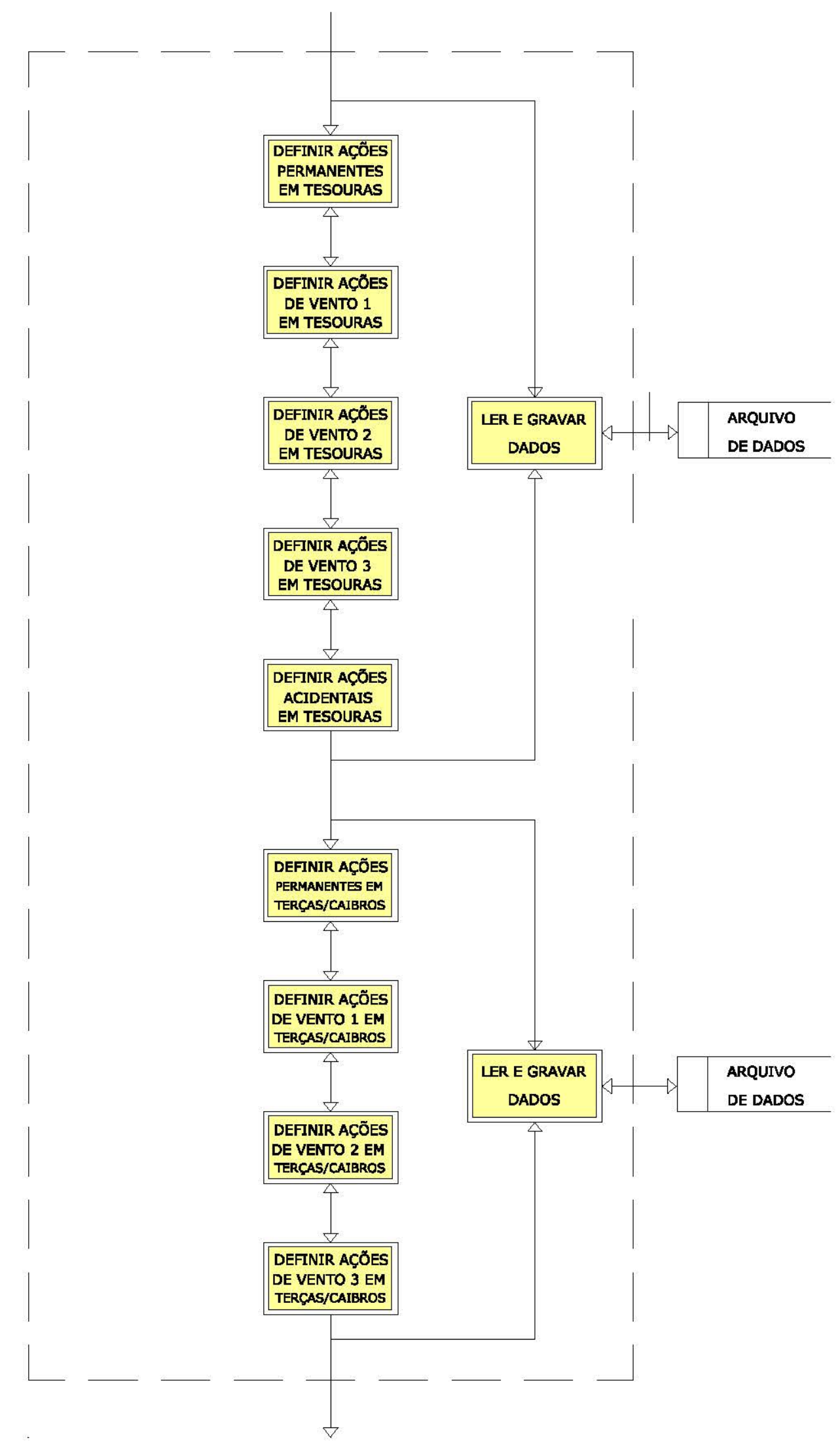

FIGURA 18 - Diagrama de Fluxo de Dados - Módulo 3. 
O sistema permite que cinco condições de ações distintas sejam aplicadas à estrutura principal:

Ações Permanentes;

Ações de Vento 1;

Ações de Vento 2;

Ações de Vento 3;

Ações Acidentais.

Os valores destas ações aplicadas à estrutura podem ser definidos pela carga distribuída na estrutura e/ou cargas concentradas aplicadas aos nós de tesouras. Em estruturas com todos os nós de tesoura articulados, as cargas distribuídas aplicadas ao banzo superior serão transportadas aos nós adjacentes das barras em forma de forças horizontais e verticais equivalentes, descartando a influência dos momentos de engastamento destas barras.

Em estruturas do tipo intermediário, ações em terças e caibros (para telhas cerâmicas) são aplicadas como ações distribuídas pela tela para definição de ações em terças e caibros. 


\subsection{4 - ESFORÇOS / DESLOCAMENTOS (MÓDULO 4)}

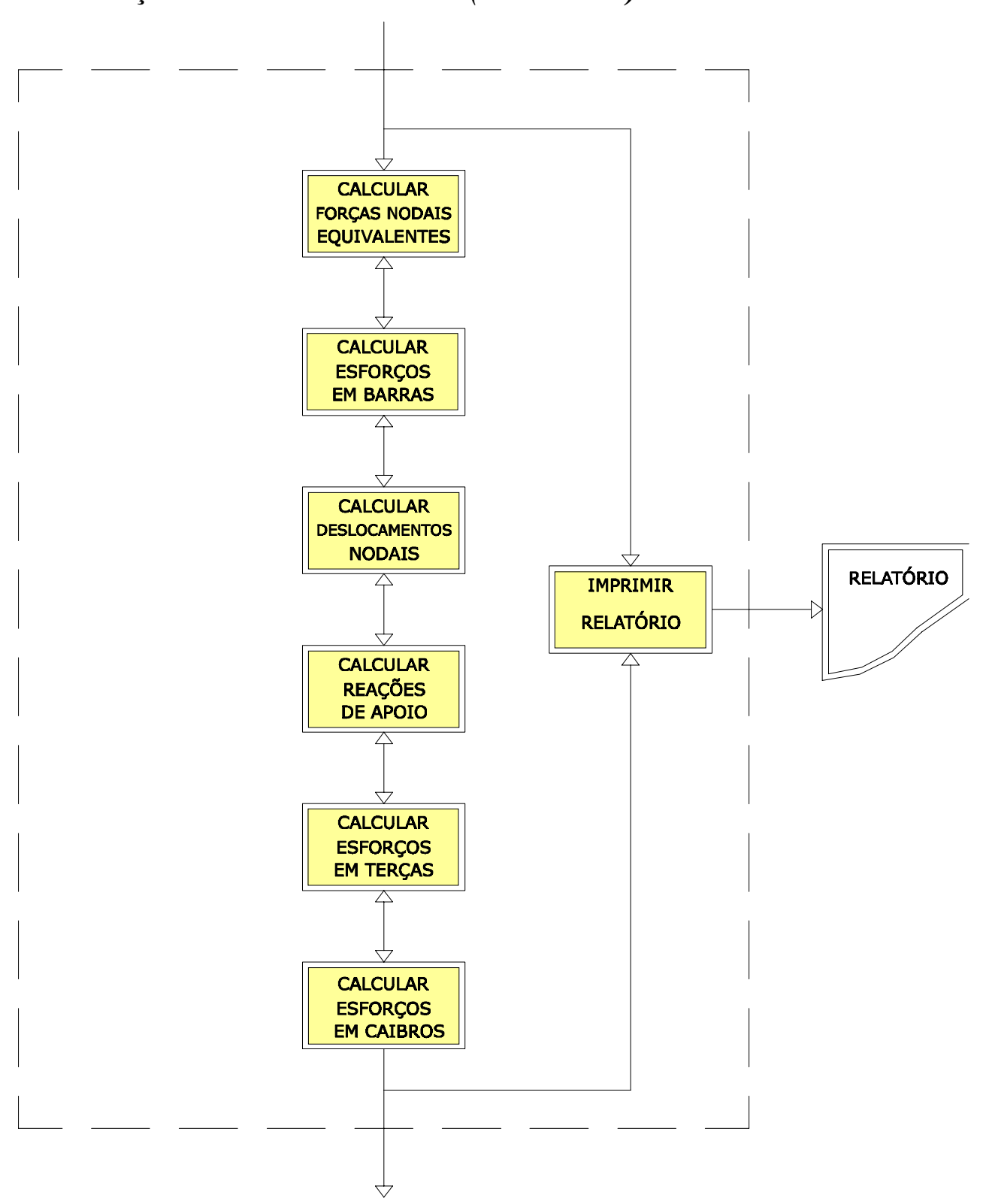

FIGURA 19 - Diagrama de Fluxo de Dados - Módulo 4.

O modelo de cálculo de esforços em barras de tesoura adotados neste sistema é baseado na proposta de GESUALDO \& GRECO (1997), descrita no ítem 2.3.1.2, que considera os banzos das tesouras como peças contínuas, com articulações nos encontros de banzos e nos pontos de mudanças de inclinação. Neste modelo, montantes e diagonais são consideradas com extremidades perfeitamente articuladas. Deve-se lembrar que emendas nos banzos devem ser posicionadas em regiões de momento nulo na barra.

A consideração da continuidade das barras dos banzos das tesouras é justificada pela disponibilidade de recursos computacionais que permitam a análise matricial de modelos estruturais mais complexos e mais próximos do fenômeno real. Além disso, ao analisarmos a 
alternativa estrutural descrita no ítem 2.2.3.3 - Sistema Pré-fabricado, notamos a ocorrência de ripas fixadas diretamente às tesouras, caracterizando a ocorrência de carga distribuída ao longo das barras do banzo superior das tesouras, e por conseqüência, solicitações de momentos fletores nestas barras. Estaticamente, tais esforços podem ser melhor avaliados por modelos que consideram a continuidade de barras dos banzos da estrutura.

A determinação de esforços e deslocamentos dos elementos estruturais das tesouras é feita pelos conceitos de análise matricial apresentados por SOUZA \& ANTUNES (1995), descritos no item 2.3.1.3. Os valores de esforços retornados pelo sistema correspondem ao esforço normal (constante ao longo da barra), ao esforço cortante máximo (nas regiões de extremidades da barra) e esforços de momento máximo ao longo da barra, calculados em função dos momentos de extremidades da barra, pela expressão :

$$
\begin{aligned}
& M_{\text {max }}=-M_{1}+\frac{V_{1}^{2}}{2 p} \\
& \text { para } 0<\mathrm{X}<\mathrm{L} \text {; onde } X=-\frac{V_{1}}{p}
\end{aligned}
$$

FIGURA 20 - Esforços de momento e cortante nas extremidades de uma barra.

Onde :

M1 e M2 são esforços de momento nas extremidades da barra;

V1 e V2 são esforços de cortante nas extremidades da barra;

L é o comprimento da barra;

P é a carga distribuída ao longo da barra.

Para X fora do intervalo especificado, o momento máximo será o momento de uma das extremidades da barra.

O cálculo de esforços de terças se faz pela consideração do modelo de viga biapoiada submetida a carregamentos inclinados em relação aos eixos principais de sua seção transversal que resultam em esforços de flexão simples oblíqua, conforme descrito no 
item 2.3.2.. Não foram considerados neste trabalho os efeitos de continuidade de terças em relação aos apoios na tesoura, por questões de disponibilidade de peças de mercado. Uma breve pesquisa no mercado fornecedor de madeiras, mostrará que barras de madeira de seções transversais $6 \times 12 \mathrm{~cm}$ e $6 \times 16 \mathrm{~cm}$ sugeridas por CALIL (1995), em comprimentos superiores a 5,5m não são facilmente encontradas, inviabilizando a prática de fixação de terças com mais de 2 tramos consecutivos sem emendas. O cálculo dos esforços de flexão em vigas contínuas de 2 tramos resulta em valor de momento fletor negativo na região do apoio intermediário igual ao valor resultante do cálculo de momento fletor positivo na região do meio de um tramo isolado, quando calculado como simplesmente apoiado. Pode-se concluir pelo exposto, que o modelo tradicional de cálculo de terças consideradas isoladamente como simplesmente apoiada em cada tramo, não considerando o efeito de continuidade da peça, é adequado para avaliação de esforços de flexão em função das dimensões comerciais de peças de madeira disponíveis no mercado.

O cálculo de esforços de caibros se faz pela consideração do modelo de viga biapoiada submetida a carregamentos inclinados em relação ao eixo longitudinal da peça que resultam em esforços de flexão composta, conforme descrito no item 2.3.3. Como no cálculo de esforços em terças, o modelo tradicional de cálculo de caibros considerados isoladamente como simplesmente apoiado em cada tramo é adequado para avaliação de esforços de flexão em função das dimensões comerciais de peças de madeira disponíveis no mercado. 
3.2.5 - DIMENSIONAMENTO (MÓDULO 5)

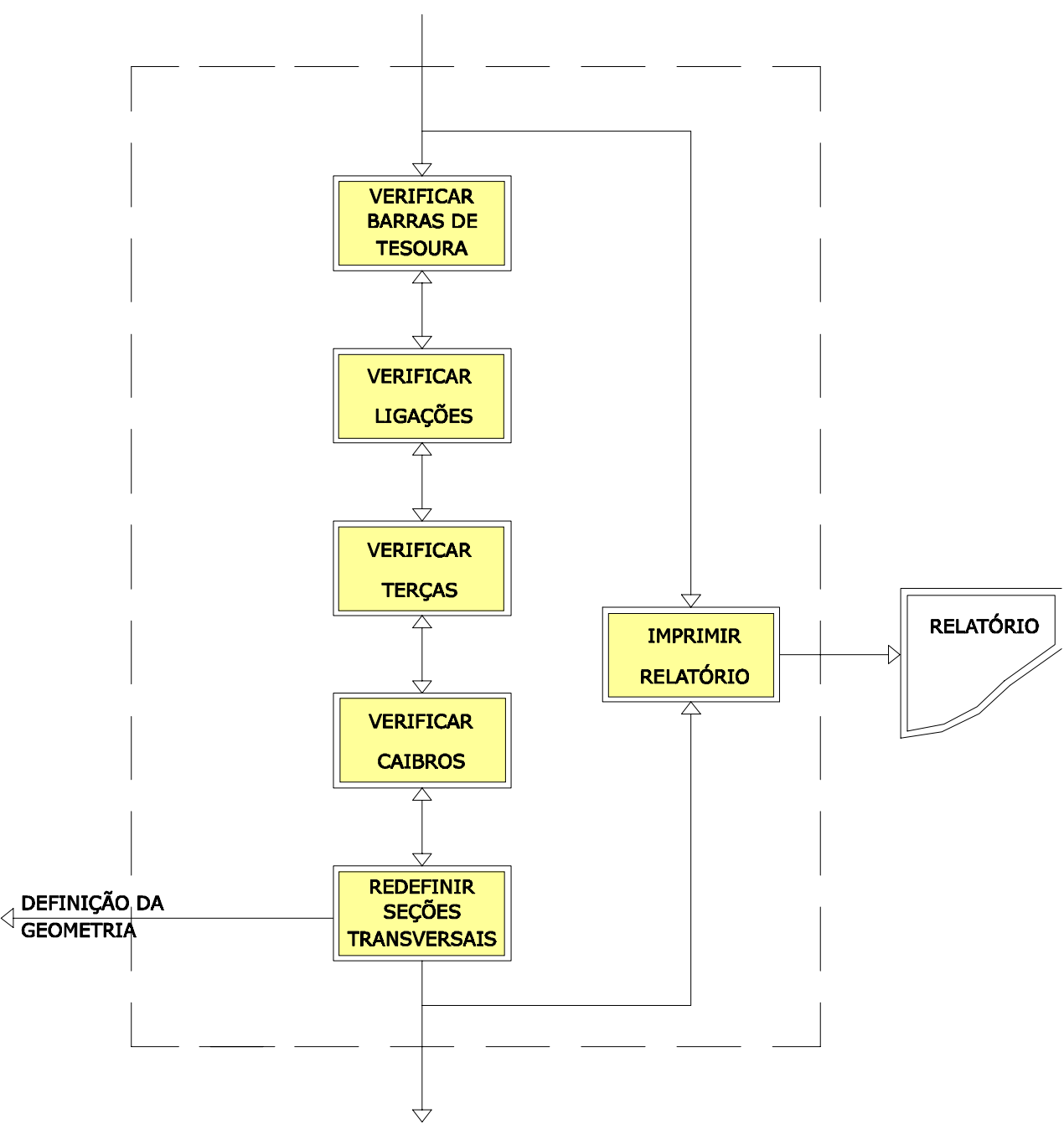

FIGURA 21 - Diagrama de Fluxo de Dados - Módulo 5. 


\subsubsection{1 - VERIFICAÇÃO DE BARRAS DE TESOURAS}

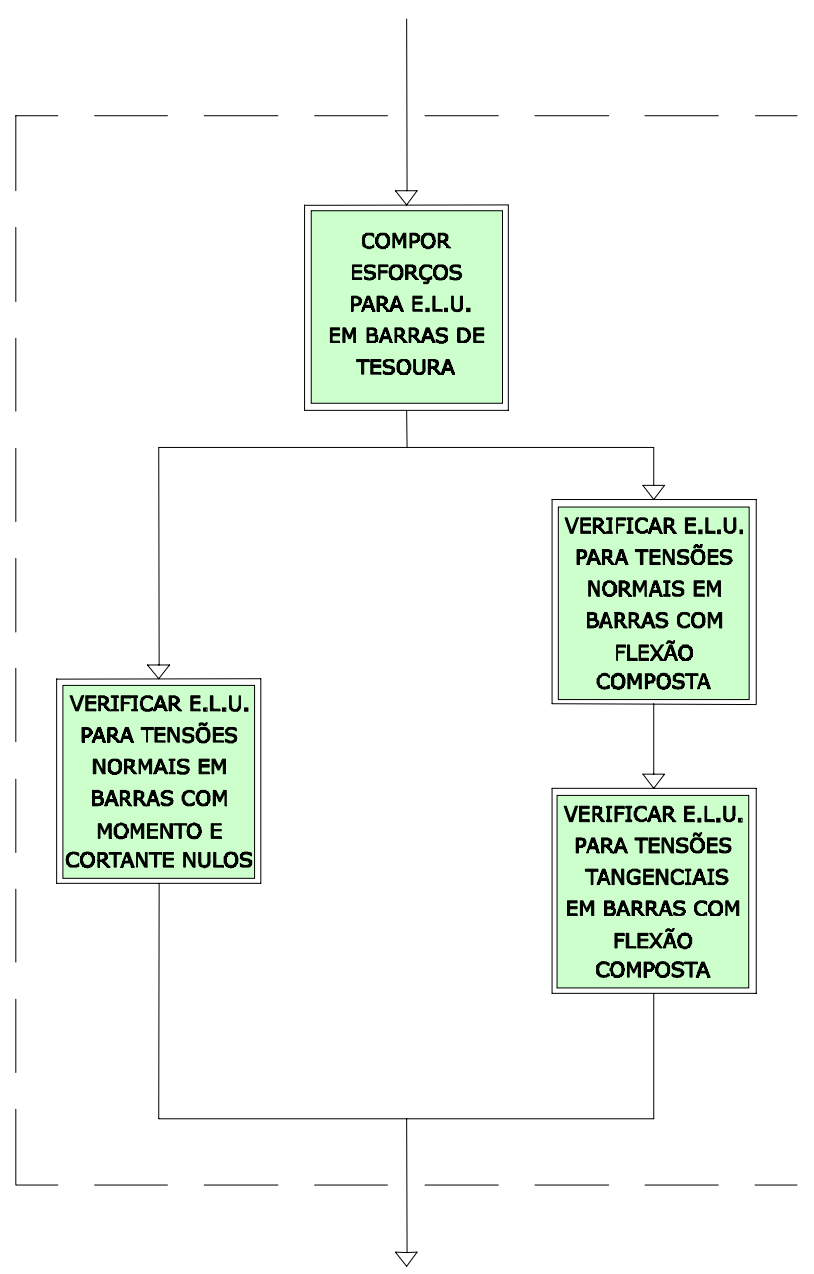

FIGURA 22 - Diagrama de Fluxo de Dados - Módulo 5.1.

O sistema calcula todas as composições possíveis de ações impostas à estrutura, considerando, para verificação dimensional de barras, os valores críticos de composição de esforços atuantes em cada barra da tesoura.

Barras de tesouras submetidas apenas a esforços normais (diagonais e montantes) têm suas dimensões verificadas em relação às condições de segurança para o estado limite último em tração paralela e compressão paralela. Em barras comprimidas com índice de esbeltez superior a 40 a verificação é feita em relação ao estado limite último de instabilidade. Os critérios de verificação da segurança de barras da estrutura principal são descritos apresentados na NBR 7190/97 e descritos nos itens 2.4.3.1.1 e 2.4.3.1.2.

Barras de tesouras solicitadas por esforços normais e momentos fletores (banzos) têm verificadas suas dimensões em relação às condições de segurança para o estado limite último em flexão composta, conforme apresentado na NBR 7190/97 e descrito no item 2.4.3.1.5. 
3.2.5.2 - VERIFICAÇÃO DE LIGAÇÕES ENTRE BARRAS DE TESOURAS

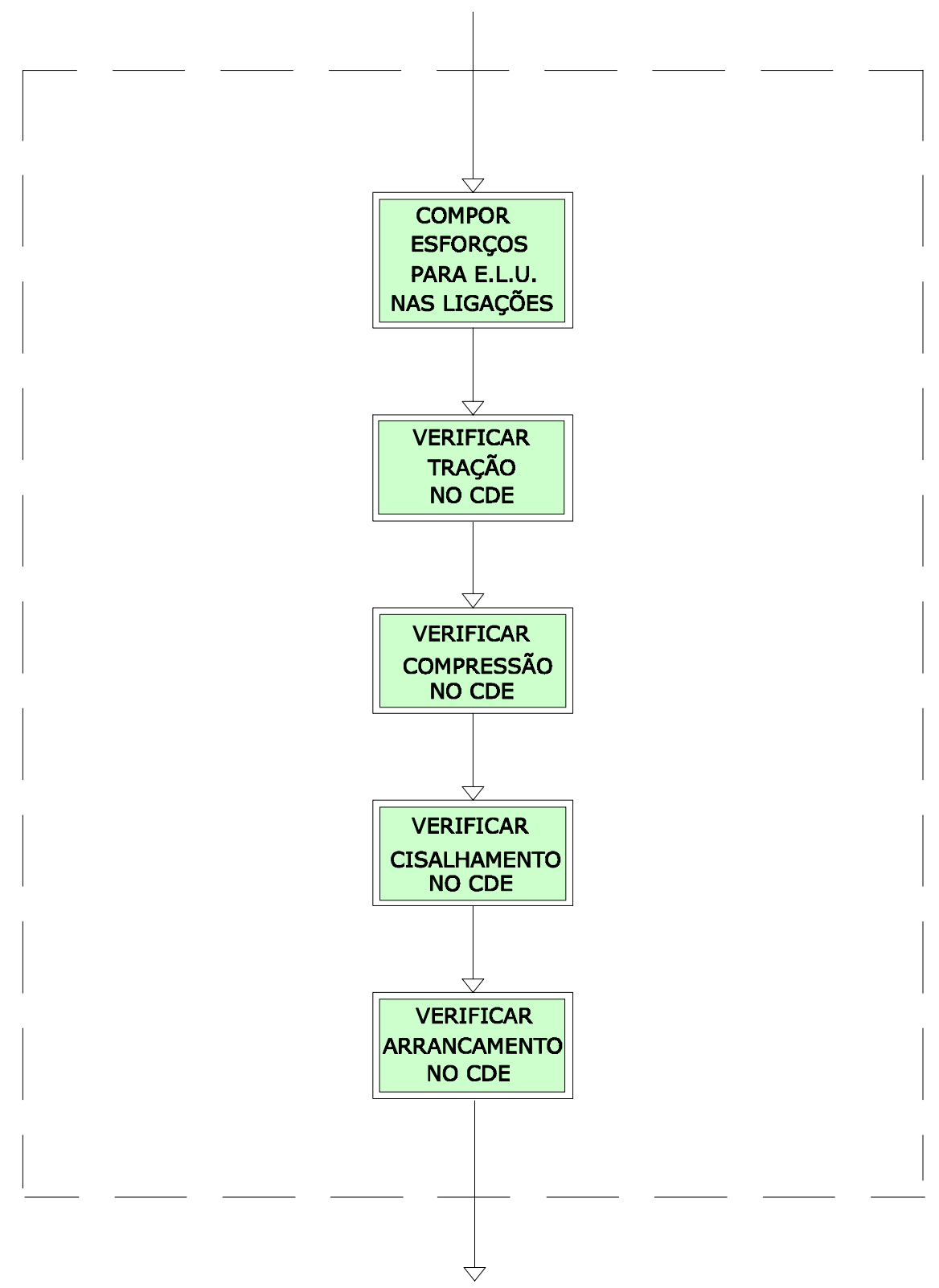

FIGURA 23 - Diagrama de Fluxo de Dados - Módulo 5.2. 
O sistema calcula todas as composições possíveis de ações impostas à estrutura, considerando, para verificação dimensional de ligações entre barras, os valores críticos de composição de esforços atuantes em cada barra da tesoura.

O sistema considera as ligações entre elementos de tesouras através de conectores metálicos de dentes estampados (CDE), previstas pela NBR 7190/97, por serem estes os mais adequados ao processo de industrialização de estruturas de cobertura. De acordo com as hipóteses de cálculo dos elementos da tesoura, as extremidades de diagonais e montantes, os encontros entre banzos e os pontos de mudança de inclinação de banzos da tesoura são considerados como perfeitamente articulados. Os esforços nas ligações entre elementos da estrutura principal são, portanto, resultado dos esforços axiais das barras que convergem a um determinado nó, considerados segundo o ângulo de incidência das barras. O modelo de cálculo de ligações entre elementos de tesouras adotado neste sistema não considera momentos fletores em barras de tesouras que resultam de elementos de ligação.

Da mesma forma, nas emendas de barras dos banzos da estrutura principal, são considerados somente os esforços axiais. Neste caso, as emendas devem se posicionadas em pontos de momentos fletores nulos nas barras dos banzos da estrutura.

As condições de segurança em ligações por conectores metálicos com dentes estampados $\mathrm{CDE}$ não têm critérios de verificação fornecidos pela norma, sendo neste trabalho verificadas pelo procedimento proposto por BARALDI (1998), e descrito no item 2.4.4. 


\subsubsection{3 - VERIFICAÇÃO DE TERÇAS DA ESTRUTURA}

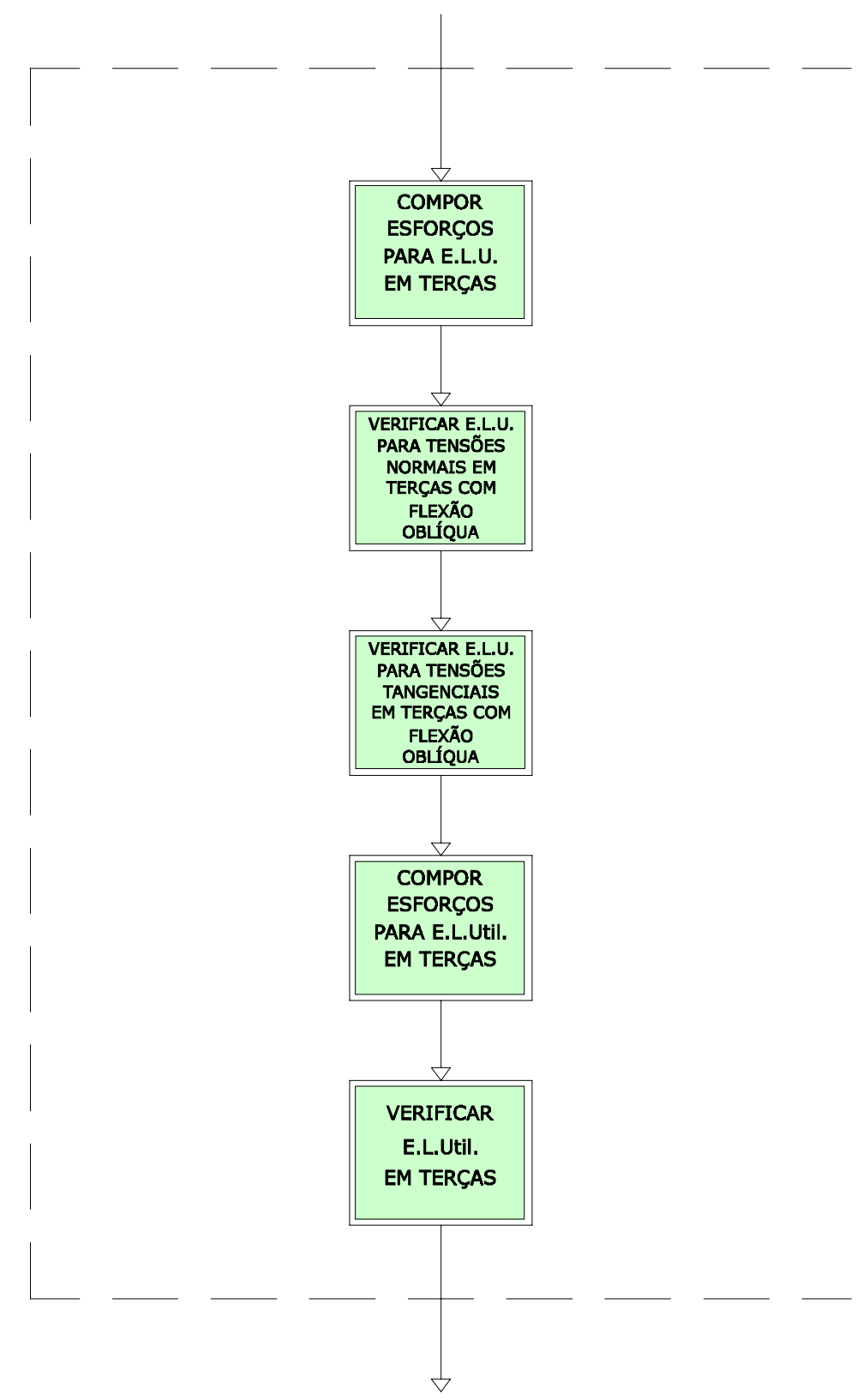

FIGURA 24 - Diagrama de Fluxo de Dados - Módulo 5.3. 
O sistema calcula todas as composições possíveis de ações impostas à terças da estrutura, considerando, para verificação dimensional de terças, os valores críticos de composição de esforços atuantes. Na composição de esforços em terças, é considerada além das ações determinadas pelo usuário, uma carga concentrada de $1 \mathrm{KN}$ aplicada no meio do vão de terças.

O sistema opera com terças de seção transversal retangular, que pela inclinação das tesouras onde se apoiam, são submetidas, no caso geral, a flexão oblíqua. As dimensões de terças são verificadas em relação às condições de segurança para estado limite último em flexão oblíqua apresentadas por CALIL et al (1998), e descritas no item 2.4.3.1.6.

As flechas devidas a esforços de flexão são determinadas pelas expressões seguintes e verificadas em relação ao estado limite de utilização, em relação aos dois eixos principais da peça, conforme descrito no item 2.4.3.2.

$$
v_{d}=\frac{p_{d} \cdot 5 \cdot L^{4}}{384 \cdot E_{c 0, e f \cdot I}} \quad ; \quad v c=\frac{P_{d} \cdot L^{3}}{48 \cdot E_{c 0, e f \cdot I}}
$$

onde :

$v_{d}=$ flecha na peça de madeira devida a carga distribuída;

$v_{c}=$ flecha na peça de madeira devida a carga concentrada;

$p_{d}=$ força distribuída de cálculo aplicada na peça de madeira;

$P_{d}=$ força concentrada de cálculo aplicada na peça de madeira;

$L=$ vão livre da peça de madeira;

$E_{c 0, e f}=$ módulo de elasticidade efetivo, na direção paralela às fibras de madeira;

$I=$ momento de inércia da seção transversal da peça de madeira. 


\subsubsection{4 - VERIFICAÇÃO DE CAIBROS DA ESTRUTURA}

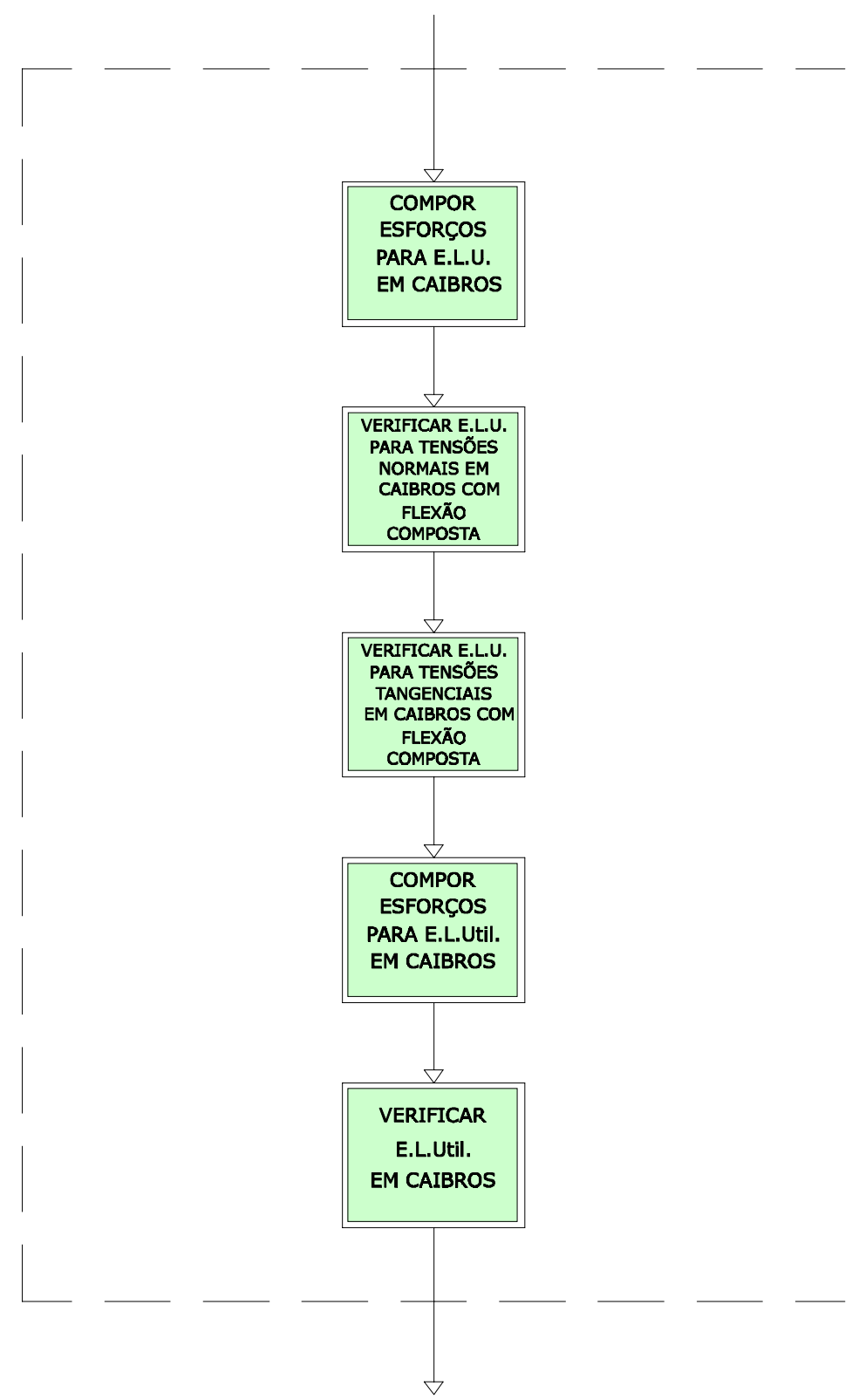

FIGURA 25 - Diagrama de Fluxo de Dados - Módulo 5.4. 
O sistema calcula todas as composições possíveis de ações impostas aos caibros do telhado, considerando, para dimensionamento de caibros, os valores críticos de composição de esforços atuantes.

O sistema opera com caibros de seção transversal retangular, que pela inclinação da estrutura principal, são submetidas a flexão composta. As dimensões de caibros são verificadas em relação às condições de segurança para estado limite último em flexão composta apresentadas por CALIL et al (1998), e descritas no item 2.4.3.1.5.

As flechas devidas a esforços de flexão são determinadas pelas expressões seguintes, e verificadas em relação ao estado limite de utilização, conforme descrito no item 2.4.3.2.

$$
v_{d}=\frac{p_{d} \cdot 5 \cdot L^{4}}{384 \cdot E_{c 0, e f \cdot I}}
$$

onde :

$v_{d}=$ flecha na peça de madeira devida a carga distribuída;

$p_{d}=$ força distribuída de cálculo aplicada na peça de madeira;

$L=$ vão livre da peça de madeira;

$E_{c 0, e f}=$ módulo de elasticidade efetivo, na direção paralela às fibras de madeira;

$I=$ momento de inércia da seção transversal da peça de madeira. 


\subsection{6 - ARQUIVO DE DADOS}

O sistema gera arquivo (com extensão PRT) para gravação e leitura de dados do projeto. $\mathrm{O}$ arquivo gerado armazena todas as informações introduzidas pelo usuário, podendo ser acessado para salvar o projeto corrente ou ler um projeto existente a qualquer momento da execução do sistema.

\subsection{7 - RELATÓRIO}

O sistema retorna ao usuário os dados resultantes da análise do projeto em questão em forma de relatório impresso ou em arquivo. $\mathrm{O}$ relatório gerado informa ao usuário os dados que definem a estrutura, as condições de carregamento, esforços calculados, deslocamentos e dimensionamento dos elementos estruturais do telhado, como descritos :

Dados de Projeto : Correspondem aos dados que o usuário informa ao sistema, tais como definição da geometria da estrutura, dados para a definição automática da geometria da estrutura, condições de vinculação da estrutura principal, dados de carregamento e dados de materiais utilizados na estrutura.

Dados de Análise Estrutural dos Elementos: Correspondem aos esforços máximos, deslocamentos calculados nos elementos da estrutura e reações de apoio da estrutura principal em função dos dados de projeto introduzidos pelo usuário.

Dados de Dimensionamento dos Elementos Estruturais: Correspondem aos coeficientes de verificação dimensional dos elementos estruturais em função dos dados de projeto e dados da análise estrutural dos elementos. Nas ligações entre elementos de tesouras, os conectores CDE tem suas dimensões mínimas efetivas registradas no relatório.

As recomendações para utilização, bem como as instruções para operação e considerações adotadas no desenvolvimento deste software são apresentadas em forma de anexo e devem ser parte integrante do software quando da utilização deste. 


\section{4 - PROJETO EXEMPLO}

Neste capítulo, foi analisada uma situação de projeto de estrutura de cobertura em madeira pelo software MADEPRO. São apresentadas as telas que compõe a interface para entrada de dados de projeto para o software, e o relatório de resultados de cálculo e dimensionamento da estrutura gerado pelo software.

\section{1 - DADOS BÁSICOS DO PROJETO :}

\section{DADOS DA GEOMETRIA DA ESTRUTURA :}

Vão livre de tesoura : 7,50m;Inclinação do telhado : $35 \%$;

Tipo de tesoura : tesoura tipo HOWE com apoio nas extremidades;

Distância entre tesouras : $150 \mathrm{~cm}$;

Distância entre caibros : $60 \mathrm{~cm}$;

Tipo de telha : telhas cerâmicas;

Sistema estrutural tipo intermediário.

\section{DADOS DOS MATERIAIS :}

Madeira:

Classe de resistência : Classe C30 Coníferas; Classe de umidade : Classe 2; Conectores CDE : (Segundo Gang Nail do Brasil)

Resistência à tração longitudinal $=205 \mathrm{daN} / \mathrm{cm}$ de largura do par de conectores;

Resistência à tração transversal $=95 \mathrm{daN} / \mathrm{cm}$ de comprimento do par de conectores;

Resistência à compressão longitudinal $=205 \mathrm{daN} / \mathrm{cm}$ de largura do par de CDE;

Resistência à compressão transversal $=95 \mathrm{daN} / \mathrm{cm}$ de comprimento do par de CDE;

Resistência ao cisalhamento longitudinal $=80 \mathrm{daN} / \mathrm{cm}$ de do par de CDE;

Resistência ao cisalhamento transversal $=170 \mathrm{daN} / \mathrm{cm}$ de largura do par de CDE;

Resistência ao arrancamento de dentes na direção longitudinal $=30 \mathrm{daN} / \mathrm{cm}^{2} \mathrm{de} C D E$;

Resistência ao arrancamento de dentes na direção transversal $=30 \mathrm{daN} / \mathrm{cm}^{2} \mathrm{de}$ CDE; 
DADOS DE AÇÕES APLICADAS NA ESTRUTURA :

Ações em tesouras:

Ações permanentes : $100 \mathrm{daN} / \mathrm{m}^{2}=0,01 \mathrm{daN} / \mathrm{cm}^{2}$;

Ações de vento de sobrepressão : $20 \mathrm{daN} / \mathrm{m}^{2}=0,002 \mathrm{daN} / \mathrm{cm}^{2}$;

Ações de vento de sucção : $60 \mathrm{daN} / \mathrm{m}^{2}=0,006 \mathrm{daN} / \mathrm{cm}^{2}$ no lado esquerdo;

$50 \mathrm{daN} / \mathrm{m}^{2}=0,005 \mathrm{daN} / \mathrm{cm}^{2}$ no lado direito;

Ações acidentais : 300 daN aplicado no meio do vão do banzo inferior da tesoura;

Ações em terças:

Ações permanentes : $140 \mathrm{daN} / \mathrm{m}=1,4 \mathrm{daN} / \mathrm{cm}$;

Ações de vento de sobrepressão : $30 \mathrm{daN} / \mathrm{m}=0,3 \mathrm{daN} / \mathrm{cm}$;

Ações de vento de sucção : $70 \mathrm{daN} / \mathrm{m}=0,7 \mathrm{daN} / \mathrm{cm}$;

Ações em caibros:

Ações permanentes : $60 \mathrm{daN} / \mathrm{m}=0,6 \mathrm{daN} / \mathrm{cm}$;

Ações de vento de sobrepressão : $10 \mathrm{daN} / \mathrm{m}=0,1 \mathrm{daN} / \mathrm{cm}$;

Ações de vento de sucção : $40 \mathrm{daN} / \mathrm{m}=0,4 \mathrm{daN} / \mathrm{cm}$;

\section{2 - ENTRADA DE DADOS PELO SOFTWARE :}

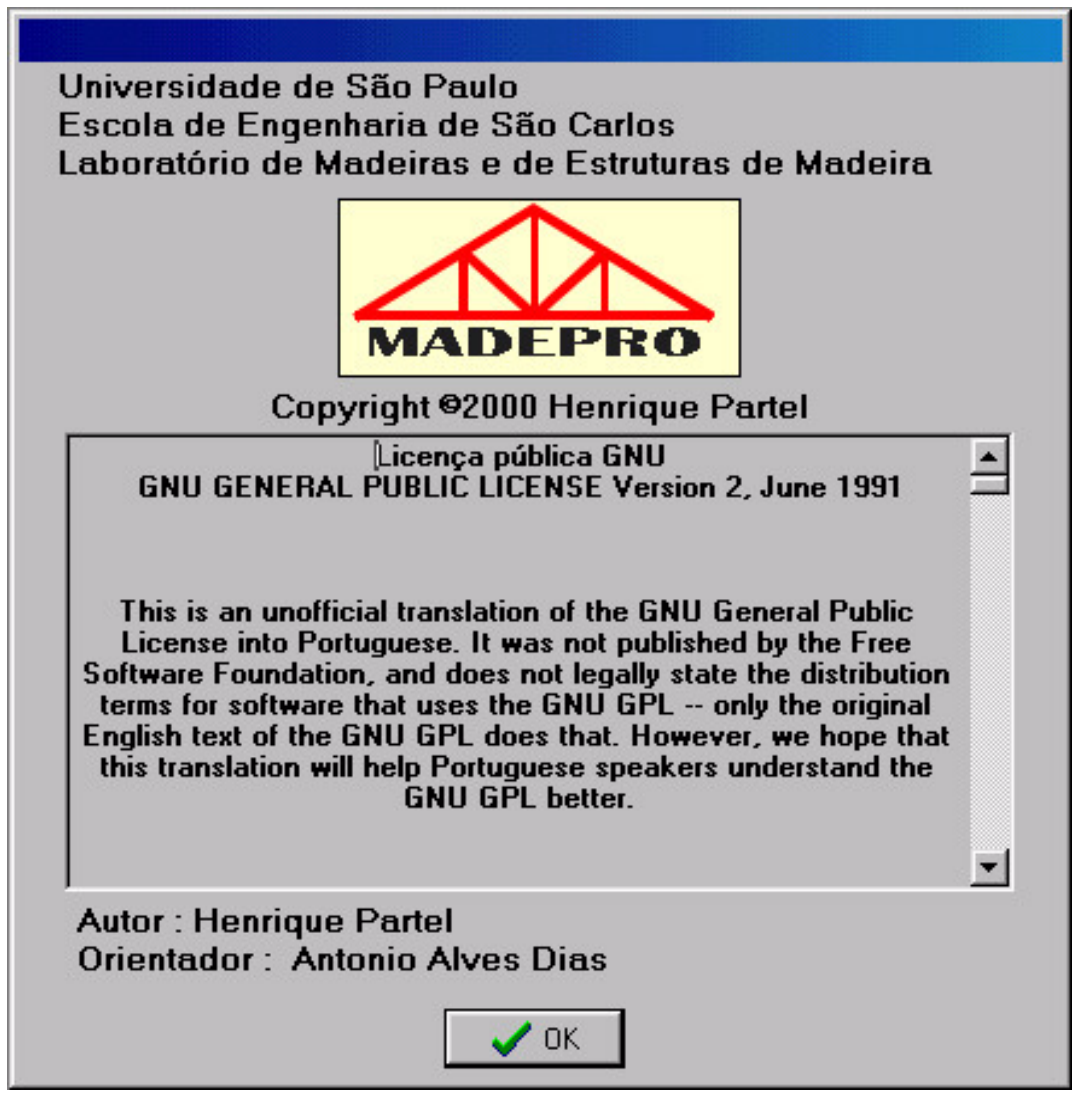

FIGURA 26 - Tela de apresentação do software 


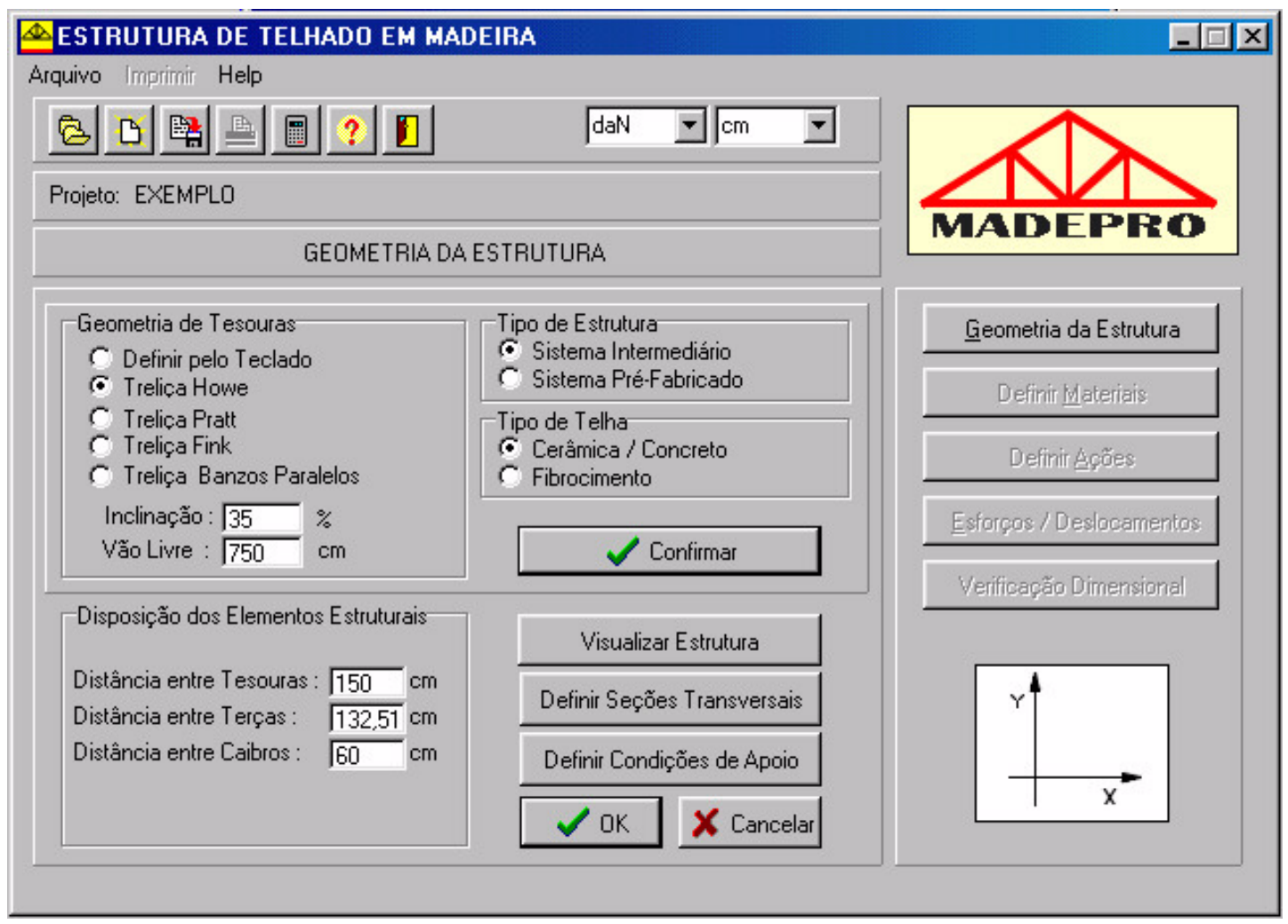

FIGURA 27 - Geometria da estrutura

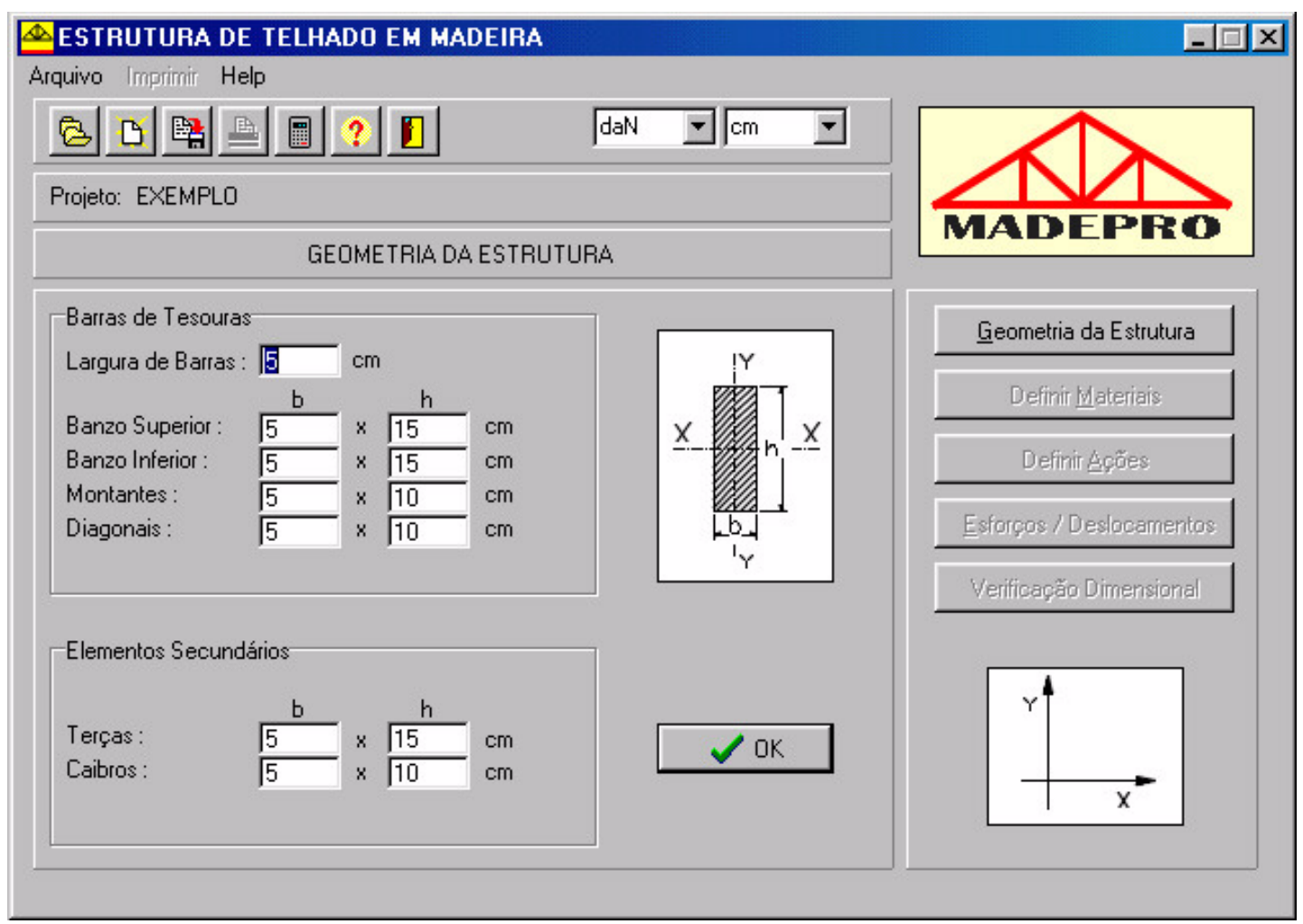

FIGURA 28 - Seções transversais dos elementos da estrutura 


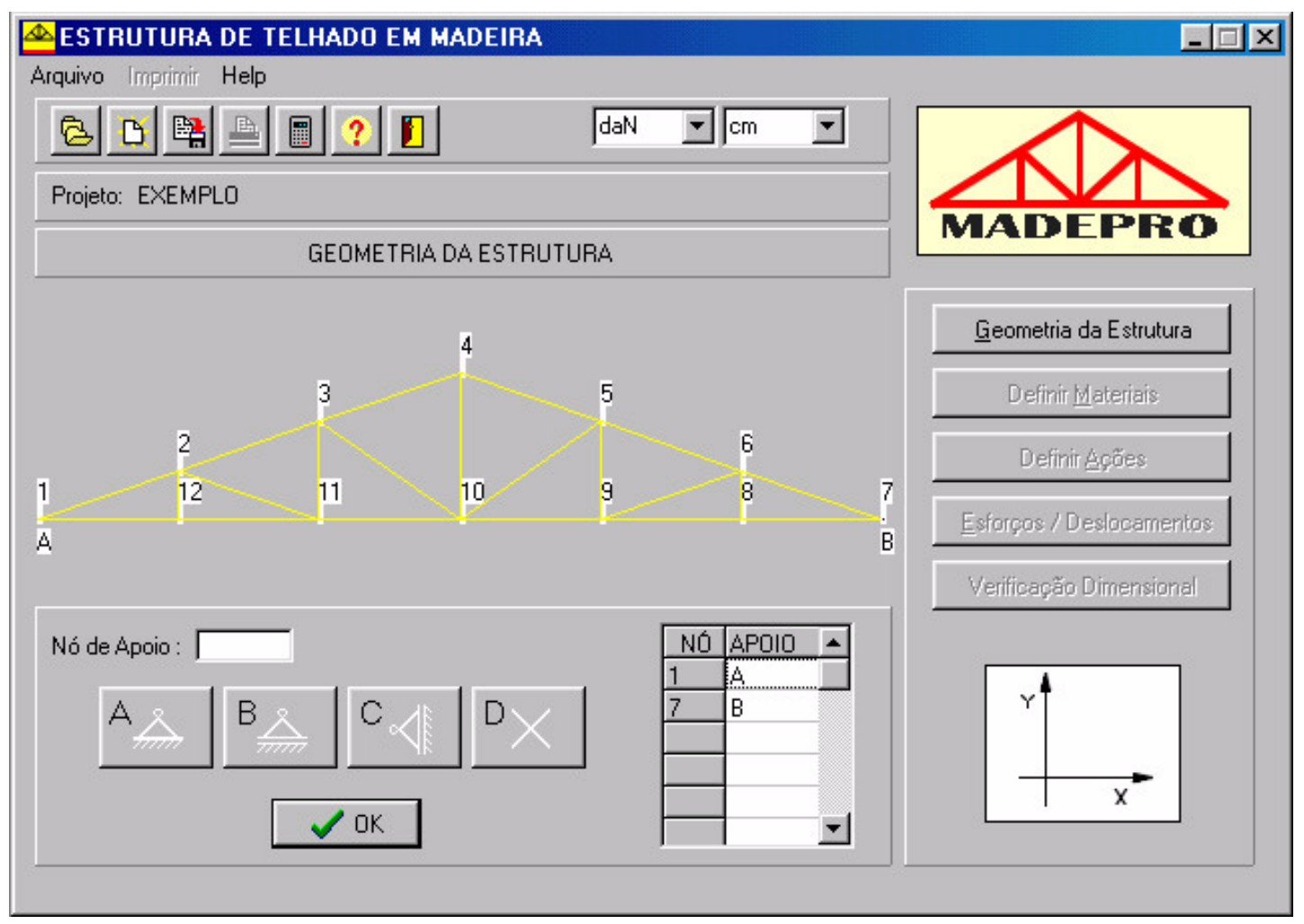

FIGURA 29 - Condições de apoio das tesouras

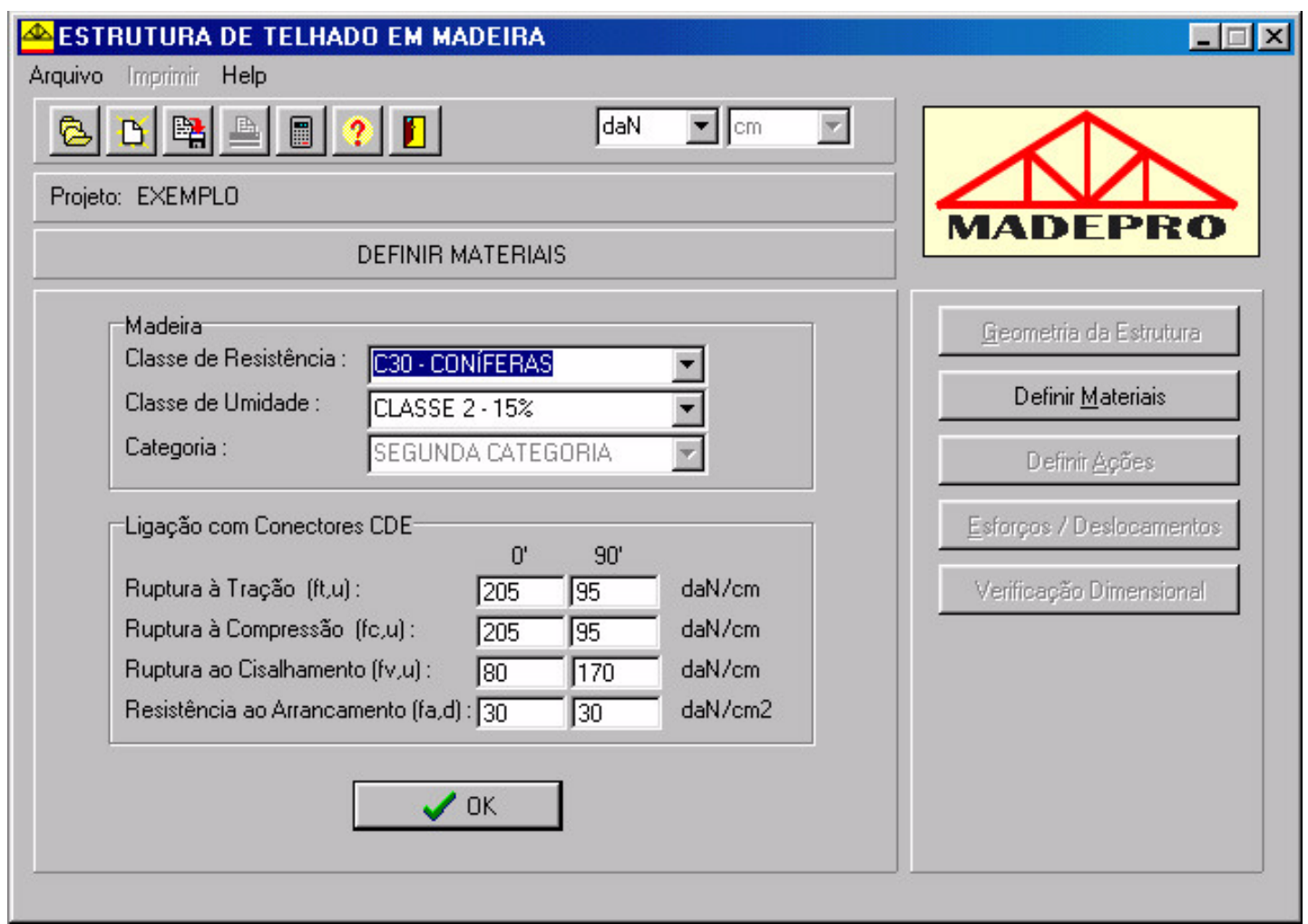

FIGURA 30 - Características de materiais para a estrutura 


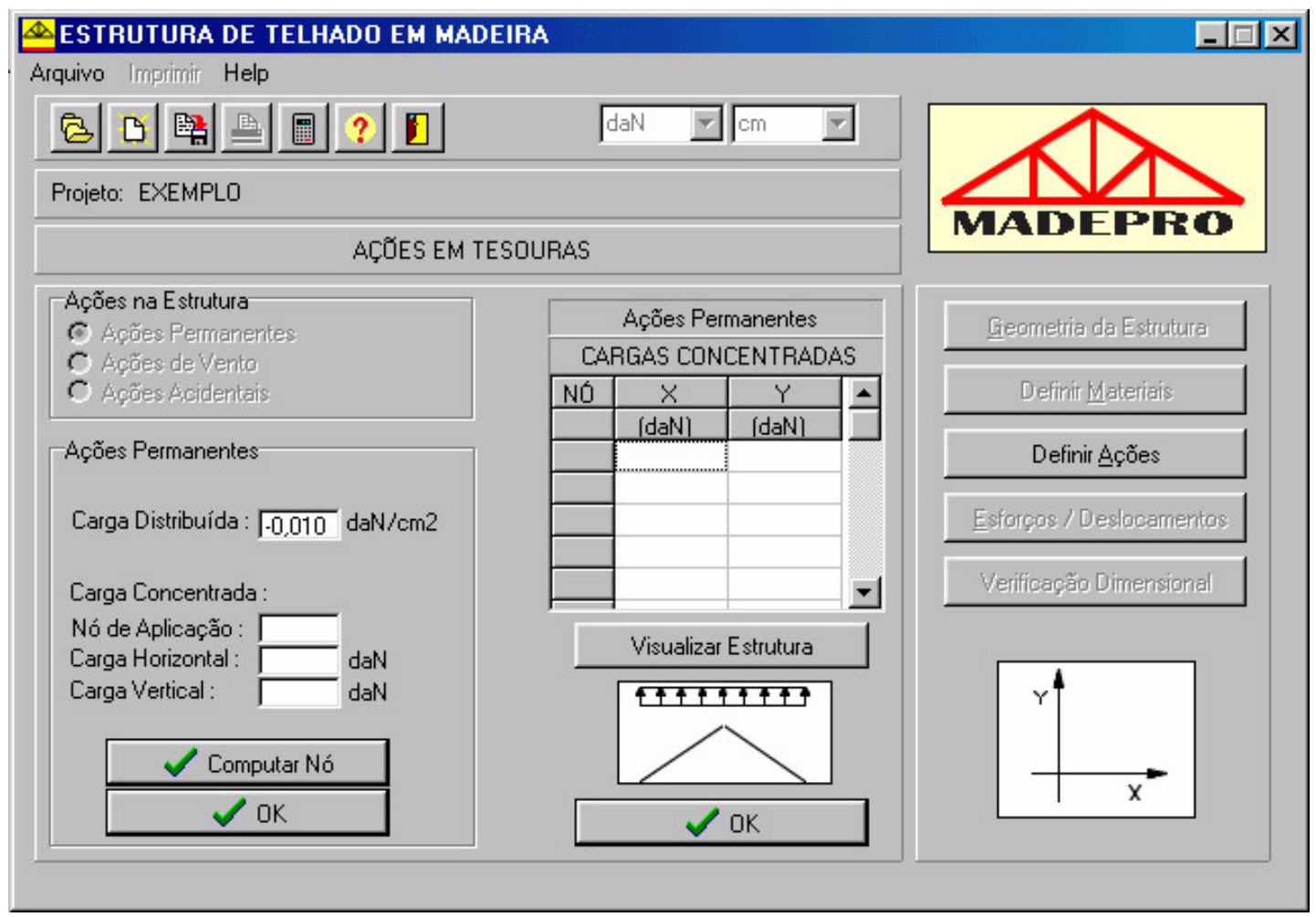

FIGURA 31 - Ações permanentes nas tesouras

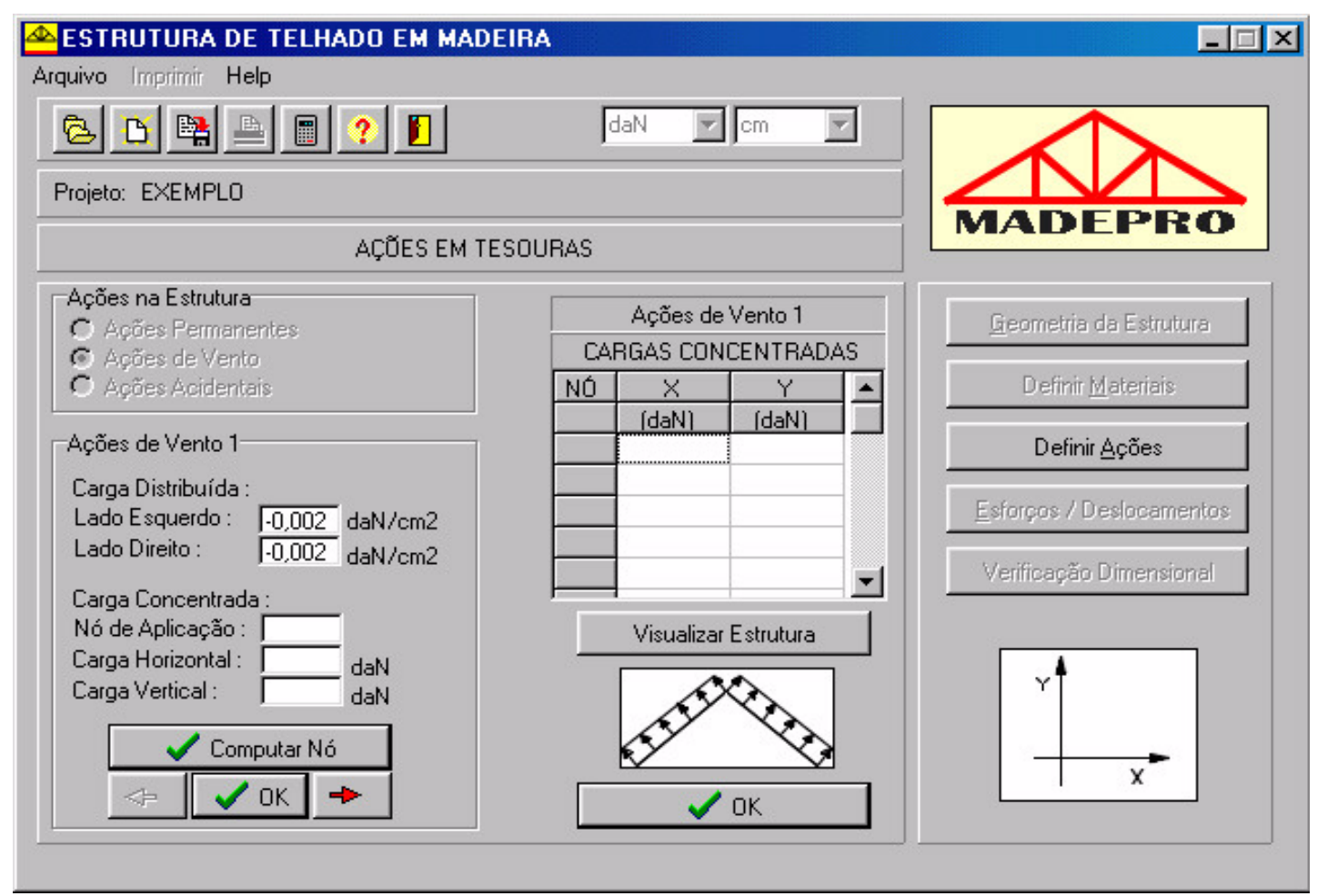

FIGURA 32 - Ações de vento de sobrepressão nas tesouras 


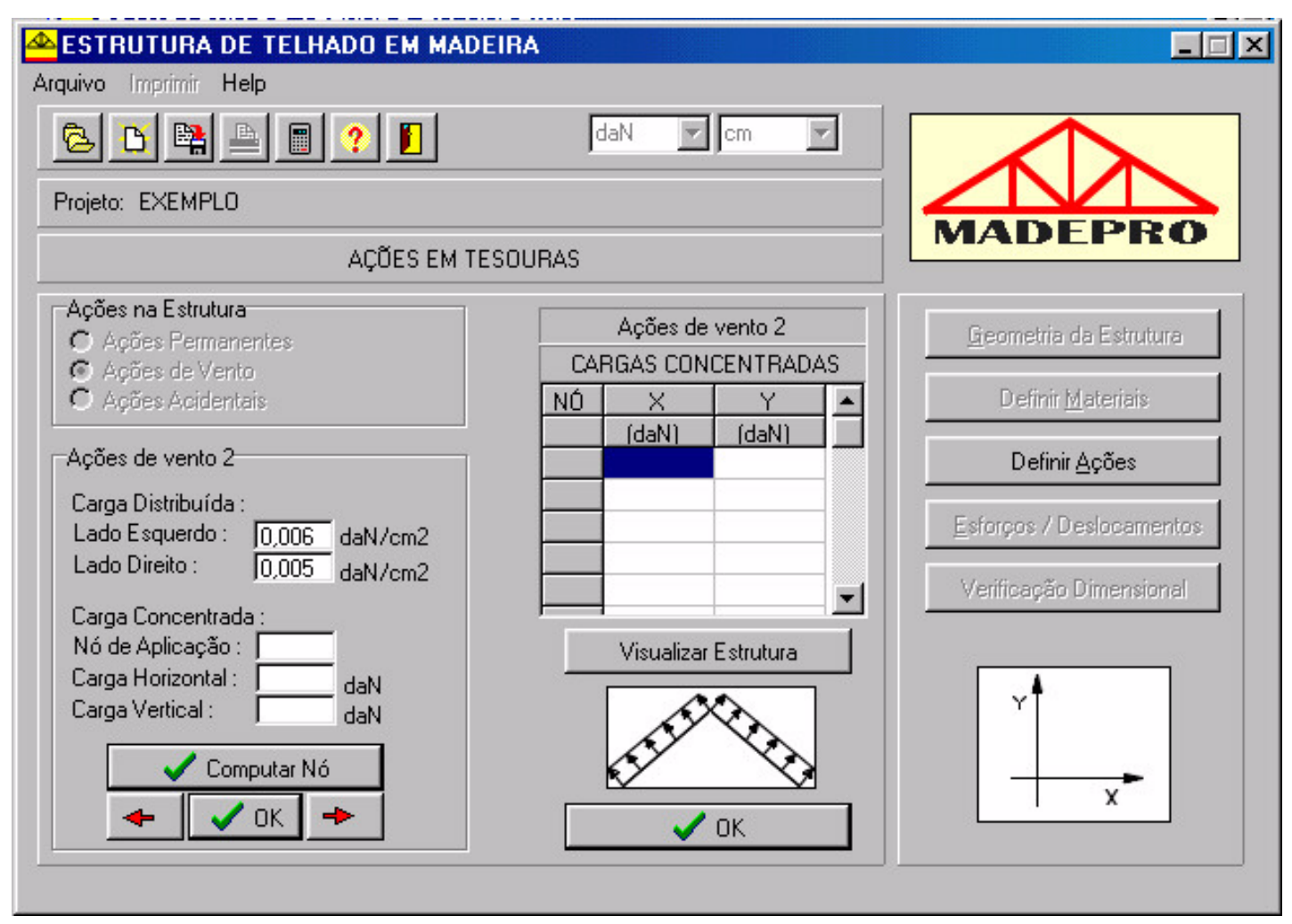

FIGURA 33 - Ações de vento de sucção nas tesouras

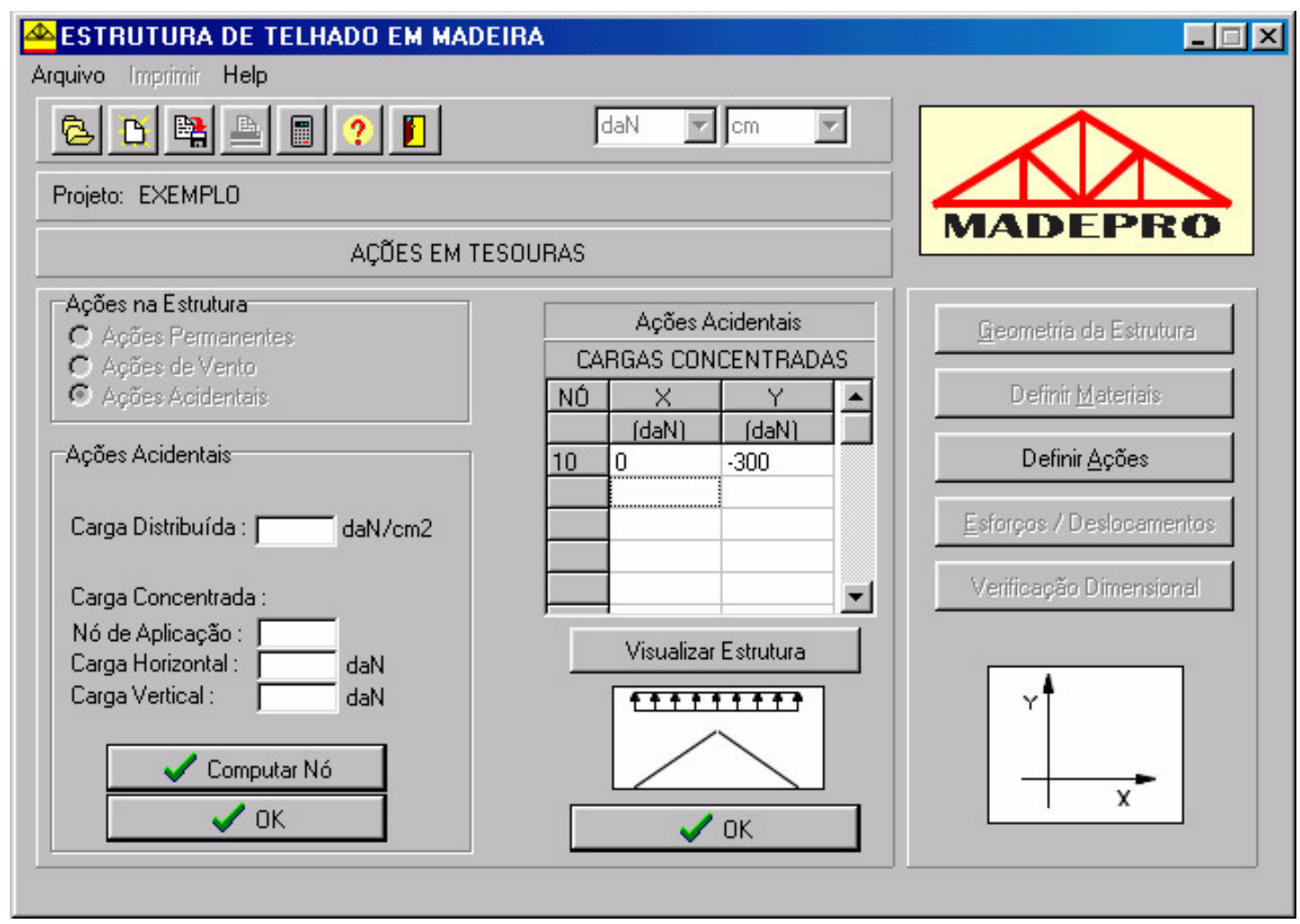

FIGURA 34 - Ações acidentais nas tesouras 


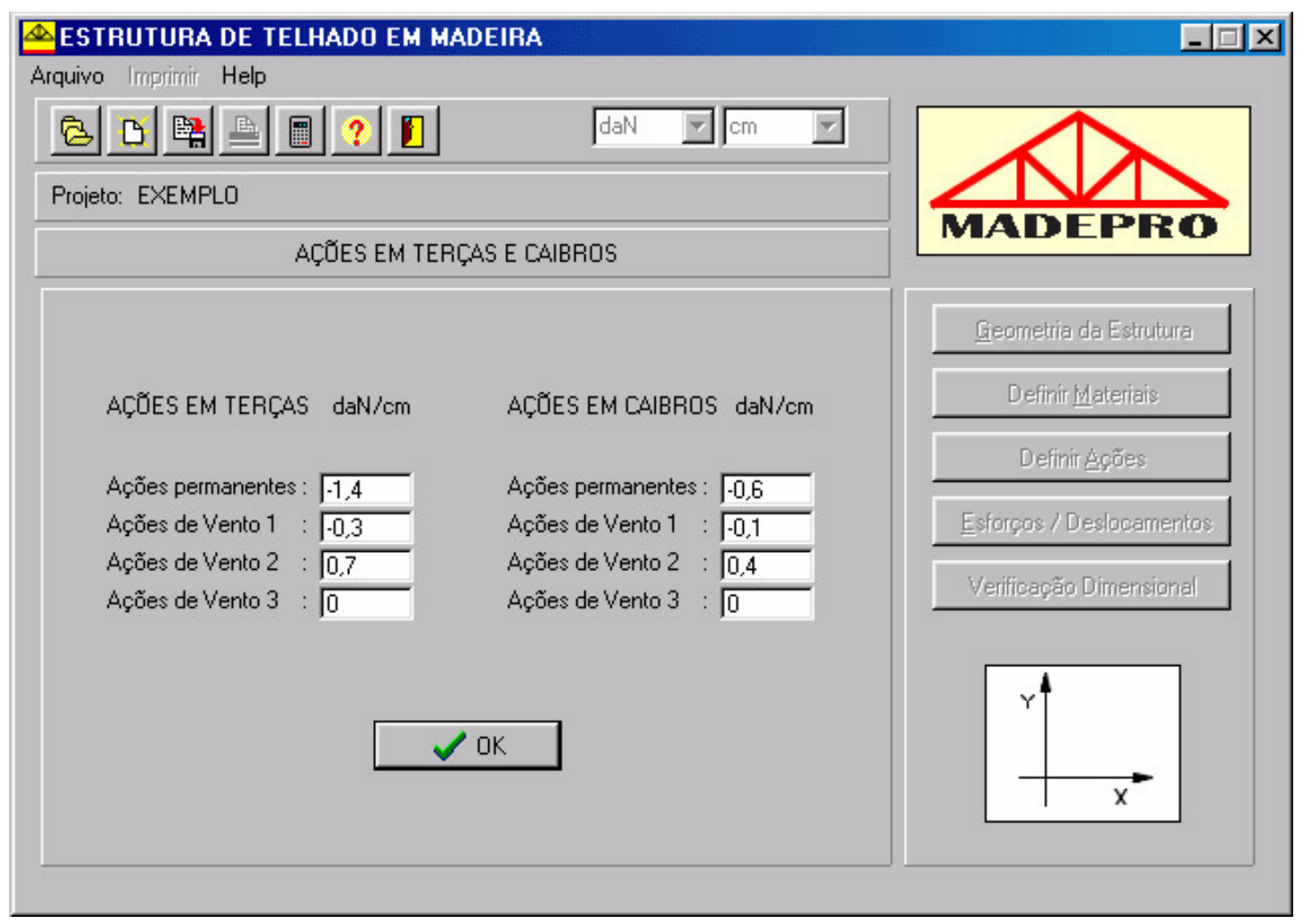

FIGURA 35 - Ações em terças e caibros da estrutura

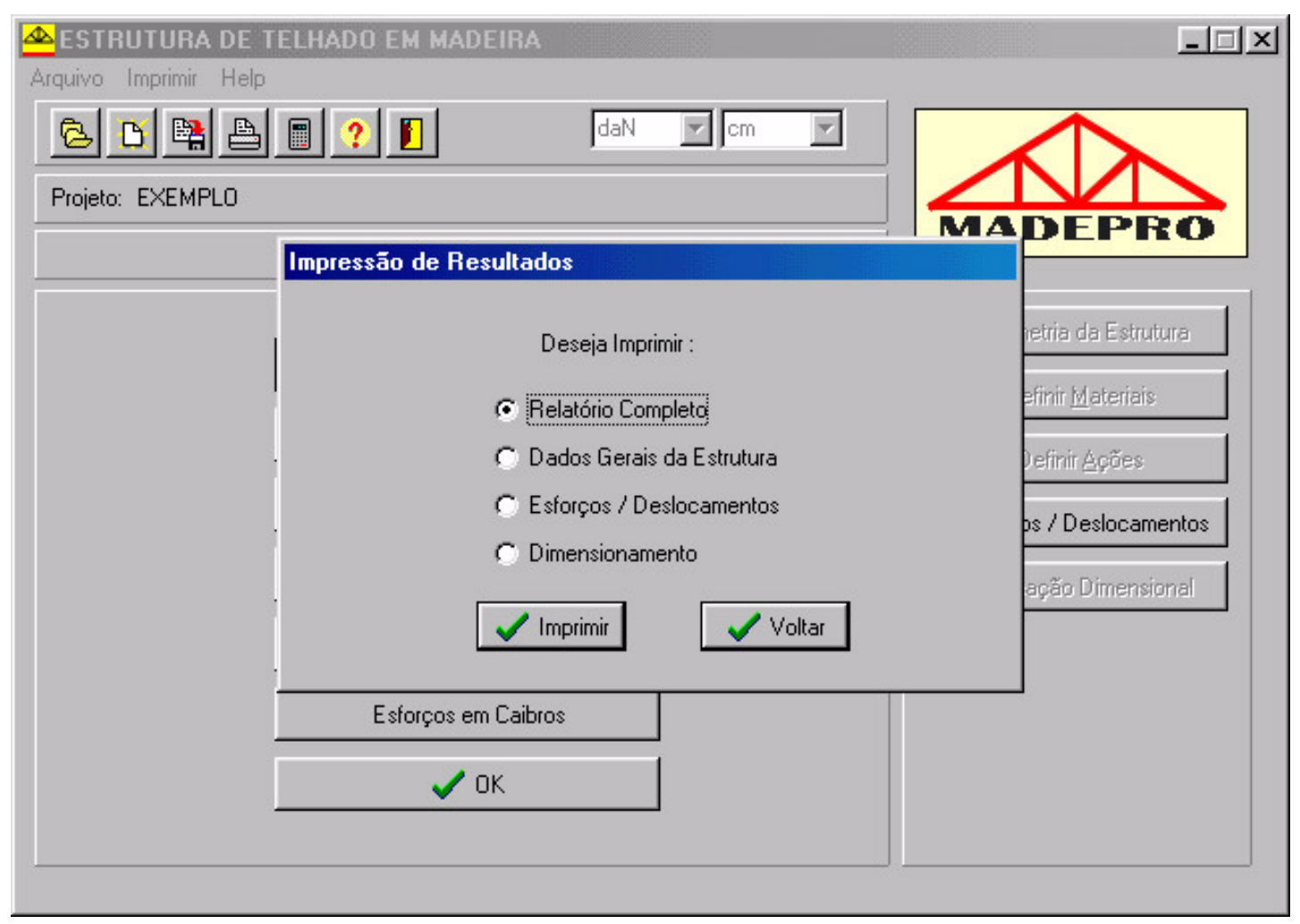

FIGURA 36 - Impressão de relatório 


\section{3 - RELATÓRIO :}

PROJETO : EXEMPLO

CARACTERÍSTICAS DA ESTRUTURA

Tipo de estrutura : Sistema intermediário

Modelo estrutural : Banzos com barras articuladas

Tipo de telha : Telha cerâmica / concreto

\section{CARACTERÍSTICAS DE MATERIAIS}

Classe de resistência da madeira : C30 - CONÍfERAS

Classe de umidade da madeira : CLASSE 2 - 15\%

Categoria da madeira : SEGUNDA CATEGORIA

Resistência CDE à tração - $\quad$ - $(0,90)$ graus : $(205,95)$ daN/cm

Resistência CDE à compressão - $\quad(0,90)$ graus : $(205,95) \mathrm{daN} / \mathrm{cm}$

Resistência CDE ao cisallhamento - $(0,90)$ graus : $(80,170) \mathrm{daN} / \mathrm{cm}$

Resistência CDE ao arrancamento - $(0,90)$ graus : $(30,30) \mathrm{daN} / \mathrm{cm} 2$

\section{CARACTERÍSTICAS DE TERÇAS}

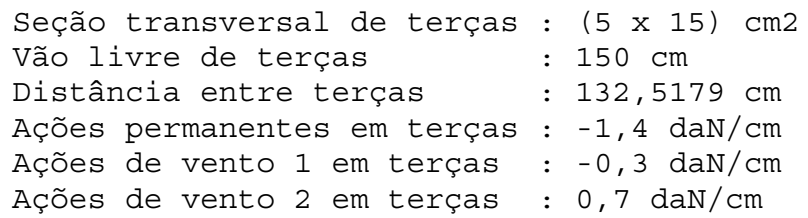

CARACTERÍSTICAS DE CAIBROS

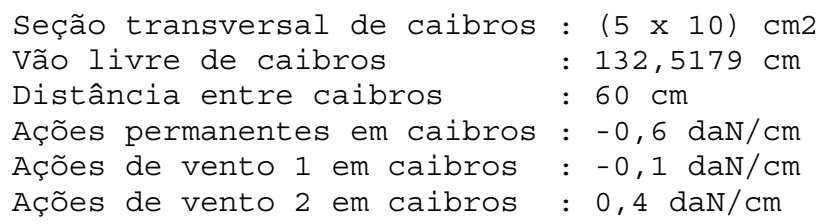

CARACTERÍSTICAS DE TESOURAS

Distância entre tesouras : $150 \mathrm{~cm}$

Número de nós : 12

Número de barras : 21 
CARACTERÍSTICAS DOS NÓS DA TESOURA

Nó Coordenada $\mathrm{X}$ Coordenada $\mathrm{Y}$

( $\mathrm{cm}) \quad(\mathrm{cm})$

Restrição X Restrição Y

\begin{tabular}{rrrrr}
1 & 0 & 0 & 1 & 1 \\
2 & 125 & 43 & 0 & 0 \\
3 & 250 & 87 & 0 & 0 \\
4 & 375 & 131 & 0 & 0 \\
5 & 500 & 87 & 0 & 0 \\
6 & 625 & 0 & 0 & 0 \\
7 & 750 & 0 & 0 & 1 \\
8 & 625 & 0 & 0 & 0 \\
9 & 500 & 0 & 0 & 0 \\
10 & 375 & 0 & 0 & 0 \\
11 & 250 & 0 & 0 & 0 \\
12 & 125 & & 0 & 0 \\
\hline
\end{tabular}

CARACTERÍSTICAS DAS BARRAS DA TESOURA

Barra Nó inicial Nó Final Seção Transversal Vinculação em Z
(cm2)

\begin{tabular}{|c|c|c|c|c|c|}
\hline 1 & 1 & 2 & $5.000 \times$ & $\mathrm{x} 15.000$ & [ART, ART] \\
\hline 2 & 2 & 3 & $5.000 x$ & $\mathrm{x} 15.000$ & {$[\mathrm{ART}, \mathrm{ART}]$} \\
\hline 3 & 3 & 4 & $5.000 x$ & $\mathrm{x} 15.000$ & {$[\mathrm{ART}, \mathrm{ART}]$} \\
\hline 4 & 4 & 5 & $5.000 x$ & $\mathrm{x} 15.000$ & {$[\mathrm{ART}, \mathrm{ART}]$} \\
\hline 5 & 5 & 6 & $5.000 x$ & $\mathrm{x} 15.000$ & {$[\mathrm{ART}, \mathrm{ART}]$} \\
\hline 6 & 6 & 7 & $5.000 x$ & $\mathrm{x} 15.000$ & {$[\mathrm{ART}, \mathrm{ART}]$} \\
\hline 7 & 7 & 8 & $5.000 x$ & $\mathrm{x} 15.000$ & {$[\mathrm{ART}, \mathrm{ART}]$} \\
\hline 8 & 8 & 9 & $5.000 x$ & $\mathrm{x} 15.000$ & {$[\mathrm{ART}, \mathrm{ART}]$} \\
\hline 9 & 9 & 10 & $5.000 x$ & $\mathrm{x} 15.000$ & {$[\mathrm{ART}, \mathrm{ART}]$} \\
\hline 10 & 10 & 11 & $5.000 x$ & $\mathrm{x} 15.000$ & {$[\mathrm{ART}, \mathrm{ART}]$} \\
\hline 11 & 11 & 12 & $5.000 x$ & $\mathrm{x} 15.000$ & {$[\mathrm{ART}, \mathrm{ART}]$} \\
\hline 12 & 12 & 1 & $5.000 x$ & $\mathrm{x} 15.000$ & {$[\mathrm{ART}, \mathrm{ART}]$} \\
\hline 13 & 2 & 12 & $5.000 \times$ & $\mathrm{x} 10.000$ & {$[\mathrm{ART}, \mathrm{ART}]$} \\
\hline 14 & 3 & 11 & $5.000 x$ & $\mathrm{x} 10.000$ & [ART, ART] \\
\hline 15 & 4 & 10 & $5.000 x$ & $x \quad 10.000$ & [ART, ART] \\
\hline 16 & 5 & 9 & $5.000 x$ & $x \quad 10.000$ & {$[\mathrm{ART}, \mathrm{ART}]$} \\
\hline 17 & 6 & 8 & $5.000 x$ & $x \quad 10.000$ & [ART, ART] \\
\hline 18 & 2 & 11 & $5.000 x$ & $x \quad 10.000$ & {$[\mathrm{ART}, \mathrm{ART}]$} \\
\hline 19 & 3 & 10 & $5.000 x$ & $x \quad 10.000$ & [ART, ART] \\
\hline 20 & 5 & 10 & $5.000 \times$ & $x \quad 10.000$ & [ART, ART] \\
\hline 21 & 6 & 9 & $5.000 x$ & $x \quad 10.000$ & {$[\mathrm{ART}, \mathrm{ART}]$} \\
\hline
\end{tabular}

AÇÕES EM TESOURAS

AÇÕES PERMANENTES

Carga vertical distribuída no plano do banzo superior: -0,010 daN/cm2

AÇÕES DE VENTO 1

Carga Distribuída no plano do banzo superior esquerdo: -0,002 daN/cm2 Carga Distribuída no plano do banzo superior direito : -0,002 daN/cm2

AÇÕES DE VENTO 2

Carga Distribuída no plano do banzo superior esquerdo: 0,006 daN/cm2 Carga Distribuída no plano do banzo superior direito : 0,005 daN/cm2 
AÇÕES ACIDENTAIS

Carga vertical distribuída no plano do banzo superior: 0 daN/cm2

\begin{tabular}{lcc}
\hline Nó Carga concentrada em X & Carga concentrada em Y \\
(daN)
\end{tabular}

ESFORÇOS E DESLOCAMENTOS NA ESTRUTURA

ESFORÇOS E DESLOCAMENTOS EM TESOURAS

AÇÕES PERMANENTES

\begin{tabular}{|c|c|c|c|c|c|c|}
\hline Nó & $\begin{array}{c}\text { Carga em } \mathrm{X} \\
\text { (daN) }\end{array}$ & $\begin{array}{c}\text { Carga em Y } \\
(\text { daN) }\end{array}$ & $\begin{array}{r}\text { M.Fletor } \\
\text { (daN.cm) }\end{array}$ & $\begin{array}{l}\text { Desl.X } \\
\text { (cm) }\end{array}$ & $\begin{array}{l}\text { Desl.Y } \\
\quad(\mathrm{cm})\end{array}$ & $\begin{array}{c}\overline{\text { Rotação }} \\
\text { (Rad) }\end{array}$ \\
\hline 1 & 0.000 & -93.750 & 0.000 & -0.00000 & -0.00000 & 0.00000 \\
\hline 2 & 0.000 & -187.500 & 0.000 & 0.05371 & -0.20997 & 0.00000 \\
\hline 3 & 0.000 & -187.500 & 0.000 & 0.05549 & -0.25696 & 0.00000 \\
\hline 4 & 0.000 & -187.500 & 0.000 & 0.04371 & -0.25483 & 0.00000 \\
\hline 5 & 0.000 & -187.500 & 0.000 & 0.03193 & -0.25696 & 0.00000 \\
\hline 6 & 0.000 & -187.500 & 0.000 & 0.03372 & -0.20997 & 0.00000 \\
\hline 7 & 0.000 & -93.750 & 0.000 & 0.08742 & -0.00000 & 0.00000 \\
\hline 8 & 0.000 & 0.000 & 0.000 & 0.07176 & -0.20997 & 0.00000 \\
\hline 9 & 0.000 & 0.000 & 0.000 & 0.05610 & -0.25814 & 0.00000 \\
\hline 10 & 0.000 & 0.000 & 0.000 & 0.04371 & -0.26168 & 0.00000 \\
\hline 11 & 0.000 & 0.000 & 0.000 & 0.03133 & -0.25814 & 0.00000 \\
\hline 12 & 0.000 & 0.000 & 0.000 & 0.01566 & -0.20997 & 0.00000 \\
\hline
\end{tabular}

ESFORÇOS EM BARRAS DE TESOURAS

\begin{tabular}{rrrrrrr} 
Barra & $\begin{array}{c}\text { Compr. } \\
\text { (cm) }\end{array}$ & \multicolumn{1}{c}{$\begin{array}{c}\text { Área } \\
\text { (cm2) }\end{array}$} & Lâmbda & $\begin{array}{c}\text { Normal } \\
\text { (daN) }\end{array}$ & $\begin{array}{c}\text { Cortante } \\
\text { (daN) }\end{array}$ & $\begin{array}{c}\text { Momento Fletor } \\
\text { (daN. cm) }\end{array}$ \\
\hline 1 & 132.189 & 75.000 & 91.58 & -1441.02 & 0.00 & 0.00 \\
2 & 132.518 & 75.000 & 91.81 & -1142.40 & 0.00 & 0.00 \\
3 & 132.518 & 75.000 & 91.81 & -853.53 & 0.00 & 0.00 \\
4 & 132.518 & 75.000 & 91.81 & -853.53 & 0.00 & 0.00 \\
5 & 132.518 & 75.000 & 91.81 & -1142.40 & 0.00 & 0.00 \\
6 & 132.189 & 75.000 & 91.58 & -1441.02 & 0.00 & 0.00 \\
7 & 125.000 & 75.000 & 86.60 & 1362.65 & 0.00 & 0.00 \\
8 & 125.000 & 75.000 & 86.60 & 1362.65 & 0.00 & 0.00 \\
9 & 125.000 & 75.000 & 86.60 & 1077.59 & 0.00 & 0.00 \\
10 & 125.000 & 75.000 & 86.60 & 1077.59 & 0.00 & 0.00 \\
11 & 125.000 & 75.000 & 86.60 & 1362.65 & 0.00 & 0.00 \\
12 & 125.000 & 75.000 & 86.60 & 1362.65 & 0.00 & 0.00 \\
13 & 43.000 & 50.000 & 29.79 & 0.00 & 0.00 & 0.00 \\
14 & 87.000 & 50.000 & 60.28 & 98.06 & 0.00 & 0.00 \\
15 & 131.000 & 50.000 & 90.76 & 379.29 & 0.00 & 0.00 \\
16 & 87.000 & 50.000 & 60.28 & 98.06 & 0.00 & 0.00 \\
17 & 43.000 & 50.000 & 29.79 & -0.00 & 0.00 & 0.00 \\
18 & 132.189 & 50.000 & 91.58 & -301.45 & 0.00 & 0.00 \\
19 & 152.296 & 50.000 & 105.51 & -331.98 & 0.00 & 0.00 \\
20 & 152.296 & 50.000 & 105.51 & -331.98 & 0.00 & 0.00 \\
21 & 132.189 & 50.000 & 91.58 & -301.45 & 0.00 & 0.00
\end{tabular}


REAÇÕES DE APOIO

\begin{tabular}{ccc} 
Nó de apoio & $\begin{array}{c}\text { Reação em X } \\
\text { (daN) }\end{array}$ & $\begin{array}{c}\text { Reação em Y } \\
\text { (daN) }\end{array}$ \\
\hline 1 & 0.00 & 562.50 \\
7 & 0.00 & 562.50
\end{tabular}

AÇÕES DE VENTO 1

\begin{tabular}{|c|c|c|c|c|c|c|}
\hline Nó & $\begin{array}{c}\text { Carga em X } \\
\text { (daN) }\end{array}$ & $\begin{array}{c}\text { Carga em Y } \\
(\text { daN })\end{array}$ & $\begin{array}{c}\text { M.Fletor } \\
\text { (daN.cm) }\end{array}$ & $\begin{array}{l}\text { Desl.X } \\
\text { (cm) }\end{array}$ & $\begin{array}{l}\text { Desl.Y } \\
\quad(\mathrm{cm})\end{array}$ & $\begin{array}{c}\text { Rotação } \\
(\text { Rad) }\end{array}$ \\
\hline 1 & 6.450 & -18.750 & 0.000 & -0.00000 & -0.00000 & 0.00000 \\
\hline 2 & 13.050 & -37.500 & 0.000 & 0.01075 & -0.04201 & 0.00000 \\
\hline 3 & 13.200 & -37.500 & 0.000 & 0.01103 & -0.05144 & 0.00000 \\
\hline 4 & 0.000 & -37.500 & 0.000 & 0.00844 & -0.05088 & 0.00000 \\
\hline 5 & -13.200 & -37.500 & 0.000 & 0.00586 & -0.05144 & 0.00000 \\
\hline 6 & -13.050 & -37.500 & 0.000 & 0.00614 & -0.04201 & 0.00000 \\
\hline 7 & -6.450 & -18.750 & 0.000 & 0.01689 & -0.00000 & 0.00000 \\
\hline 8 & 0.000 & 0.000 & 0.000 & 0.01383 & -0.04201 & 0.00000 \\
\hline 9 & 0.000 & 0.000 & 0.000 & 0.01077 & -0.05170 & 0.00000 \\
\hline 10 & 0.000 & 0.000 & 0.000 & 0.00844 & -0.05241 & 0.00000 \\
\hline 11 & 0.000 & 0.000 & 0.000 & 0.00612 & -0.05170 & 0.00000 \\
\hline 12 & 0.000 & 0.000 & 0.000 & 0.00306 & -0.04201 & 0.00000 \\
\hline
\end{tabular}

ESFORÇOS EM BARRAS DE TESOURA

\begin{tabular}{rrrrrrr} 
Barra & $\begin{array}{c}\text { Compr. } \\
\text { (cm) }\end{array}$ & \multicolumn{1}{c}{$\begin{array}{c}\text { Área } \\
\text { (cm2) }\end{array}$} & Lâmbda & $\begin{array}{c}\text { Normal } \\
\text { (daN) }\end{array}$ & $\begin{array}{c}\text { Cortante } \\
\text { (daN) }\end{array}$ & $\begin{array}{c}\text { Momento Fletor } \\
\text { (daN.cm) }\end{array}$ \\
\hline 1 & 132.189 & 75.000 & 91.58 & -288.20 & 0.00 & 0.00 \\
2 & 132.518 & 75.000 & 91.81 & -235.32 & 0.00 & 0.00 \\
3 & 132.518 & 75.000 & 91.81 & -184.54 & 0.00 & 0.00 \\
4 & 132.518 & 75.000 & 91.81 & -184.54 & 0.00 & 0.00 \\
5 & 132.518 & 75.000 & 91.81 & -235.32 & 0.00 & 0.00 \\
6 & 132.189 & 75.000 & 91.58 & -288.20 & 0.00 & 0.00 \\
7 & 125.000 & 75.000 & 86.60 & 266.08 & 0.00 & 0.00 \\
8 & 125.000 & 75.000 & 86.60 & 266.08 & 0.00 & 0.00 \\
9 & 125.000 & 75.000 & 86.60 & 202.47 & 0.00 & 0.00 \\
10 & 125.000 & 75.000 & 86.60 & 202.47 & 0.00 & 0.00 \\
11 & 125.000 & 75.000 & 86.60 & 266.08 & 0.00 & 0.00 \\
12 & 125.000 & 75.000 & 86.60 & 266.08 & 0.00 & 0.00 \\
13 & 43.000 & 50.000 & 29.79 & -0.00 & 0.00 & 0.00 \\
14 & 87.000 & 50.000 & 60.28 & 21.88 & 0.00 & 0.00 \\
15 & 131.000 & 50.000 & 90.76 & 85.05 & 0.00 & 0.00 \\
16 & 87.000 & 50.000 & 60.28 & 21.88 & 0.00 & 0.00 \\
17 & 43.000 & 50.000 & 29.79 & 0.00 & 0.00 & 0.00 \\
18 & 132.189 & 50.000 & 91.58 & -67.27 & 0.00 & 0.00 \\
19 & 152.296 & 50.000 & 105.51 & -74.44 & 0.00 & 0.00 \\
20 & 152.296 & 50.000 & 105.51 & -74.44 & 0.00 & \\
21 & 132.189 & 50.000 & 91.58 & -67.27 & 0.00 & \\
\hline
\end{tabular}

REAÇÕES DE APOIO

\begin{tabular}{ccc} 
Nó de apoio & $\begin{array}{c}\text { Reação em X } \\
\text { (daN) }\end{array}$ & $\begin{array}{c}\text { Reação em } Y \\
\text { (daN) }\end{array}$ \\
\hline 1 & 0.00 & 112.50 \\
7 & 0.00 & 112.50
\end{tabular}


AÇÕES DE VENTO 2

CARGAS RESULTANTES APLICADAS E DESLOCAMENTOS NODAIS EM TESOURAS Nó Carga em X Carga em Y M.Fletor Desl.X Desl.Y Rotação $\begin{array}{lllll}(\mathrm{daN}) & (\mathrm{daN}) & (\mathrm{daN} . \mathrm{cm}) & (\mathrm{cm}) & (\mathrm{cm})\end{array}$

\begin{tabular}{rrrrrrr}
\hline 1 & -19.350 & 56.250 & 0.000 & -0.00000 & 0.00000 & 0.00000 \\
2 & -39.150 & 112.500 & 0.000 & -0.03050 & 0.11916 & 0.00000 \\
3 & -39.600 & 112.500 & 0.000 & -0.03080 & 0.14417 & 0.00000 \\
4 & -3.300 & 103.125 & 0.000 & -0.02312 & 0.14089 & 0.00000 \\
5 & 33.000 & 93.750 & 0.000 & -0.01660 & 0.14072 & 0.00000 \\
6 & 32.625 & 93.750 & 0.000 & -0.01795 & 0.11354 & 0.00000 \\
7 & 16.125 & 46.875 & 0.000 & -0.04712 & 0.00000 & 0.00000 \\
8 & 0.000 & 0.000 & 0.000 & -0.03895 & 0.11354 & 0.00000 \\
9 & 0.000 & 0.000 & 0.000 & -0.03077 & 0.14137 & 0.00000 \\
10 & 0.000 & 0.000 & 0.000 & -0.02443 & 0.14512 & 0.00000 \\
11 & 0.000 & 0.000 & 0.000 & -0.01775 & 0.14495 & 0.00000 \\
12 & 0.000 & 0.000 & 0.000 & -0.00887 & 0.11916 & 0.00000 \\
\hline
\end{tabular}

ESFORÇOS EM BARRAS DE TESOURA

\begin{tabular}{rrrrrrr} 
Barra & $\begin{array}{c}\text { Compr. } \\
(\mathrm{cm})\end{array}$ & $\begin{array}{c}\text { Área } \\
(\mathrm{cm} 2)\end{array}$ & Lâmbda & $\begin{array}{c}\text { Normal } \\
\text { (daN) }\end{array}$ & $\begin{array}{c}\text { Cortante } \\
\text { (daN) }\end{array}$ & $\begin{array}{c}\text { Momento Fletor } \\
\text { (daN.cm) }\end{array}$ \\
\hline 1 & 132.189 & 75.000 & 91.58 & 816.10 & 0.00 & 0.00 \\
2 & 132.518 & 75.000 & 91.81 & 657.88 & 0.00 & 0.00 \\
3 & 132.518 & 75.000 & 91.81 & 505.74 & 0.00 & 0.00 \\
4 & 132.518 & 75.000 & 91.81 & 509.23 & 0.00 & 0.00 \\
5 & 132.518 & 75.000 & 91.81 & 636.36 & 0.00 & 0.00 \\
6 & 132.189 & 75.000 & 91.58 & 769.01 & 0.00 & 0.00 \\
7 & 125.000 & 75.000 & 86.60 & -711.07 & 0.00 & 0.00 \\
8 & 125.000 & 75.000 & 86.60 & -711.07 & 0.00 & 0.00 \\
9 & 125.000 & 75.000 & 86.60 & -551.51 & 0.00 & 0.00 \\
10 & 125.000 & 75.000 & 86.60 & -581.71 & 0.00 & 0.00 \\
11 & 125.000 & 75.000 & 86.60 & -772.02 & 0.00 & 0.00 \\
12 & 125.000 & 75.000 & 86.60 & -772.02 & 0.00 & 0.00 \\
13 & 43.000 & 50.000 & 29.79 & 0.00 & 0.00 & 0.00 \\
14 & 87.000 & 50.000 & 60.28 & -65.47 & 0.00 & 0.00 \\
15 & 131.000 & 50.000 & 90.76 & -233.88 & 0.00 & 0.00 \\
16 & 87.000 & 50.000 & 60.28 & -54.89 & 0.00 & 0.00 \\
17 & 43.000 & 50.000 & 29.79 & -0.00 & 0.00 & 0.00 \\
18 & 132.189 & 50.000 & 91.58 & 201.25 & 0.00 & 0.00 \\
19 & 152.296 & 50.000 & 105.51 & 223.10 & 0.00 & 0.00 \\
20 & 152.296 & 50.000 & 105.51 & 186.30 & 0.00 & 0.00 \\
21 & 132.189 & 50.000 & 91.58 & 168.73 & 0.00 & \\
& & & & & & \\
\hline & & & & & &
\end{tabular}

REAÇÕES DE APOIO

\begin{tabular}{ccc} 
Nó de apoio & $\begin{array}{c}\text { Reação em X } \\
\text { (daN) }\end{array}$ & $\begin{array}{c}\text { Reação em } \mathrm{Y} \\
\text { (daN) }\end{array}$ \\
\hline 1 & 19.65 & -321.72 \\
7 & 0.00 & -297.03
\end{tabular}


AÇÕES ACIDENTAIS

\begin{tabular}{|c|c|c|c|c|c|c|}
\hline Nó & $\underset{(\text { daN })}{\text { Carga em } x}$ & $\begin{array}{c}\text { Carga em } Y \\
(\text { daN })\end{array}$ & $\begin{array}{c}\text { M.Fletor } \\
\text { (daN.cm) }\end{array}$ & $\begin{array}{l}\text { Desl.X } \\
\quad(\mathrm{cm})\end{array}$ & $\begin{array}{c}\text { Desl.Y } \\
\text { (cm) }\end{array}$ & $\begin{array}{c}\text { Rotação } \\
\text { (Rad) }\end{array}$ \\
\hline 1 & 0.000 & 0.000 & 0.000 & -0.00000 & -0.00000 & 0.00000 \\
\hline 2 & 0.000 & 0.000 & 0.000 & 0.01802 & -0.06960 & 0.00000 \\
\hline 3 & 0.000 & 0.000 & 0.000 & 0.02018 & -0.09252 & 0.00000 \\
\hline 4 & 0.000 & 0.000 & 0.000 & 0.01498 & -0.09445 & 0.00000 \\
\hline 5 & 0.000 & 0.000 & 0.000 & 0.00978 & -0.09252 & 0.00000 \\
\hline 6 & 0.000 & 0.000 & 0.000 & 0.01194 & -0.06960 & 0.00000 \\
\hline 7 & 0.000 & 0.000 & 0.000 & 0.02996 & -0.00000 & 0.00000 \\
\hline 8 & 0.000 & 0.000 & 0.000 & 0.02494 & -0.06960 & 0.00000 \\
\hline 9 & 0.000 & 0.000 & 0.000 & 0.01993 & -0.09254 & 0.00000 \\
\hline 10 & 0.000 & -300.000 & 0.000 & 0.01498 & -0.09991 & 0.00000 \\
\hline 11 & 0.000 & 0.000 & 0.000 & 0.01002 & -0.09254 & 0.00000 \\
\hline 12 & 0.000 & 0.000 & 0.000 & 0.00501 & -0.06960 & 0.00000 \\
\hline
\end{tabular}

ESFORÇOS EM BARRAS DE TESOURA

\begin{tabular}{rrrrrrr} 
Barra & $\begin{array}{c}\text { Compr. } \\
(\mathrm{cm})\end{array}$ & $\begin{array}{c}\text { Área } \\
(\mathrm{cm} 2)\end{array}$ & Lâmbda & $\begin{array}{c}\text { Normal } \\
\text { (daN) }\end{array}$ & $\begin{array}{c}\text { Cortante } \\
\text { (daN) }\end{array}$ & $\begin{array}{c}\text { Momento Fletor } \\
\text { (daN.cm) }\end{array}$ \\
\hline 1 & 132.189 & 75.000 & 91.58 & -461.13 & 0.00 & 0.00 \\
2 & 132.518 & 75.000 & 91.81 & -456.96 & 0.00 & 0.00 \\
3 & 132.518 & 75.000 & 91.81 & -455.21 & 0.00 & 0.00 \\
4 & 132.518 & 75.000 & 91.81 & -455.21 & 0.00 & 0.00 \\
5 & 132.518 & 75.000 & 91.81 & -456.96 & 0.00 & 0.00 \\
6 & 132.189 & 75.000 & 91.58 & -461.13 & 0.00 & 0.00 \\
7 & 125.000 & 75.000 & 86.60 & 436.05 & 0.00 & 0.00 \\
8 & 125.000 & 75.000 & 86.60 & 436.05 & 0.00 & 0.00 \\
9 & 125.000 & 75.000 & 86.60 & 431.03 & 0.00 & 0.00 \\
10 & 125.000 & 75.000 & 86.60 & 431.03 & 0.00 & 0.00 \\
11 & 125.000 & 75.000 & 86.60 & 436.05 & 0.00 & 0.00 \\
12 & 125.000 & 75.000 & 86.60 & 436.05 & 0.00 & 0.00 \\
13 & 43.000 & 50.000 & 29.79 & 0.00 & 0.00 & 0.00 \\
14 & 87.000 & 50.000 & 60.28 & 1.72 & 0.00 & 0.00 \\
15 & 131.000 & 50.000 & 90.76 & 302.29 & 0.00 & 0.00 \\
16 & 87.000 & 50.000 & 60.28 & 1.72 & 0.00 & 0.00 \\
17 & 43.000 & 50.000 & 29.79 & 0.00 & 0.00 & 0.00 \\
18 & 132.189 & 50.000 & 91.58 & -5.30 & 0.00 & 0.00 \\
19 & 152.296 & 50.000 & 105.51 & -2.00 & 0.00 & 0.00 \\
20 & 152.296 & 50.000 & 105.51 & -2.00 & 0.00 & 0.00 \\
21 & 132.189 & 50.000 & 91.58 & -5.30 & 0.00 & 0.00 \\
& & & & & & \\
\hline & & & & & &
\end{tabular}

REAÇÕES DE APOIO

\begin{tabular}{ccc} 
Nó de apoio & $\begin{array}{c}\text { Reação em X } \\
\text { (daN) }\end{array}$ & $\begin{array}{c}\text { Reação em } \mathrm{Y} \\
\text { (daN) }\end{array}$ \\
\hline 1 & 0.00 & 150.00 \\
7 & 0.00 & 150.00
\end{tabular}


ESFORÇOS EM TERÇAS

AÇÕES PERMANENTES

Momento em X-X Momento em Y-Y Cortante em X-X Cortante em Y-Y

$\begin{array}{llll}(\mathrm{daN} . \mathrm{cm}) & (\mathrm{daN} . \mathrm{cm}) & (\mathrm{daN}) & (\mathrm{daN})\end{array}$

\begin{tabular}{llll} 
& & & \\
\hline 3716.442 & 1300.755 & 99.105 & 34.687 \\
\hline
\end{tabular}

AÇÕES DE VENTO 1

Momento em X-X Momento em Y-Y Cortante em X-X Cortante em Y-Y $(\mathrm{daN} . \mathrm{cm})$

(daN.cm)

(daN)

(daN)

\begin{tabular}{|c|c|c|c|}
\hline 843.750 & 0.000 & 22.500 & 0.000 \\
\hline \multicolumn{4}{|l|}{ AÇÕES DE VENTO 2} \\
\hline $\begin{array}{c}\text { Momento em X-X } \\
(\text { daN.cm) }\end{array}$ & $\begin{array}{l}\text { Momento em Y-Y } \\
\quad(\text { daN. cm) }\end{array}$ & $\begin{array}{c}\text { Cortante em } \mathrm{X}-\mathrm{X} \\
\text { (daN) }\end{array}$ & $\begin{array}{c}\text { Cortante em Y-Y } \\
\text { (daN) }\end{array}$ \\
\hline 1968.750 & 0.000 & 52.500 & 0.000 \\
\hline
\end{tabular}

ESFORÇOS EM CAIBROS

\section{AÇÕES PERMANENTES}

Momento em $\mathrm{X}-\overline{\mathrm{X}}$

(daN.cm)

Força Normal

(daN)

Cortante em $\mathrm{X}-\mathrm{X}$

1243.132

26.266

(daN)

\begin{tabular}{lcc}
\hline 1243.132 & 26.266 & 37.523 \\
\hline
\end{tabular}

AÇÕES DE VENTO 1

Momento em $\mathrm{X}-\mathrm{X}$

(daN.cm)

Força Normal

(daN)

Cortante em X-X

219.512

0.000

(daN)

\begin{tabular}{lcc}
\hline 219.512 & 0.000 & 6.626 \\
\hline
\end{tabular}

AÇÕES DE VENTO 2

Momento em $\mathrm{X}-\mathrm{X}$

(daN.cm)

Força Normal

(daN)

Cortante em X-X

878.050

0.000

(daN)

\begin{tabular}{lll}
\hline 878.050 & 0.000 & 26.504 \\
\hline
\end{tabular}


DIMENSIONAMENTO DA ESTRUTURA

DIMENSIONAMENTO DE BARRAS DE TESOURA

[Indice $<=1(\mathrm{OK})]-$ [Indice $>1$ (NÃO OK) ]

Barra Compressão Tração Cisalhamento Estab.X Estab.Y OBS

\begin{tabular}{rllllll}
\hline 1 & 0.32 & 0.00 & 0.00 & 0.00 & 0.78 & OK \\
2 & 0.27 & 0.00 & 0.00 & 0.00 & 0.61 & OK \\
3 & 0.22 & 0.00 & 0.00 & 0.00 & 0.46 & OK \\
4 & 0.22 & 0.00 & 0.00 & 0.00 & 0.46 & OK \\
5 & 0.27 & 0.00 & 0.00 & 0.00 & 0.61 & OK \\
6 & 0.32 & 0.00 & 0.00 & 0.00 & 0.78 & OK \\
7 & 0.00 & 0.30 & 0.00 & 0.00 & 0.00 & OK \\
8 & 0.00 & 0.30 & 0.00 & 0.00 & 0.00 & OK \\
9 & 0.00 & 0.25 & 0.00 & 0.00 & 0.00 & OK \\
10 & 0.00 & 0.25 & 0.00 & 0.00 & 0.00 & OK \\
11 & 0.00 & 0.30 & 0.00 & 0.00 & 0.00 & OK \\
12 & 0.00 & 0.30 & 0.00 & 0.00 & 0.00 & OK \\
13 & 0.00 & 0.00 & 0.00 & 0.00 & 0.00 & OK \\
14 & 0.00 & 0.03 & 0.00 & 0.00 & 0.00 & OK \\
15 & 0.00 & 0.17 & 0.00 & 0.00 & 0.00 & OK \\
16 & 0.00 & 0.03 & 0.00 & 0.00 & 0.00 & OK \\
17 & 0.00 & 0.00 & 0.00 & 0.00 & 0.00 & OK \\
18 & 0.08 & 0.00 & 0.00 & 0.00 & 0.13 & OK \\
19 & 0.09 & 0.00 & 0.00 & 0.00 & 0.15 & OK \\
20 & 0.09 & 0.00 & 0.00 & 0.00 & 0.15 & OK \\
21 & 0.08 & 0.00 & 0.00 & & 0.13 & OK \\
\hline & & & & & &
\end{tabular}

DIMENSIONAMENTO DAS LIGAÇÕES (CDE)

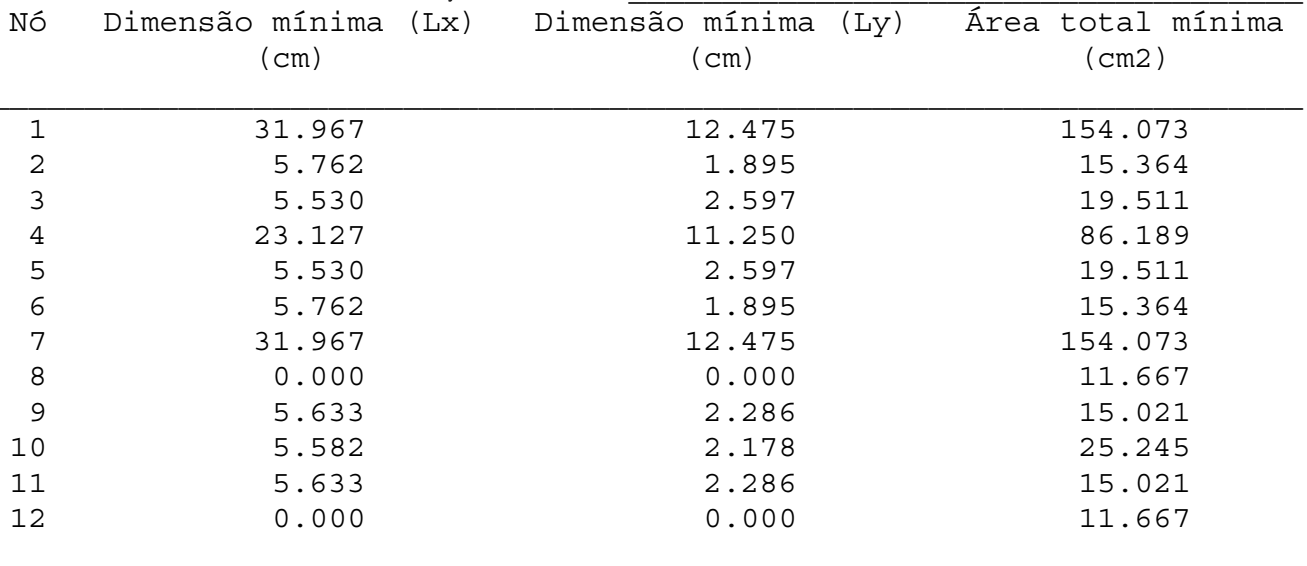

DIMENSIONAMENTO DE TERÇAS

[Indice $<=1$ (OK) ] - [Indice $>1$ (NÃO OK)

Flexão(1) Flexão(2) Cisalhamento Flecha X-X(cm) Flecha Y-Y(cm) OBS

\begin{tabular}{llllll}
\hline 0.689 & 0.700 & 0.233 & -0.088 & $* * * *$ & OK \\
\hline
\end{tabular}

DIMENSIONAMENTO DE CAIBROS

$[$ Indice $<=1(\overline{\mathrm{OK}})]-[$ Indice $>1$ (NÃO OK) $]$

\begin{tabular}{ccccc}
\hline Flexo-compressão & Cisalhamento & Estabilidade & Flecha $(\mathrm{cm})$ & OBS \\
\hline 0.197 & 0.096 & 0.205 & -0.067 & OK \\
\hline
\end{tabular}




\section{5 - CONCLUSÕES}

Da revisão bibliográfica, foram destacados os aspectos fundamentais do processo de industrialização da construção, bem como as configurações estruturais para telhados mais adequadas ao processo de industrialização. Tais configurações (Sistema Pré-Fabricado e Sistema Intermediário) foram as premissas para o desenvolvimento deste trabalho.

Foram identificados métodos de análise estática da estrutura principal (tesouras) compatíveis com os recursos computacionais disponíveis, bem como rotinas de cálculo matricial de estruturas adequadas á análise estática considerada.

As premissa destacadas da revisão bibliográficas aliadas aos conceitos da NBR 7190/97 para projeto e dimensionamento de estruturas de madeira foram as diretrizes para o desenvolvimento deste trabalho, resultando no pacote técnico composto por software de domínio público para projeto e dimensionamento de estruturas treliçadas em madeira para telhados, e o correspondente manual básico de operação com as recomendações para utilização, bem como as instruções para operação e considerações adotadas no desenvolvimento deste.

A contribuição deste trabalho no ambiente de industrialização de estruturas de madeira torna possível o projeto de estruturas treliçadas típicas de madeira para telhados pelos conceitos da NBR 7190/97 em tempo reduzido, minimizando a prática de dimensionamento de estruturas feitos de forma empírica e por pessoal não capacitado.

No meio acadêmico, este software poderá contribuir em trabalhos futuros voltados ao detalhamento do projeto, ou em análise e otimização de estruturas típicas de telhados pelos resultados de dimensionamento gerados pelo software. 


\section{ANEXO A - MANUAL BÁSICO DE OPERAÇÃO}

Este manual de operação do sistema traz, juntamente com o texto desta dissertação, as diretrizes básicas necessárias ao entendimento e operação deste software. Além disso, o arquivo de ajuda disponível durante a execução do Software, contém as considerações estruturais adotadas neste trabalho, as recomendações para a entrada de dados da estrutura, bem como a descrição dos resultados obtidos.

\section{I - INICIANDO A OPERAÇÃO DO SISTEMA}

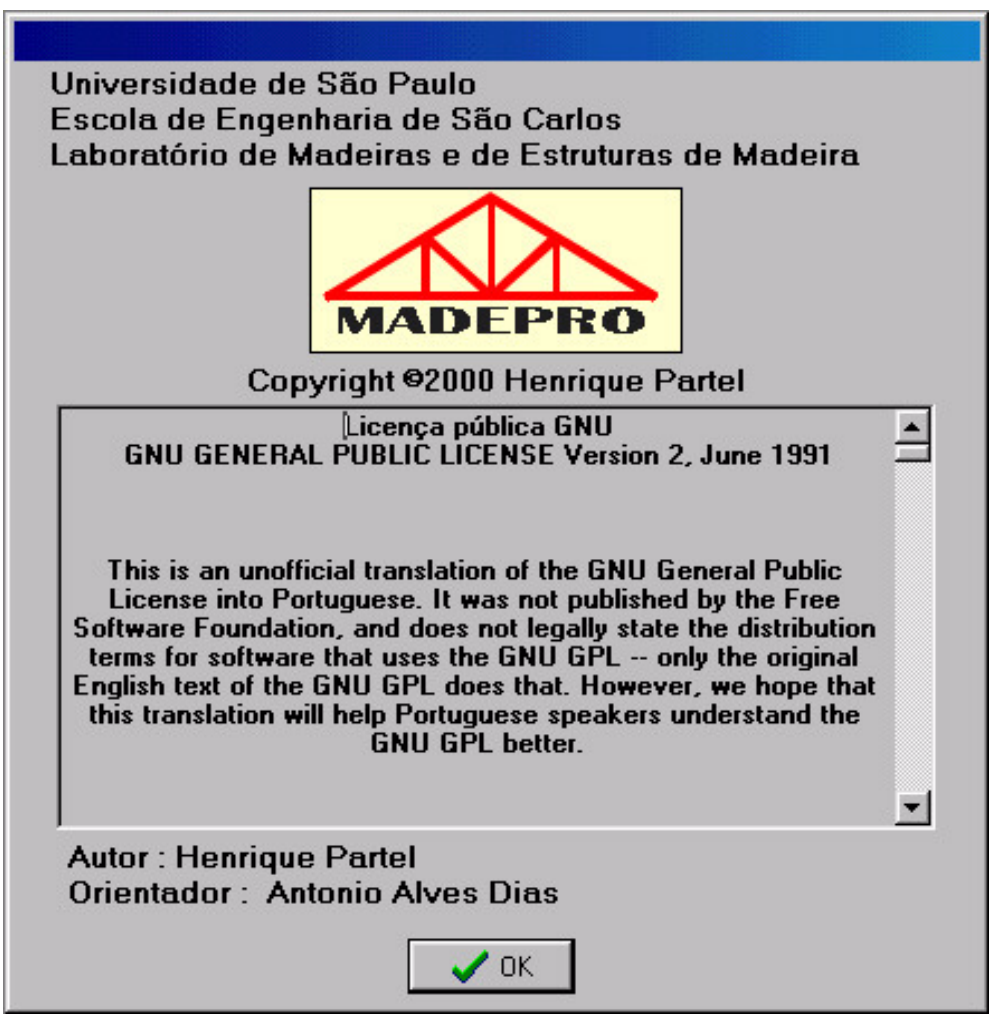

Termos da "GNU GENERAL PUBLIC LICENSE" 
O início da operação do Software é precedido pelas telas informativas iniciais, contendo os termos da "GNU GENERAL PUBLIC LICENSE" e recomendações que devem ser rigorosamente observadas pelo usuário.

Nas telas informativas iniciais, o nome do projeto deve ser definido para identificar a estrutura corrente que estará sendo analisada. O nome definido estará visível na barra superior da tela do software durante toda a execução deste. O nome do projeto não será necessariamente o nome do arquivo de dados para gravação dos dados da estrutura.

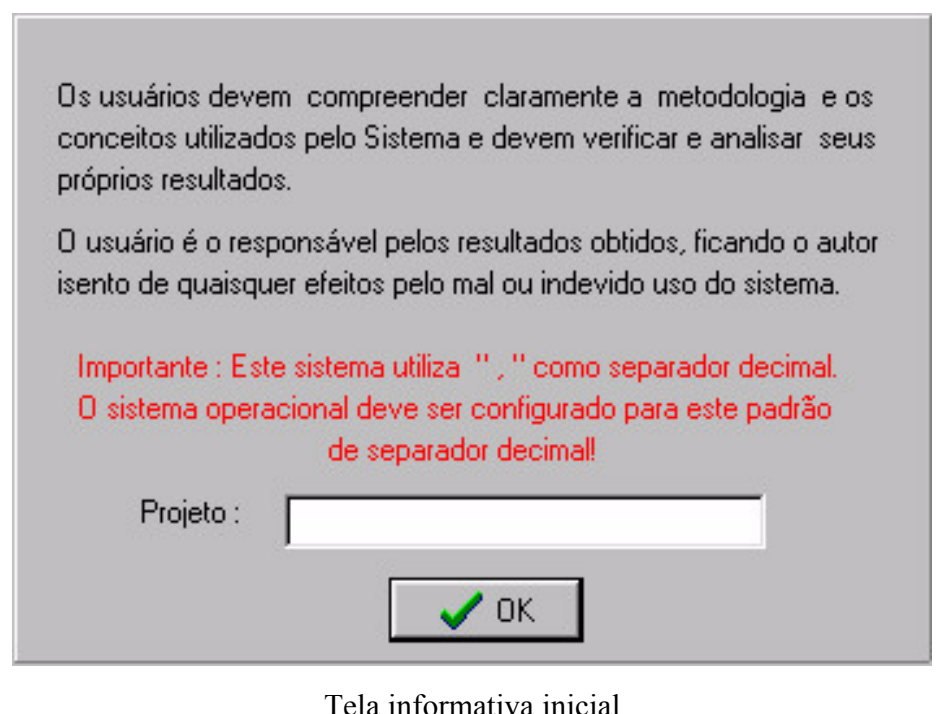

Definido o nome do projeto, são habilitadas as operações do painel de operações no lado direito da tela para a análise e dimensionamento da estrutura, obedecendo uma seqüência lógica de operações que serão descritas com detalhes nos itens subsequentes.

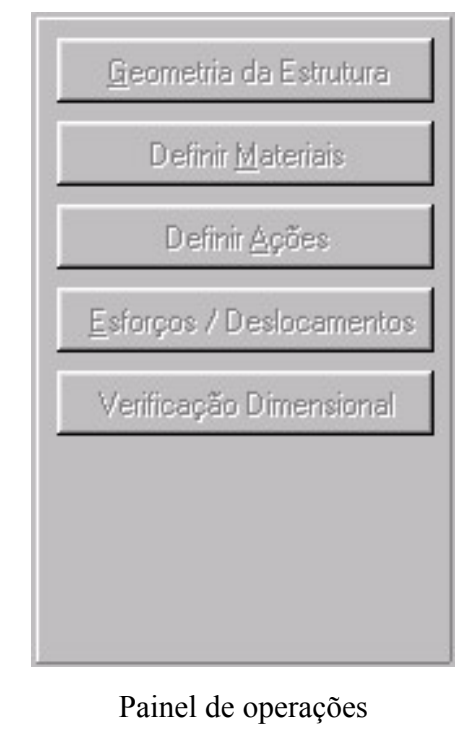


A barra de ferramentas superior permite que o usuário possa a qualquer tempo salvar o projeto corrente, abrir um projeto existente ou iniciar a execução de um novo projeto. A operação de impressão de resultados é possível após a execução das operações de determinação de Esforços/Deslocamentos e Verificação Dimensional respectivamente. A barra de ferramentas superior permite ainda que o arquivo de ajuda, a calculadora e a saída do sistema sejam acessados.

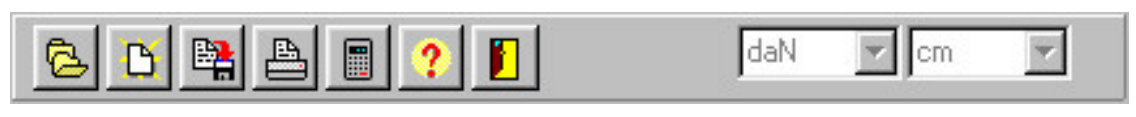

Barra de ferramentas superior

OBS : O usuário deve selecionar as unidades que serão adotadas para a entrada de dados e cálculo de resultados da estrutura, pelos menus da barra de ferramentas superior.

\section{II - GEOMETRIA DA ESTRUTURA}

A geometria da estrutura é definida em quatro etapas :

Geometria da tesoura;

Disposições entre elementos estruturais;

Definir seções transversais;

Definir condições de apoio.

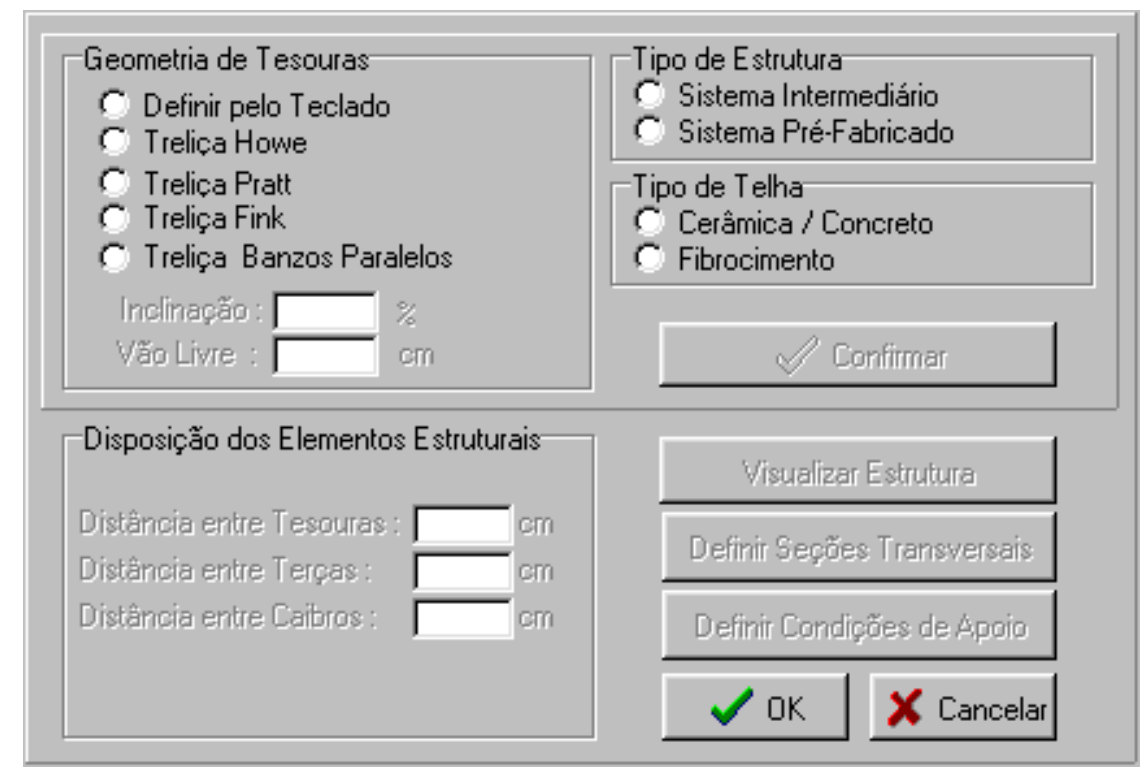

Tela para definição da geometria da estrutura 


\section{GEOMETRIA DA TESOURA}

A geometria da estrutura principal (tesouras) pode ser definida de duas maneiras distintas :

\section{DEFINIR TESOURAS DE MODO AUTOMÁTICO}

A Definição automática considera os tipos mais usuais de tesouras, e de acordo com valores de vão livre e inclinação de banzos superiores, bem como do tipo de telha adotada, gera as coordenadas nodais e a incidência de barras da tesoura.

$\mathrm{Na}$ definição automática da geometria da tesoura, o espaçamento entre montantes é determinado pelo tipo de telha utilizado, de acordo com as considerações seguintes :

Telhas Cerâmicas/Concreto : Os montantes são espaçados em intervalos iguais e limitados pelo valor máximo de $150 \mathrm{~cm}$;

Telhas de fibrocimento : Os montantes são espaçados da cumeeira à extremidade, prevendo o uso de telhas de $153 \mathrm{~cm}$ e recobrimento de $14 \mathrm{~cm}$.

A vinculação das barras das tesouras é determinada pelo tipo de estrutura, de acordo com as considerações seguintes :

Sistema Pré-fabricado : A principal característica das estruturas treliçadas pré-fabricadas consideradas neste trabalho é o uso de conectores metálicos com dentes estampados, conhecidos como conectores "GANG-NAIL", nas ligações entre barras de tesoura. A utilização deste tipo de conectores exige que todas as barras da estrutura treliçada, tracionadas ou comprimidas, tenham a mesma espessura e se situem no mesmo plano de montagem.

No sistema pré-fabricado, o princípio básico é o da substituição das peças secundárias (terças, e caibros) por tesouras pré-fabricadas. Os espaçamentos entre tesouras no sistema convencional ou intermediário variam, em função das particularidades de cada projeto, de 2,0 a 3,0 metros para coberturas com telhas cerâmicas, e de 3,0 a 4,5 metros para coberturas com telhas onduladas de fibrocimento, metálicas, etc... No sistema pré-fabricado, o espaçamento entre as tesouras são reduzidos para faixas de 0,8 a 1,0 metro para os casos com telhas cerâmicas, e para 1,5 a 2,0 metros para as demais. As tesouras pré-fabricadas são bem mais esbeltas e leves, em função, é claro, das cargas de projeto e da menor área de influência. Substitui-se todo o madeiramento complementar somente por sarrafos que cumprem a função das ripas para apoio de telhas cerâmicas ou das terças, no caso de telhas de fibro-cimento ou metálica. 
No sistema pré-fabricado, a fixação de ripas diretamente às barras do banzo superior caracteriza carga distribuída aplicada ao longo das barras do banzo superior, contrariando o modelo clássico de cálculo de treliças que considera apenas esforços axiais em barras, e todos os nós articulados. Neste software, na definição automática da geometria das tesouras para o sistema pré-fabricado, as tesouras serão consideradas com barras de banzos superiores e inferiores contínuas com articulações apenas nos pontos de mudança de inclinação, encontro de banzos e cumeeira.

A determinação da distância entre tesouras completa a definição da geometria da estrutura do tipo pré-fabricado.

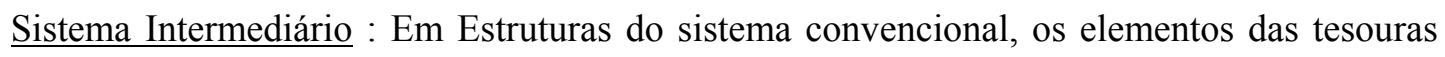
bem como os componentes chamados auxiliares (terças, caibros, ripas e contraventamentos) são montados no próprio local da obra, utilizando ligações com entalhes em barras comprimidas e ligações com elementos convencionais prescritos em norma, ou sejam pinos metálicos, cavilhas de madeira e anéis metálicos, em barras tracionadas. A característica principal de estruturas treliçadas do sistema convencional, além dos elementos de ligação, são as barras diagonais ou montantes submetidas a esforços de tração situadas em planos diferentes do plano das demais barras, a fim de otimizar as ligações entre barras através dos elementos convencionais de ligação já citados.

Estruturas do tipo intermediário são caracterizadas pela simples substituição da estrutura principal convencional por tesouras pré-fabricadas, com a manutenção de todas as demais particularidades do sistema convencional, tais como espaçamento entre tesouras e componentes secundários.

$\mathrm{Na}$ definição automática da geometria das tesouras para o sistema intermediário, o software adota o modelo clássico de cálculo de treliças com todos os nós articulados, já que neste tipo de estrutura as cargas são aplicadas de forma concentrada nos nós das tesouras.

A determinação da distância entre tesouras, distância entre terças e distância entre caibros (para telhas cerâmicas) completam a definição da geometria da estrutura do tipo intermediário.

Obs : -

a) Na definição automática de tesouras, a distância entre as terças da estrutura é definida pelo software como a distância entre montantes adjacentes da tesoura; 
b) A opção do modelo estrutural de cálculo de tesouras (nós articulados ou barras contínuas) deve ser explicitamente determinada quando da definição da geometria de tesouras pelo teclado. Isto permite que o usuário possa calcular estruturas do tipo intermediário com barras de banzo contínuas, ou estruturas do tipo pré-fabricadas com todos os nós articulados.

\section{DEFINIR TESOURAS PELO TECLADO}

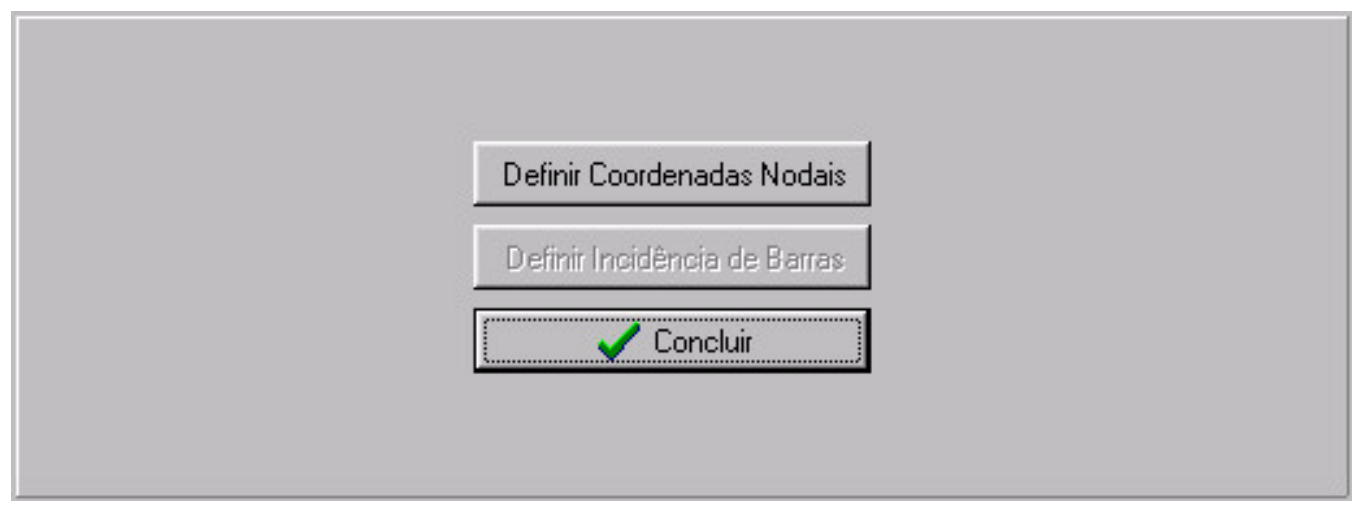

Tela para definição da geometria da estrutura pelo teclado

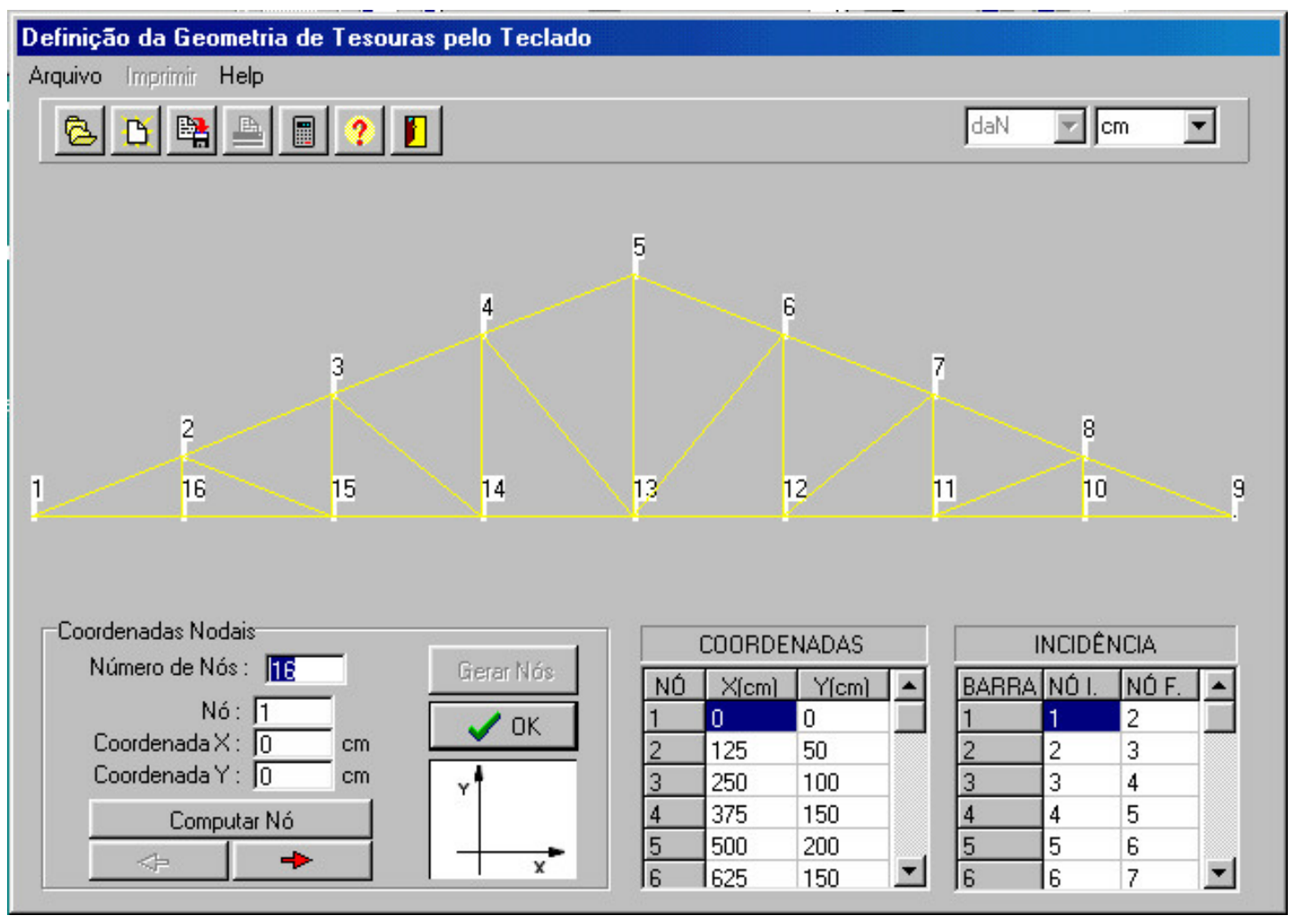

Tela para definição de coordenadas nodais da estrutura principal

A definição da geometria da estrutura principal pode ser feita explicitamente pela determinação via teclado das coordenadas nodais, incidência de barras e vinculação de 
barras, como descrito nos tópicos seguintes. A habilitação destas operações é gerenciada através da tela para definição da geometria da estrutura pelo teclado.

O painel inferior esquerdo da tela para definição de coordenadas nodais da estrutura principal permite a definição das coordenadas nodais da estrutura. Os nós definidos e computados são mostrados com as respectivas coordenadas no painel inferior "COORDENADAS". A orientação em relação aos eixos de referência e as unidades adotadas devem ser respeitadas.

Após a definição das coordenadas nodais da estrutura, o modelo de cálculo de tesouras deve ser definido por uma das alternativas descritas na tela para definição do modelo de cálculo de tesouras :

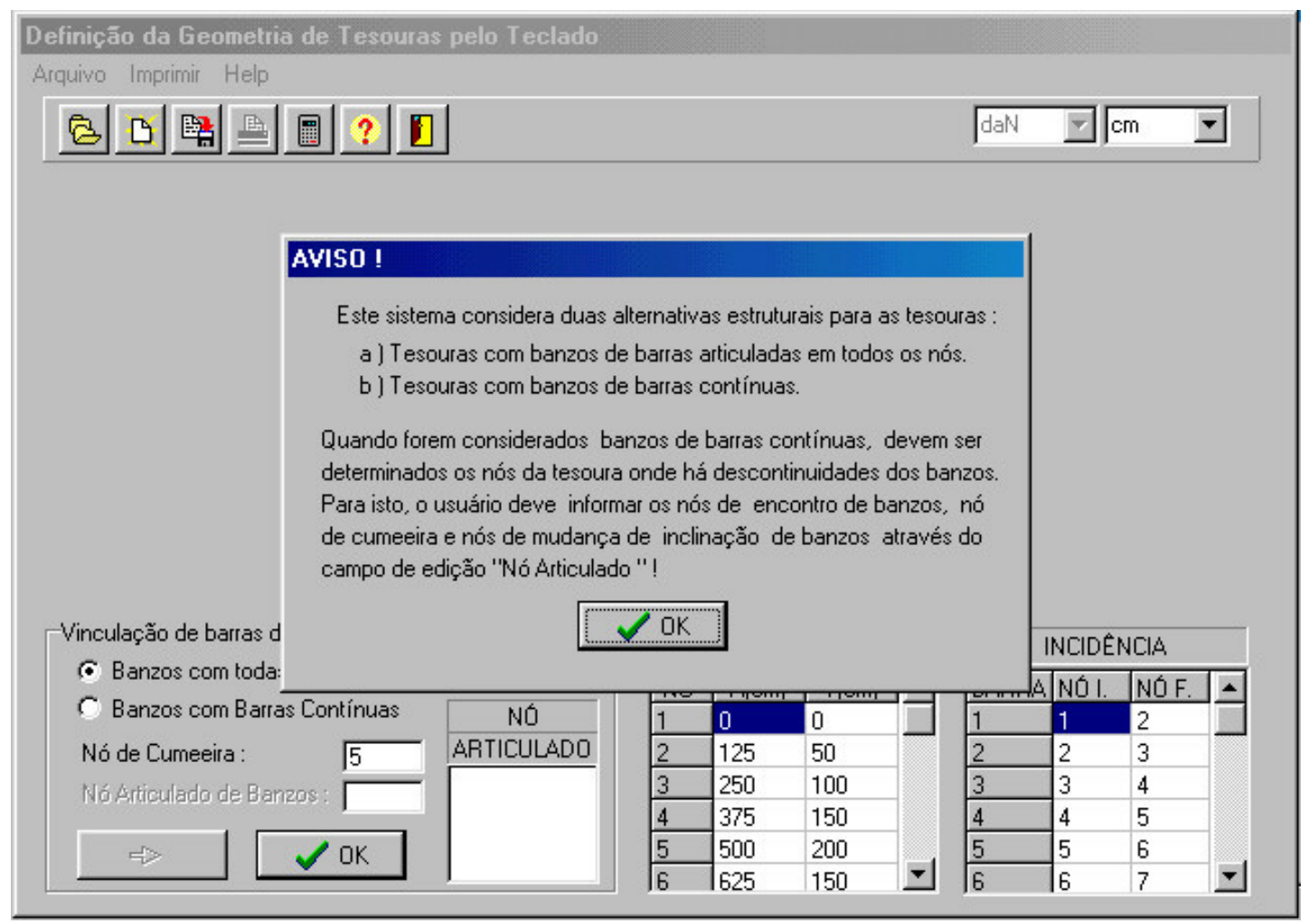

Tela para definição do modelo de cálculo de tesouras

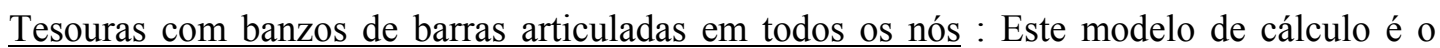
modelo clássico de cálculo de tesouras, onde todos os nós da estrutura são articulados, e as barras de tesouras são solicitadas apenas por esforços normais.

Tesouras com banzos de barras contínuas : Este modelo de cálculo considera a continuidade de barras de banzos de tesoura, e a influência dos esforços de cortante e momento resultantes nestas barras. É o modelo de cálculo que melhor representa o comportamento real de uma estrutura treliçada. 
Quando adotado o modelo de tesouras com banzos de barras contínuas, devem ser definidos os nós da tesoura onde há articulações nos banzos, ou seja, onde há descontinuidade dos banzos de tesoura (cumeeira, mudança de inclinação e encontro de banzo superior e banzo inferior).

Finalmente, as barras de tesoura são definidas pela tela para definição de incidência de barras da tesoura :

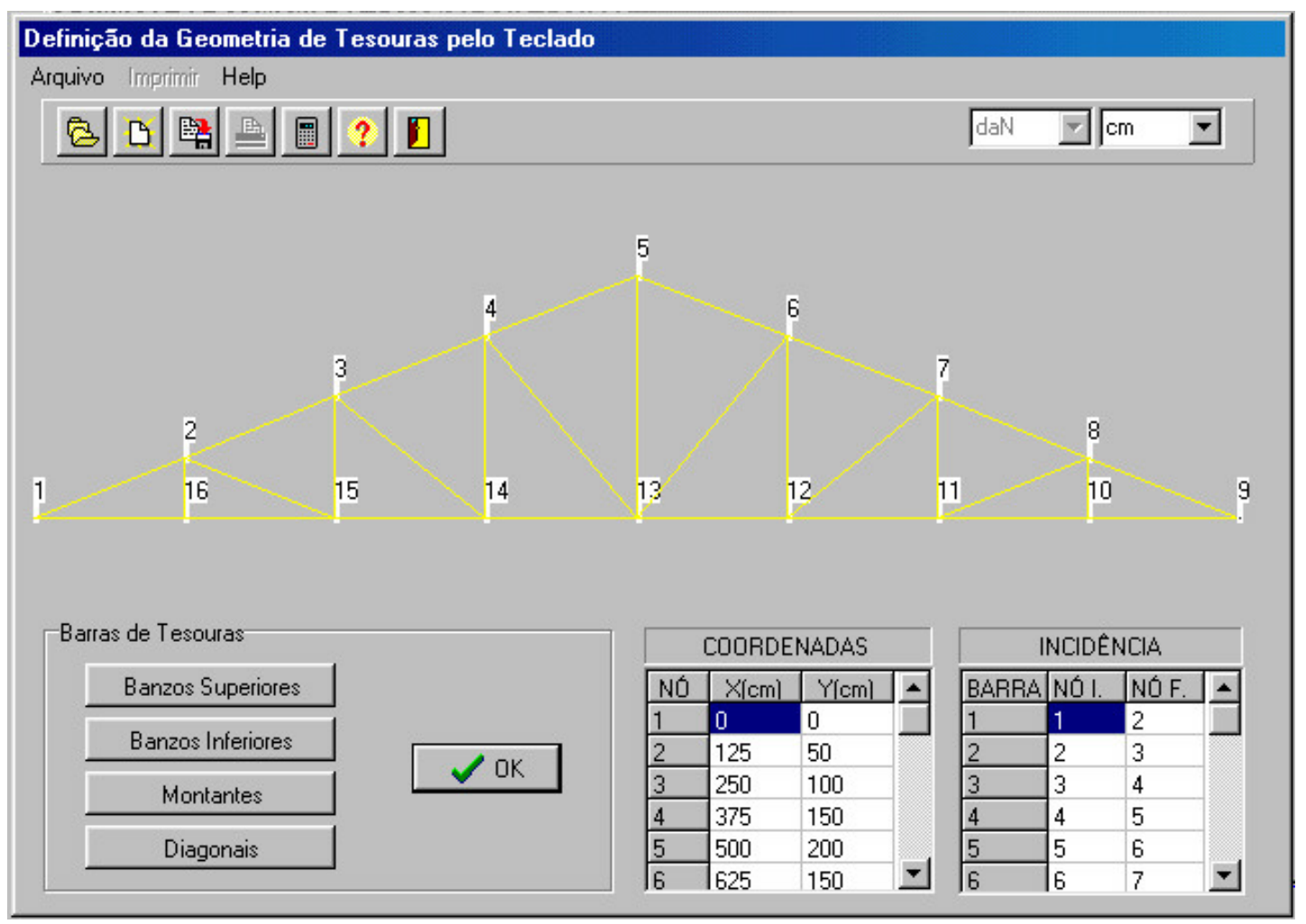

Tela para definição de incidência de barras da tesoura

O painel inferior esquerdo desta tela permite a definição da incidência de barras da estrutura. As barras definidas com os respectivos nó inicial e nó final são mostrados no painel inferior "INCIDÊNCIA". Da mesma forma a tela gráfica mostra a posição das barras definidas em relação aos nós da estrutura. 
A disposição entre elementos estruturais determina os espaçamentos entre estes elementos na estrutura global. A ocorrência de terças e caibros é determinada pelo tipo de telha e tipo de estrutura, sendo os campos de entrada de dados de espaçamentos entre estes elementos habilitados e desabilitados automaticamente pelo sistema.

DEFINIR SEÇÕES TRANSVERSAIS

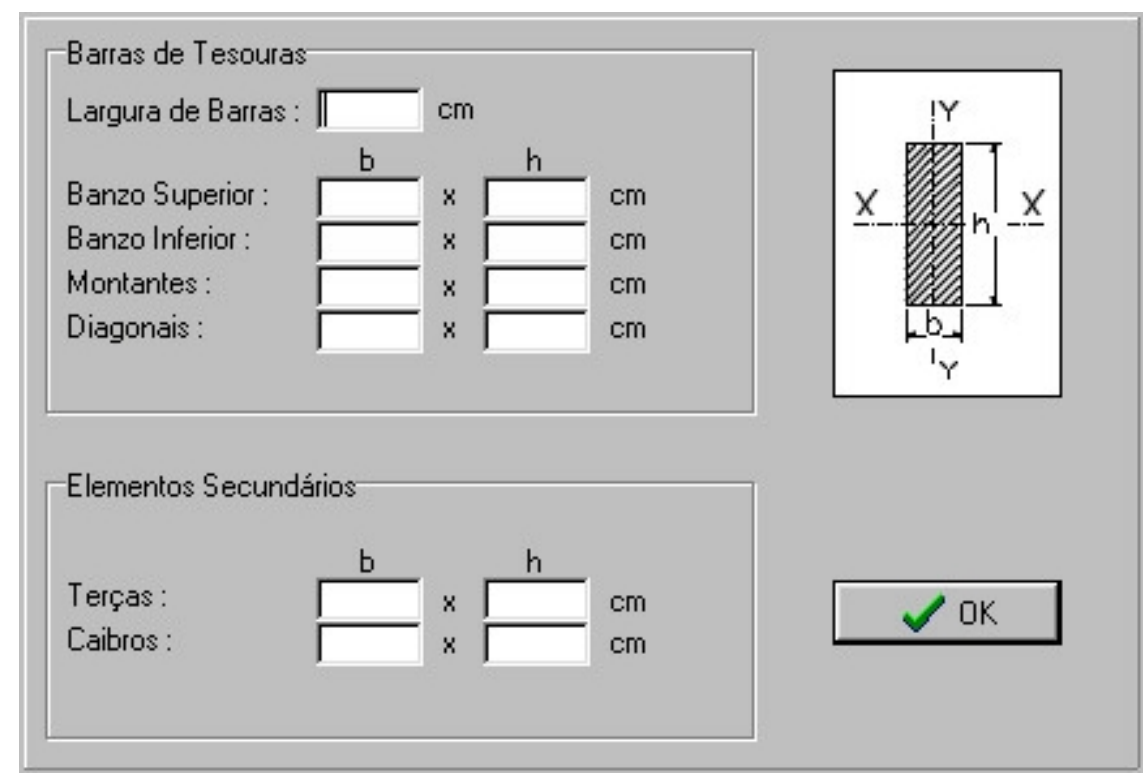

Tela para definição de seções transversais dos elementos da estrutura

Através desta tela são definidas as dimensões das seções transversais de barras de tesouras, terças e caibros (quando aplicável). A orientação em relação aos eixos de referência e as unidades adotadas devem ser respeitadas.

OBS : As ligações de barras de tesoura por conectores dentados com dentes estampados (CDE) exige que a largura (b) de todas as barras de tesoura seja a mesma. 


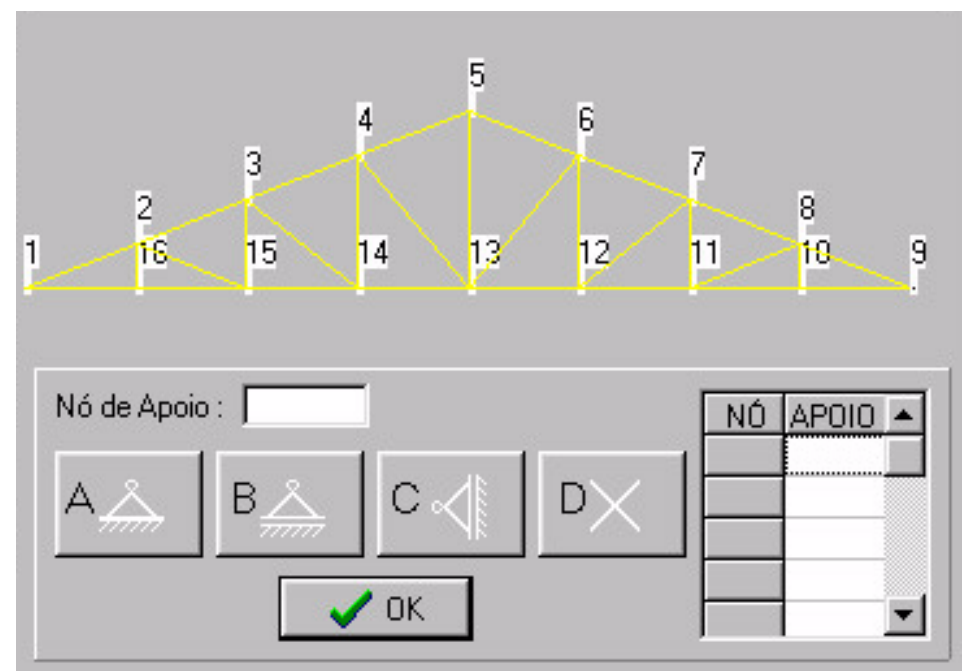

Tela para definição de apoios da estrutura principal

As condições de apoio da estrutura são determinadas pela tela para definição de apoios da estrutura principal, onde os nós de apoio são definidos como :

A - Apoio fixo;

B - Apoio móvel em relação ao eixo X;

C - Apoio móvel em relação ao eixo Y.

A opção D anula qualquer opção anterior selecionada para um determinado nó de apoio.

\section{III - DEFINIR MATERIAIS}

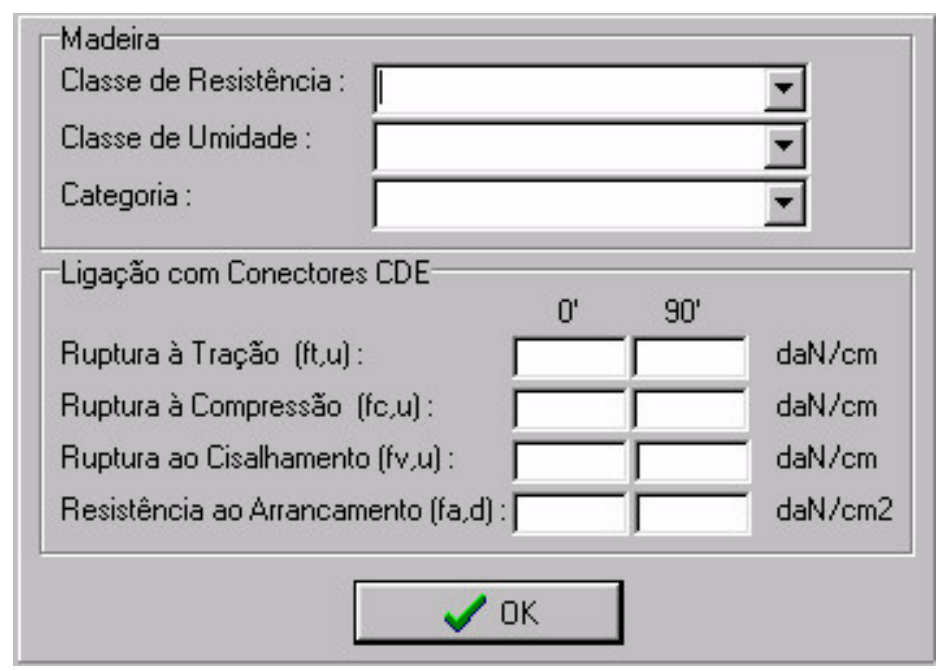

Tela para definição de materiais 
A definição das propriedades físicas e mecânicas da madeira adotada é feita pela tela para definição de materiais, de acordo com os parâmetros considerados pela NBR 7190/97, ou seja, Classe de Resistência, Classe de umidade e Categoria.

A definição das propriedades mecânicas dos conectores metálicos de dentes estampados, é feita pelos valores de resistência à ruptura especificados pelo fabricante.

\section{IV - DEFINIR AÇÕES NA ESTRUTURA}

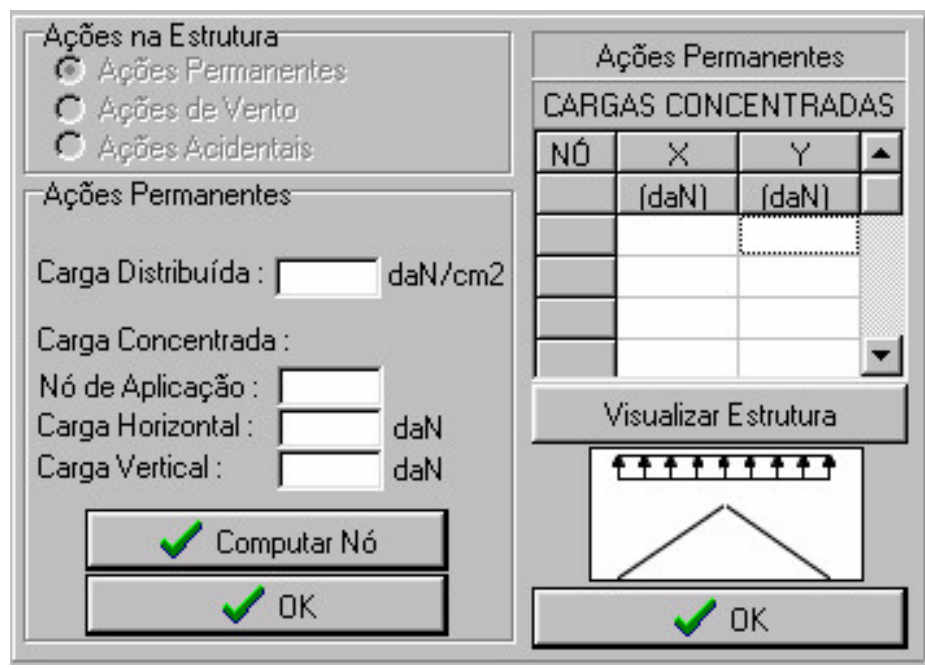

Tela para definição de ações na estrutura principal

Este software permite que cinco condições de ações distintas sejam aplicadas à estrutura principal:

Ações Permanentes;

Ações de Vento 1;

Ações de Vento 2;

Ações de Vento 3;

Ações Acidentais.

Os valores destas ações aplicadas à estrutura podem ser definidos pela definição de carga distribuída na estrutura e/ou cargas concentradas aplicadas aos nós de tesouras como apresentado na tela para definição de ações na estrutura principal. Em estruturas com todos os nós de tesoura articulados, as cargas distribuídas aplicadas ao banzo superior serão transportadas aos nós adjacentes das barras em forma de forças horizontais e verticais equivalentes, descartando a influência dos momentos de engastamento destas barras.

As unidades de força e área adotadas, bem como a orientação em relação aos eixos de referência para cada ação devem ser respeitados. 


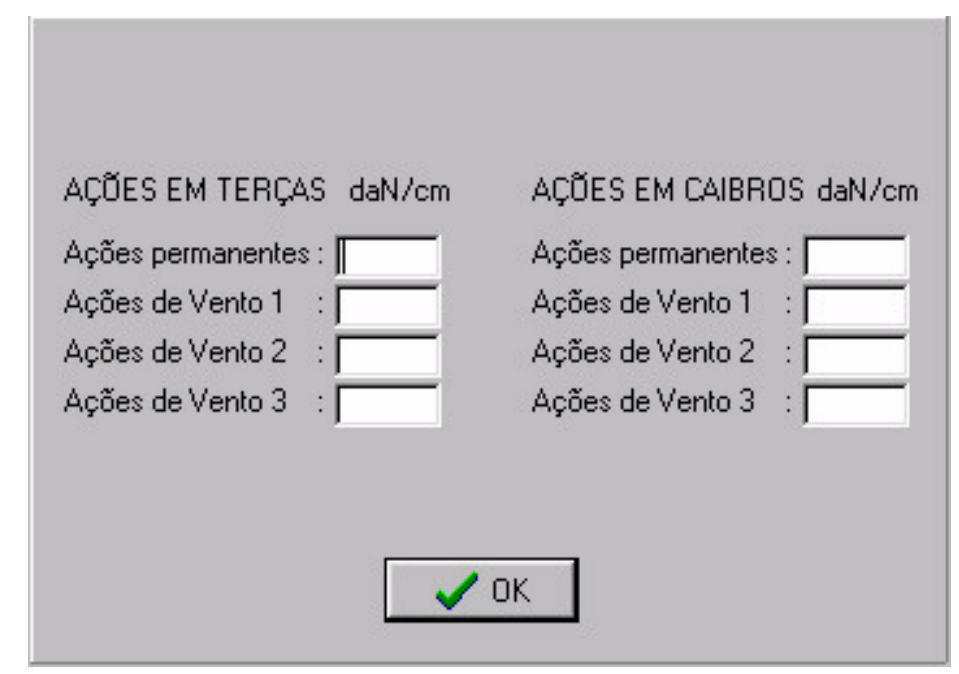

Tela para definição de ações em terças e caibros

Em estruturas do tipo intermediário, ações em terças e caibros (para telhas cerâmicas) são aplicadas como ações distribuídas pela tela para definição de ações em terças e caibros. 


\section{V - CÁLCULO DE ESFORÇOS E DESLOCAMENTOS NA ESTRUTURA}

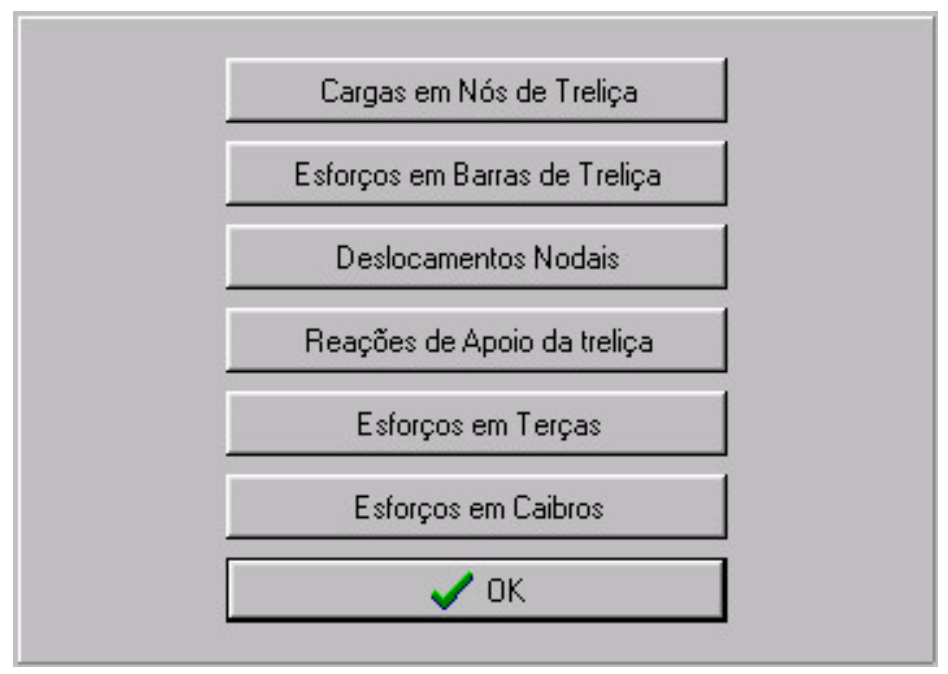

Tela para Exibição de Esforços e Deslocamentos da Estrutura

A tela para exibição de esforços e deslocamentos da estrutura permite a visualização dos resultados da análise estrutural da estrutura submetida às ações definidas pelo usuário, em forma de tabelas numéricas. Os resultados visualizados referem-se à cada uma das ações individualmente, sem aplicação de coeficientes de ponderação para combinação de ações. Os resultados disponíveis para visualização são : 
Cargas em nós de Tesoura :

São os valores resultantes das ações concentradas aplicadas aos nós de tesoura somados aos valores de forças nodais equivalentes às ações distribuídas aplicadas às barras dos banzos superiores de tesouras. Devemos lembrar que em tesouras com todos os nós articulados, os esforços de momento de engastamento de barras dos banzos superiores submetidas a ações distribuídas são descartados.

\begin{tabular}{|c|c|c|c|c|}
\hline \multicolumn{4}{|c|}{ QESTRUTURA DE TELHADO EM MADEIRA } & $-\square \times$ \\
\hline \multicolumn{5}{|c|}{ Arquivo Imprimir Help } \\
\hline \multicolumn{5}{|c|}{ RESULTANTE DE FORÇAS EM NÓS DE TESOURAS - AÇÕES PERMÁNENTES } \\
\hline \multirow[t]{2}{*}{ NÓ } & Força em $x$ & Força & Momento & \\
\hline & {$[\mathrm{daN}]$} & Ida & [daN.cm] & \\
\hline 1 & 0.00000 & -125.00000 & 0.00000 & \\
\hline 2 & 0.00000 & -250.00000 & 0.00000 & \\
\hline 3 & 0.00000 & -250.00000 & 0.00000 & \\
\hline 4 & 0.00000 & -250.00000 & 0.00000 & \\
\hline 5 & 0.00000 & -250.00000 & 0.00000 & \\
\hline 6 & 0.00000 & -250.00000 & 0.00000 & \\
\hline 7 & 0.00000 & -250.00000 & 0.00000 & \\
\hline 8 & 0.00000 & -250.00000 & 0.00000 & \\
\hline 9 & 0.00000 & -125.00000 & 0.00000 & \\
\hline 10 & 0.00000 & 0.00000 & 0.00000 & \\
\hline 11 & 0.00000 & 0.00000 & 0.00000 & \\
\hline 12 & 0.00000 & 0.00000 & 0.00000 & \\
\hline 13 & 0.00000 & 0.00000 & 0.00000 & \\
\hline 14 & 0.00000 & 0.00000 & 0.00000 & \\
\hline 15 & 0.00000 & 0.00000 & 0.00000 & \\
\hline \multirow[t]{2}{*}{16} & 0.00000 & 0.00000 & 0.00000 & \\
\hline & & $\checkmark \mathrm{OK}$ & & \\
\hline
\end{tabular}

Tela com valores de cargas em nós de tesouras 
Esforços em Barras de Tesoura :

São os valores de esforços normais, esforços de cortante máximo e esforços de momento máximo nas barras de tesoura, resultantes da análise matricial da estrutura solicitada às ações definidas, calculados no plano das tesouras. Devemos lembrar que em estruturas com todos os nós articulados, os esforços de cortante e momento são nulos nas barras de tesoura.

Além dos esforços internos das barras, são visualizadas características dimensionais das barras de tesoura (comprimento, área e índice de esbeltez mínimo).

\begin{tabular}{|c|c|c|c|c|c|c|c|}
\hline \multicolumn{6}{|c|}{ QESTRUTURA DE TELHADO EM MADEIRA } & \multicolumn{2}{|c|}{$-\square x$} \\
\hline \multicolumn{8}{|c|}{ Arquivo Imprimir Help } \\
\hline \multicolumn{8}{|c|}{ ESFORÇOS EM BARRASS DE TESOURAS - AÇŐES PERMANENTES } \\
\hline \multirow{2}{*}{ BARRA } & Comprimento & Area & Força normal & Força cortante & Momento & Lambda & $\Delta$ \\
\hline & {$[\mathrm{cm}]$} & {$[\mathrm{cm} 2]$} & {$[\mathrm{daN}]$} & {$[\mathrm{daN}]$} & [daN.cm] & & \\
\hline 1 & 134.63 & 60.00 & .2356 .01 & 0.00 & 0.00 & 93.27 & \\
\hline 2 & 134.63 & 60.00 & -2019.44 & 0.00 & 0.00 & 93.27 & \\
\hline 3 & 134.63 & 60.00 & -1682.86 & 0.00 & 0.00 & 93.27 & \\
\hline 4 & 134.63 & 60.00 & -1346.29 & 0.00 & 0.00 & 93.27 & \\
\hline 5 & 134.63 & 60.00 & -1346.29 & 0.00 & 0.00 & 93.27 & \\
\hline 6 & 134.63 & 60.00 & -1682.86 & 0.00 & 0.00 & 93.27 & \\
\hline 7 & 134.63 & 60.00 & .2019 .44 & 0.00 & 0.00 & 93.27 & \\
\hline 8 & 134.63 & 60.00 & .2356 .01 & 0.00 & 0.00 & 93.27 & \\
\hline 9 & 125.00 & 60.00 & 2187.50 & 0.00 & 0.00 & 86.60 & \\
\hline 10 & 125.00 & 60.00 & 2187.50 & 0.00 & 0.00 & 86.60 & \\
\hline 11 & 125.00 & 60.00 & 1875.00 & 0.00 & 0.00 & 86.60 & \\
\hline 12 & 125.00 & 60.00 & 1562.50 & 0.00 & 0.00 & 86.60 & \\
\hline 13 & 125.00 & 60.00 & 1562.50 & 0.00 & 0.00 & 86.60 & \\
\hline 14 & 125.00 & 60.00 & 1875.00 & 0.00 & 0.00 & 86.60 & \\
\hline 15 & 125.00 & 60.00 & 2187.50 & 0.00 & 0.00 & 86.60 & \\
\hline 16 & 125.00 & 60.00 & 2187.50 & 0.00 & 0.00 & 86.60 & \\
\hline \multirow[t]{2}{*}{17} & 50.00 & 50.00 & -0.00 & 0.00 & 0.00 & 34.64 & -1 \\
\hline & & & $\checkmark$ OK & $\Rightarrow$ & & & \\
\hline
\end{tabular}

Tela com valores de esforços em barras de tesouras 
Deslocamentos Nodais :

São os deslocamentos dos nós da estrutura resultante das deformações axiais de barras de tesouras. Não são consideradas as deformações resultantes da acomodação das ligações em nós de tesouras.

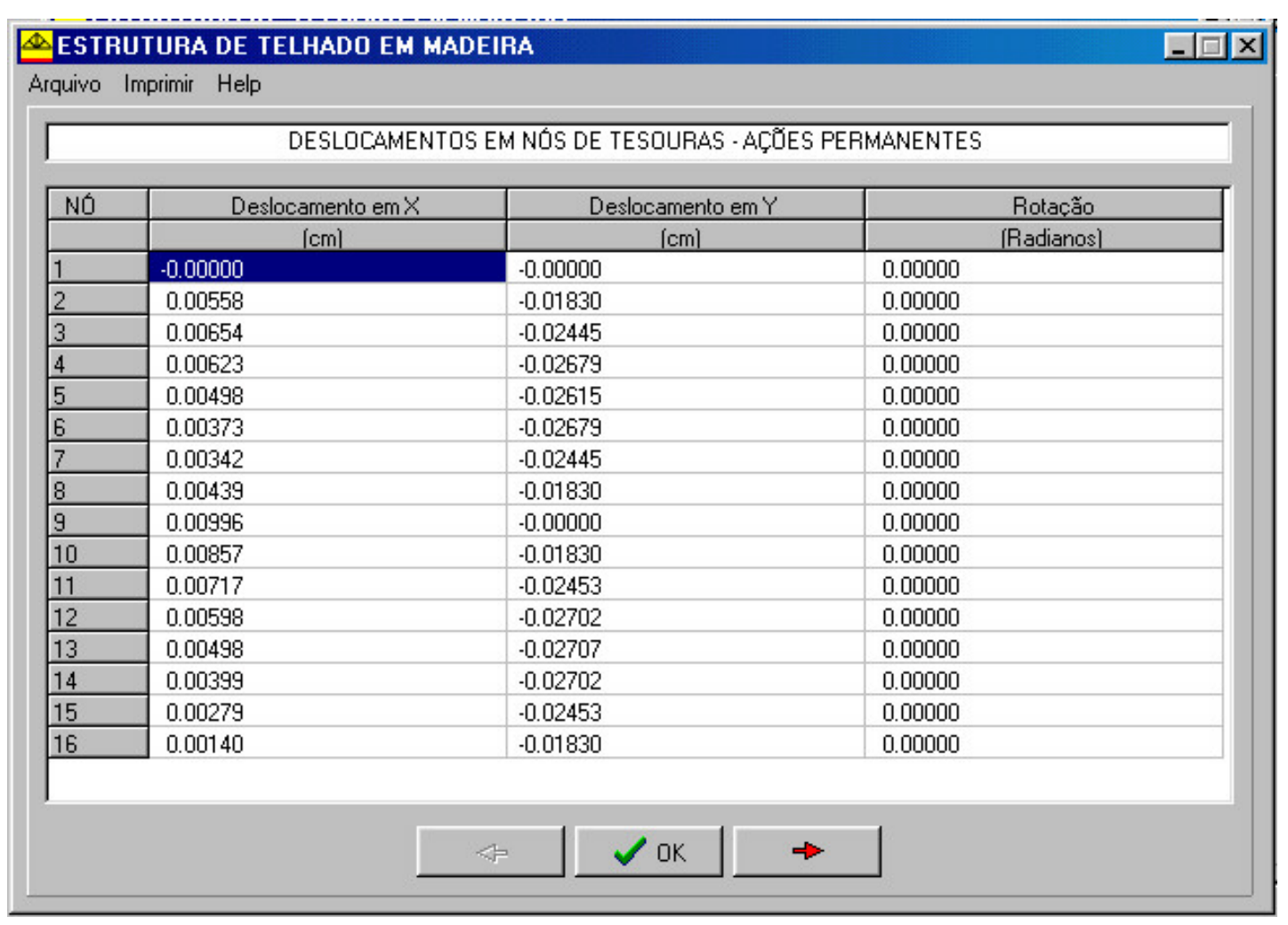

Tela com valores de deslocamentos em nós de tesouras 


\section{$\underline{\text { Reações de Apoio de Tesouras : }}$}

São as reações horizontais e verticais nos nós definidos como nós de apoio da estrutura. São valores resultantes das ações aplicadas à estrutura de acordo com o tipo de apoio definido.

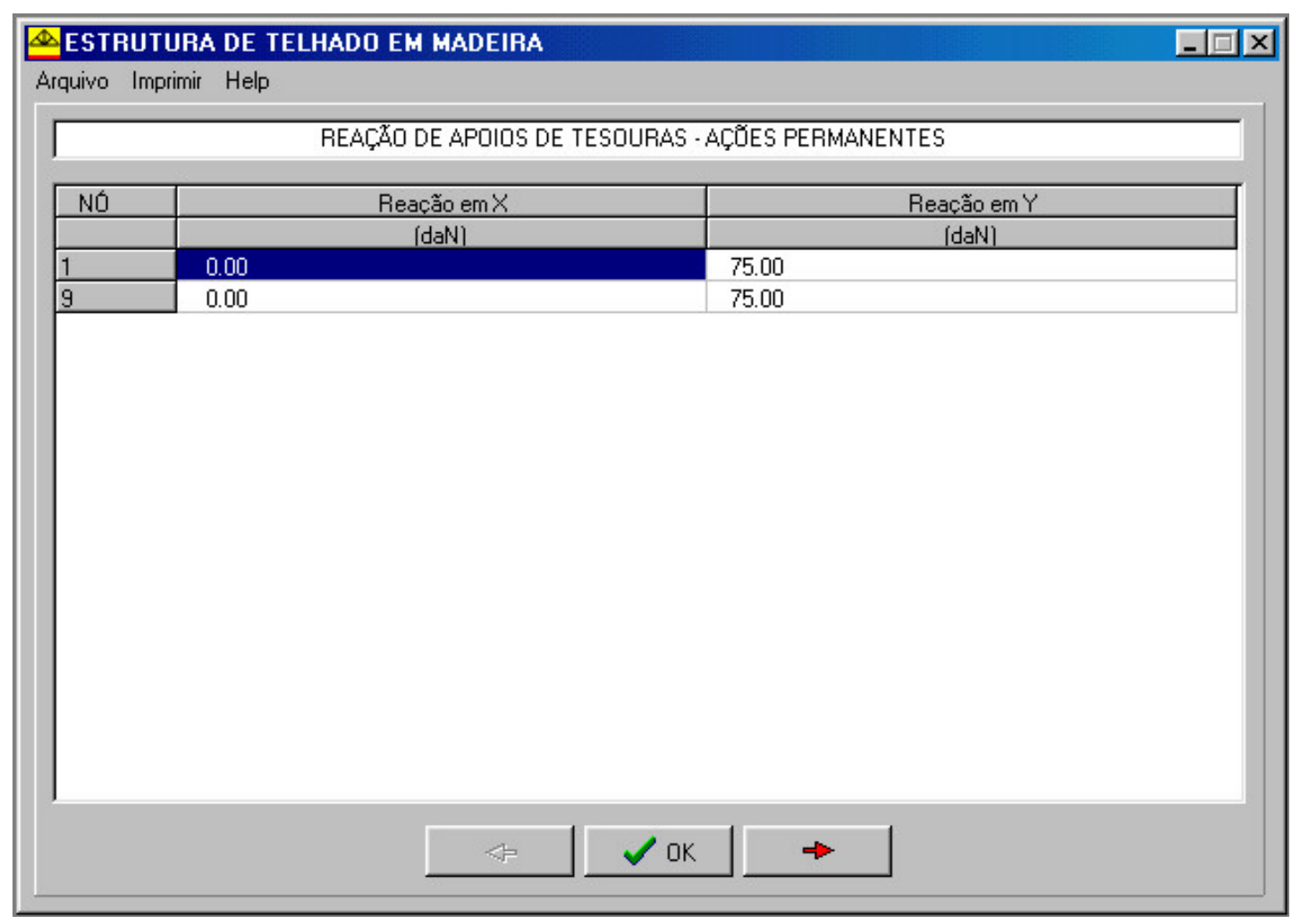

Tela com valores de reações em nós de apoio de tesouras 


\section{Esforços em Terças :}

São os esforços máximos de cortante e momento em relação aos dois eixos principais de terças submetidas a flexão oblíqua, resultantes da aplicação de ações distribuídas e uma sobrecarga de $1 \mathrm{KN}$ aplicada no meio do vão te terças.

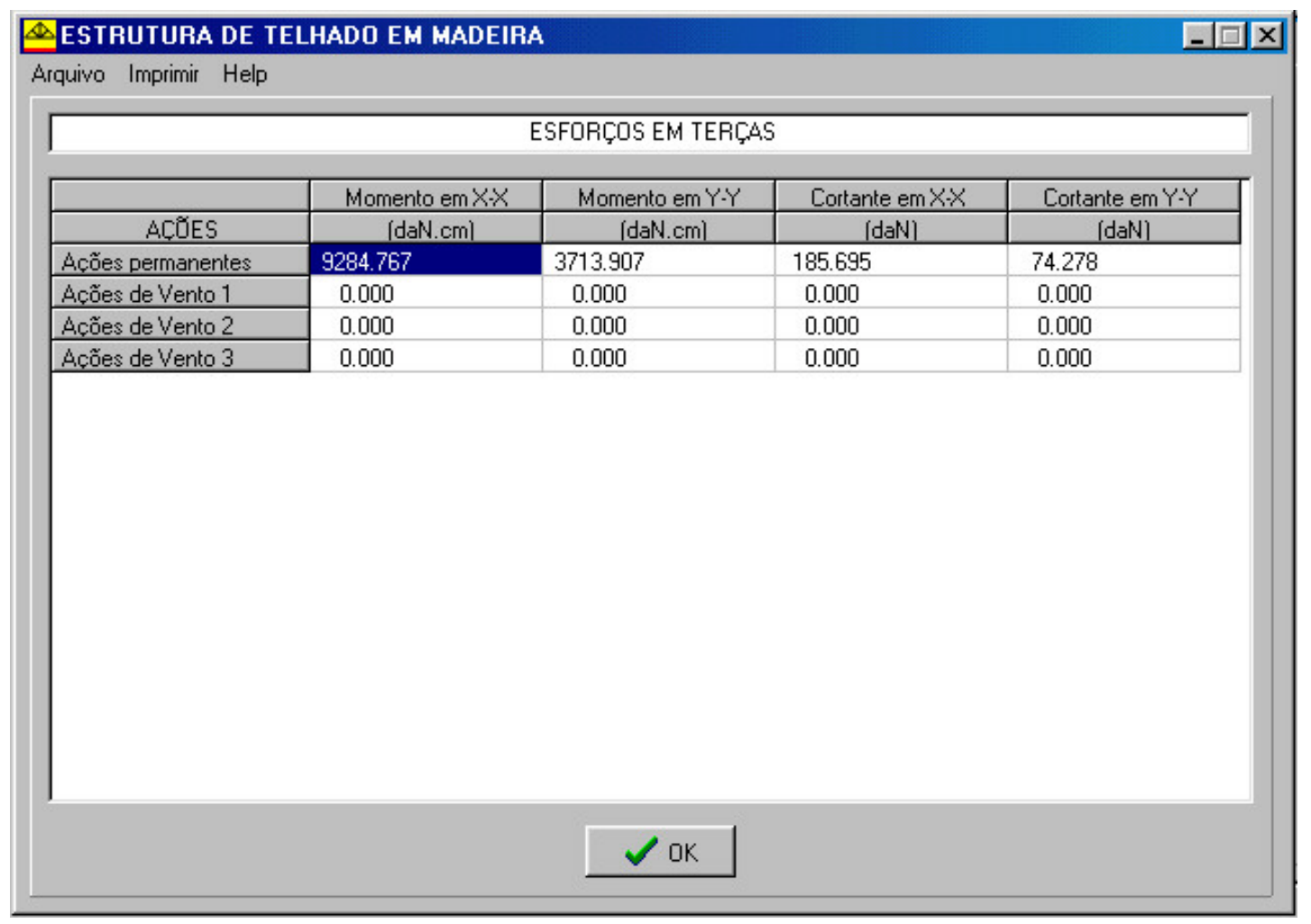

Tela com valores de esforços em terças 


\section{Esforços em Caibros :}

São os esforços máximos axiais, de cortante e momento em relação ao plano do eixo X-X de caibros submetidos a flexão composta, resultantes da aplicação de ações distribuídas.

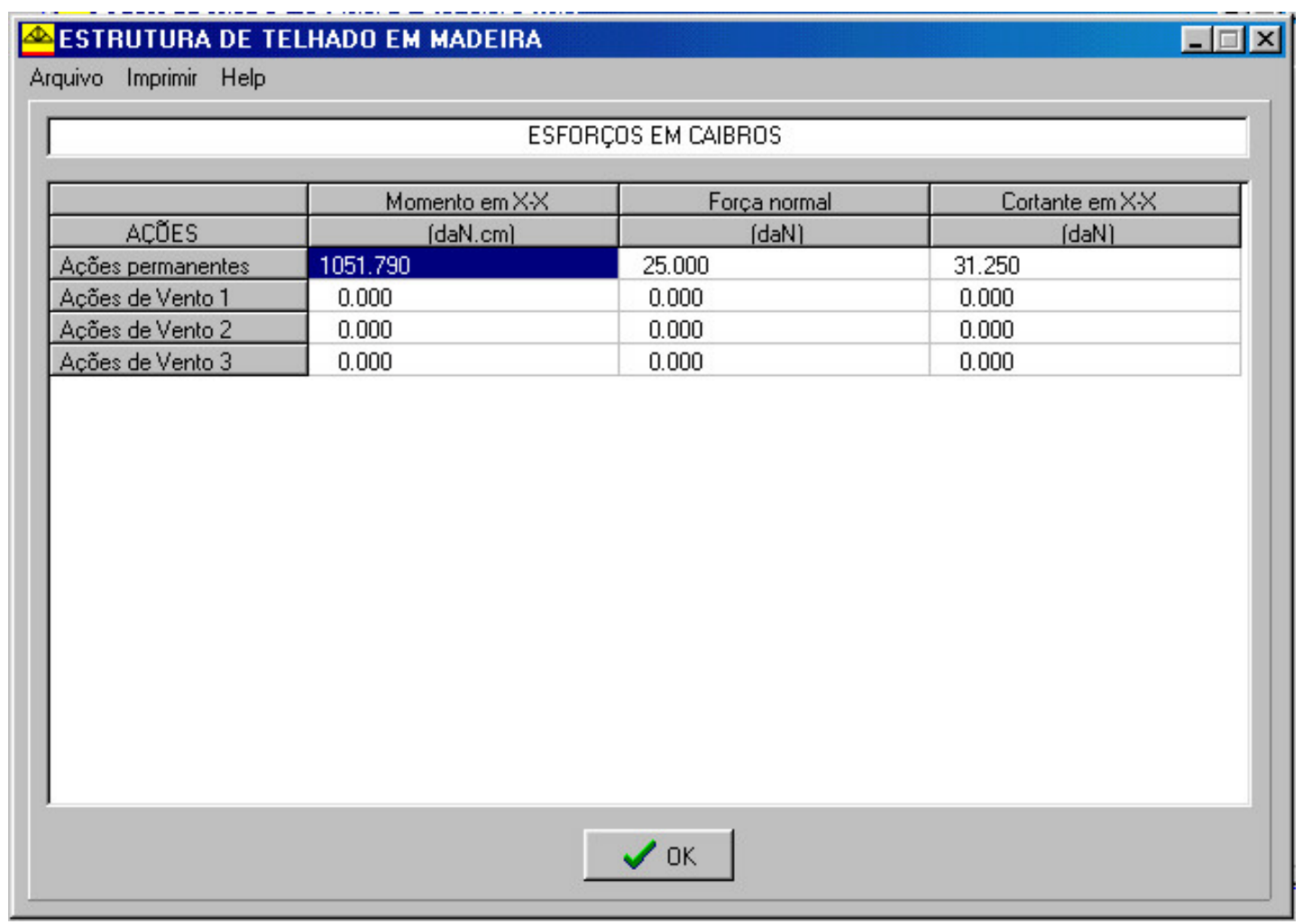

Tela com valores de esforços em caibros 


\section{VI - DIMENSIONAMENTO DOS ELEMENTOS DA ESTRUTURA}

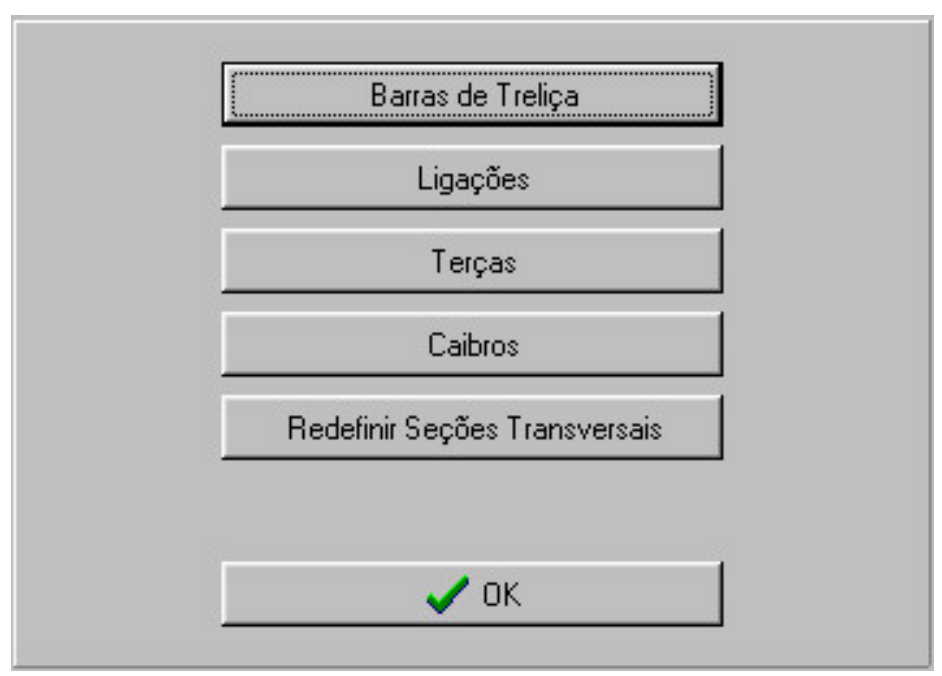

Tela para verificação dimensional da estrutura

Este software verifica as dimensões dos elementos da estrutura de acordo com as combinações das ações aplicadas. A combinação crítica de ações para cada verificação é obtida entre todas as combinações de ações possíveis, obedecendo os coeficientes e recomendações da NBR 7190/97.

A tela para verificação dimensional da estrutura permite a visualização de parâmetros de dimensionamento dos elementos da estrutura como segue : 


\section{Barras de Tesoura :}

Os critérios de verificação de barras de tesoura são ditados pela NBR 7190/97.

As barras de tesoura são verificadas de maneira distinta para os dois modelos de cálculo possíveis :

A - Tesoura com todos os nós articulados : Neste modelo de cálculo, as barras de tesoura são verificadas em relação às tensões normais (tração e compressão) :

B - Tesoura com banzos de barras contínuas : Neste modelo de cálculo, as barras de banzos são verificadas em relação às solicitações de flexão composta.

\begin{tabular}{|c|c|c|c|c|c|c|c|}
\hline \multicolumn{7}{|c|}{$\triangle E S T R U T U R A$ DE TELHADO EM MADEIRA } & \multirow[t]{2}{*}{$-\square \times$} \\
\hline Arquivo I & mprimir Help & & & & & & \\
\hline \multicolumn{8}{|c|}{ INDICES PARA VERIFICAÇZO DE BARRAS DA TESOURA - [Indice $<=1$ [OK)] - [Indice $>1$ [NROO OK)] } \\
\hline BARRA & Compressão & Tração & Cisalhamento & Estabilidade X & Estabilidade $Y$ & OBS & $\Delta$ \\
\hline 1 & 0.21 & 0.00 & 0.00 & 0.00 & 0.45 & OK & $\square$ \\
\hline 2 & 0.18 & 0.00 & 0.00 & 0.00 & 0.36 & OK & \\
\hline 3 & 0.15 & 0.00 & 0.00 & 0.00 & 0.29 & OK & \\
\hline 4 & 0.12 & 0.00 & 0.00 & 0.00 & 0.23 & OK & \\
\hline 5 & 0.12 & 0.00 & 0.00 & 0.00 & 0.23 & OK & \\
\hline 6 & 0.15 & 0.00 & 0.00 & 0.00 & 0.29 & OK & \\
\hline 7 & 0.18 & 0.00 & 0.00 & 0.00 & 0.36 & OK & \\
\hline 8 & 0.21 & 0.00 & 0.00 & 0.00 & 0.45 & OK & \\
\hline 9 & 0.00 & 0.20 & 0.00 & 0.00 & 0.00 & OK & \\
\hline 10 & 0.00 & 0.20 & 0.00 & 0.00 & 0.00 & OK & \\
\hline 11 & 0.00 & 0.17 & 0.00 & 0.00 & 0.00 & OK & \\
\hline 12 & 0.00 & 0.14 & 0.00 & 0.00 & 0.00 & OK & \\
\hline 13 & 0.00 & 0.14 & 0.00 & 0.00 & 0.00 & OK & \\
\hline 14 & 0.00 & 0.17 & 0.00 & 0.00 & 0.00 & OK & \\
\hline 15 & 0.00 & 0.20 & 0.00 & 0.00 & 0.00 & OK & \\
\hline 16 & 0.00 & 0.20 & 0.00 & 0.00 & 0.00 & OK & \\
\hline 17 & 0.00 & 0.00 & 0.00 & 0.00 & 0.00 & OK & \\
\hline 18 & 0.00 & 0.01 & 0.00 & 0.00 & 0.00 & $\begin{array}{l}\text { OK } \\
-. .\end{array}$ & $\nabla$ \\
\hline & & & $\checkmark 0$ & & & & \\
\hline
\end{tabular}

Tela com índices de verificação dimensional em barras de tesouras

\section{Ligações :}

Este software considera as ligações entre elementos da estrutura principal através de conectores metálicos de dentes estampados (CDE), previstas pela NBR 7190/97, por serem estes os mais adequados ao processo de industrialização de estruturas de cobertura. De acordo com as hipóteses de cálculo dos elementos da tesoura, as extremidades de diagonais e montantes, os encontros entre banzos e os pontos de mudança de inclinação de banzos da tesoura são considerados como perfeitamente articulados. Os esforços nas ligações entre 
elementos da estrutura principal são, portanto, resultado dos esforços axiais das barras que convergem a um determinado nó, considerados segundo o ângulo de incidência das barras. $\mathrm{O}$ modelo de cálculo de ligações entre elementos da estrutura principal adotado neste sistema não considera momentos fletores em barras de tesoura que resultam de elementos de ligação. Da mesma forma, nas emendas de barras dos banzos da estrutura principal, são considerados somente os esforços axiais. Neste caso, as emendas são posicionadas em pontos de momentos fletores nulos nas barras dos banzos da estrutura.

As condições de segurança em ligações por conectores metálicos com dentes estampados CDE não têm critérios de verificação fornecidos pela norma, sendo neste trabalho verificadas pelo procedimento proposto por BARALDI (1998).

Este software calcula os valores mínimos efetivos (sem a redução na área líquida das extremidades das chapas e bordas de barras de madeira) de comprimento em $\mathrm{x}$, y e área de conector para as solicitações de tração, compressão, cisalhamento e arrancamento de dentes da ligação.

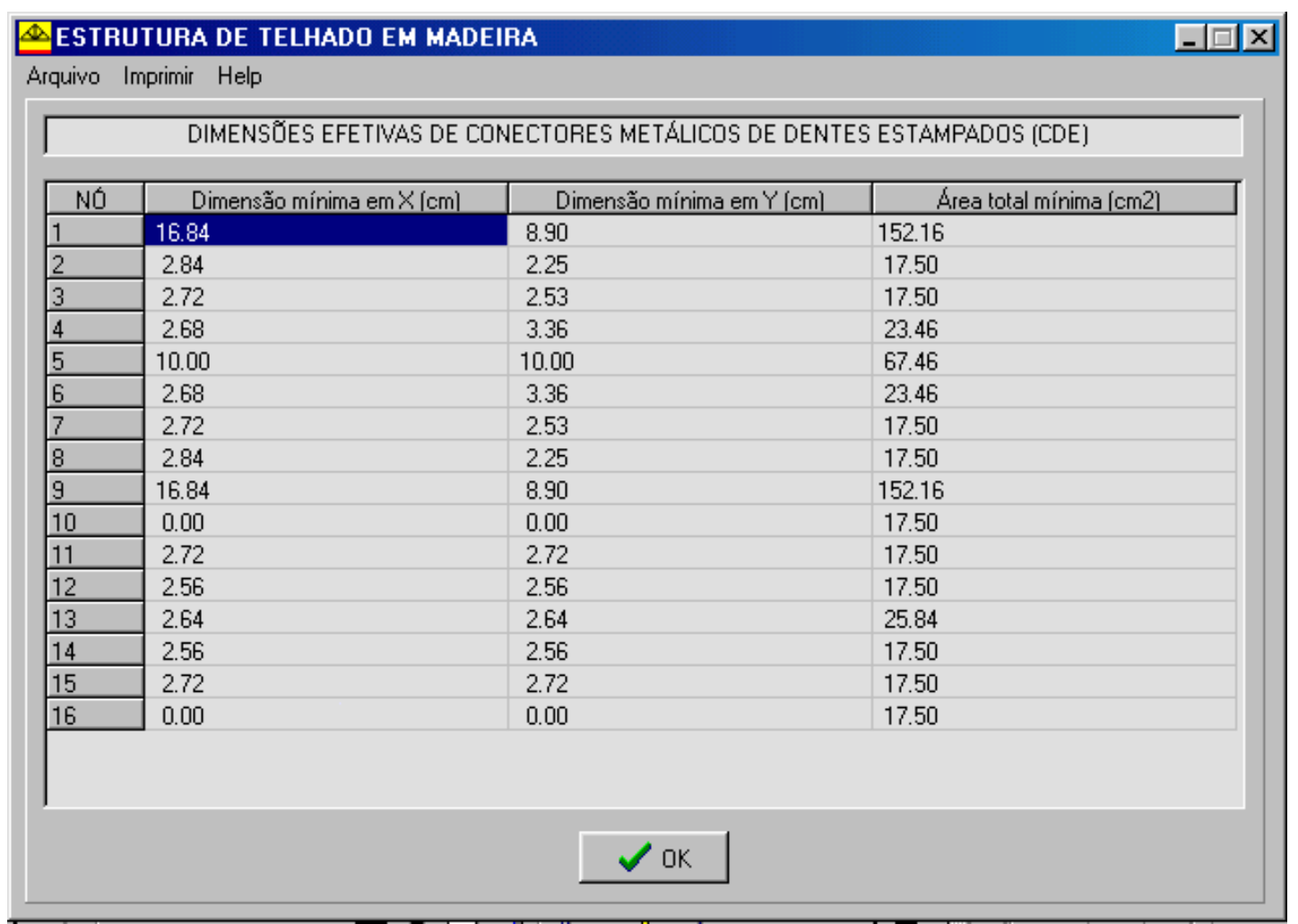

Tela com dimensões mínimas efetivas de conectores CDE 


\section{Terças:}

Este software opera com terças de seção transversal retangular, que pela inclinação da estrutura principal onde se apoiam, são submetidas, no caso geral, a flexão oblíqua. As dimensões de terças são verificadas em relação às condições de segurança para estado limite último e estado limite de utilização em flexão oblíqua.

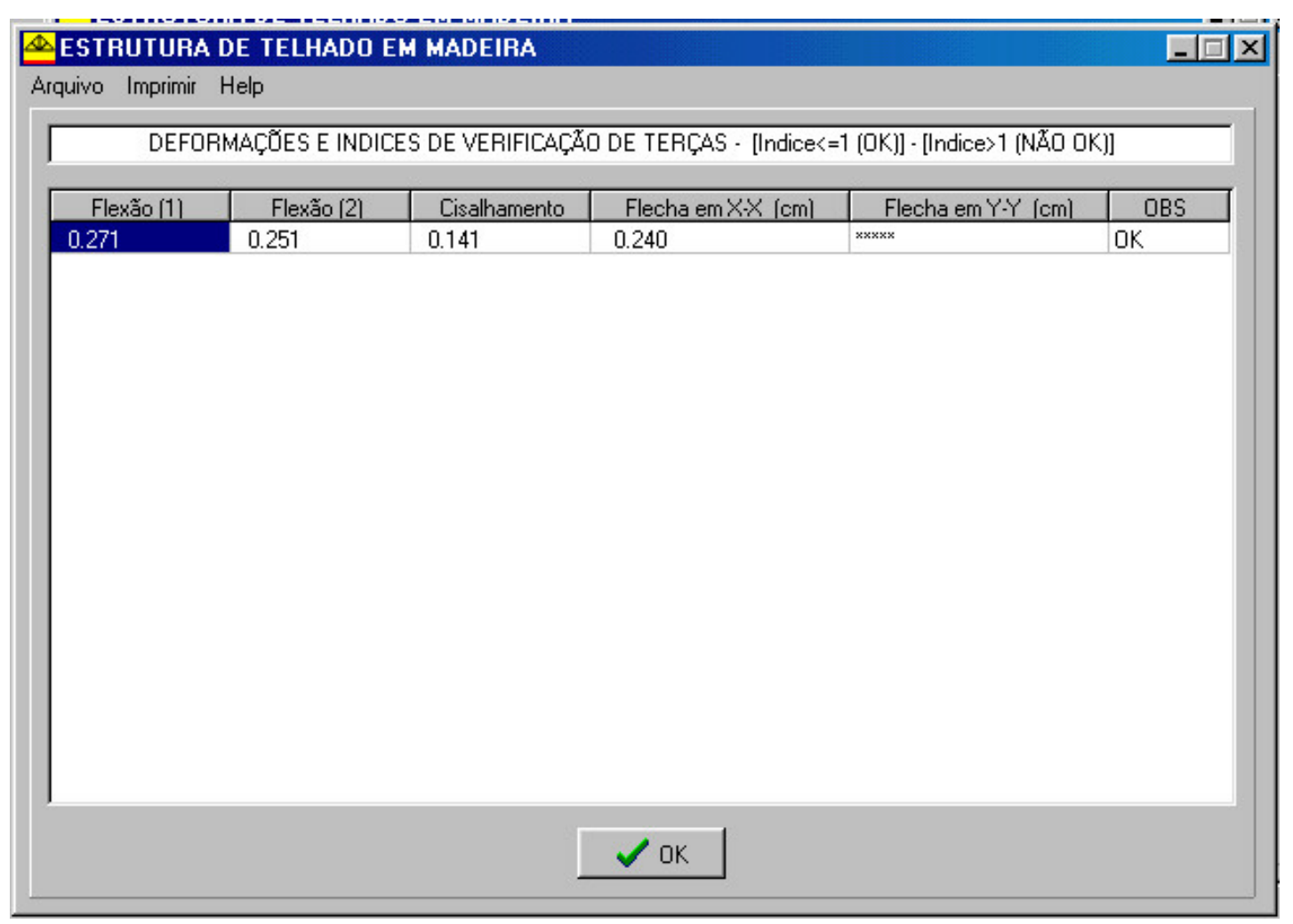

Tela com índices de verificação dimensional e flechas em terças 


\section{Caibros:}

Este software opera com caibros de seção transversal retangular, que pela inclinação do telhado, são submetidas, no caso geral, a flexão composta. As dimensões de caibros são verificadas em relação às condições de segurança para estado limite último e estado limite de utilização em flexão composta.

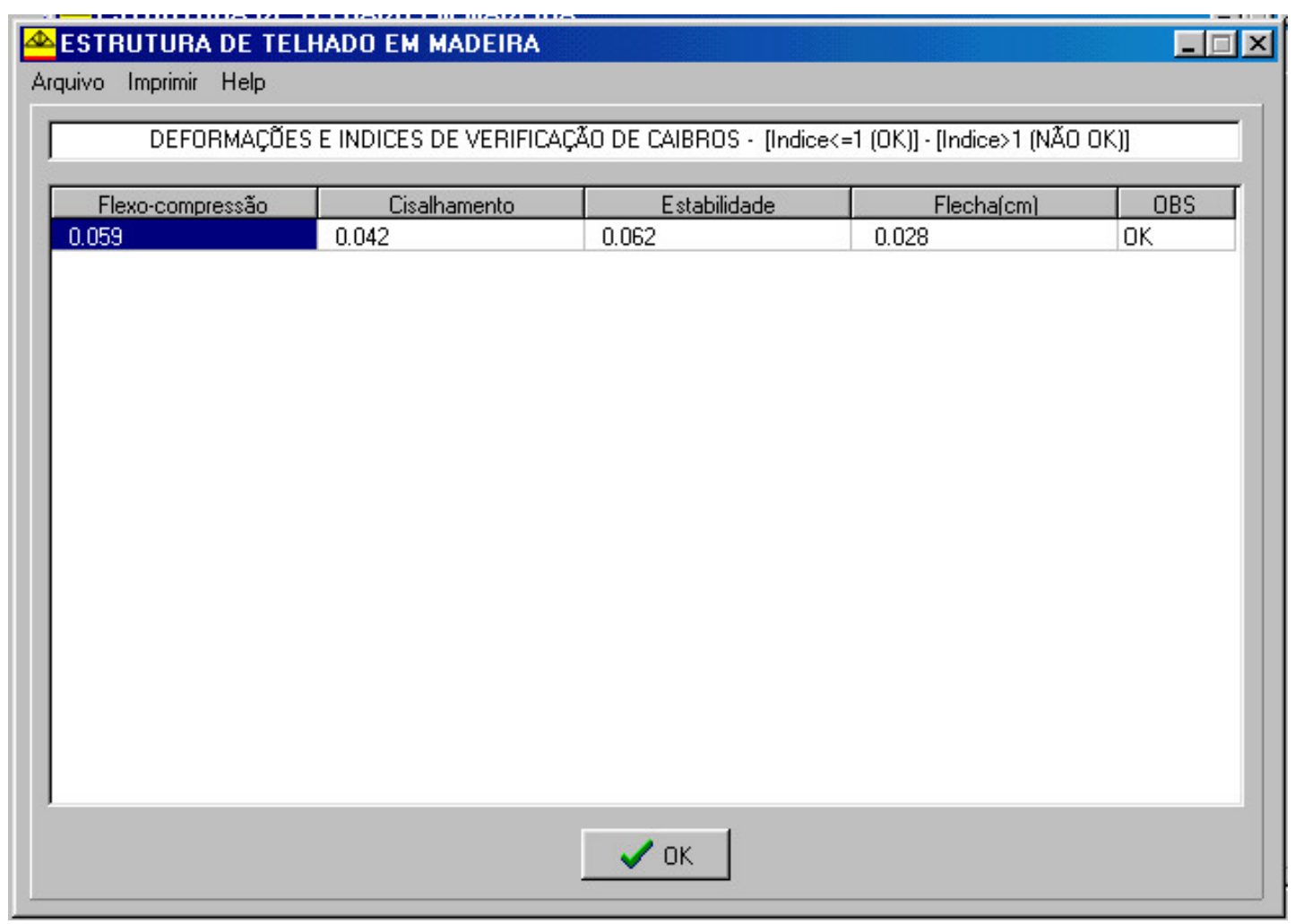

Tela com índices de verificação dimensional e flechas em caibros 
ANEXO B - CÓDIGOS FONTE

O código fonte do software "MADEPRO" desenvolvido neste trabalho é disponibilizado em forma de arquivos de código criados pelo aplicativo "BORLAND DELPHI 3", armazenados por meio magnético (disco flexível 3,5").

Todos os arquivos disponibilizados trazem no seu conteúdo os termos da "GNU GENERAL PUBLIC LICENSE Version 2, June 1991", órgão que regulamenta a veiculação de softwares de livre distribuição. 


\section{ANEXO C - SOFTWARE "MADEPRO" INSTALÁVEL}

O software "MADEPRO" desenvolvido neste trabalho é disponibilizado em forma de discos magnéticos para instalação em micro computadores padrão IBM PC. As instruções e configurações básicas para a instalação do MADEPRO são descritas durante a execução do aplicativo de instalação (SETUP.EXE).

Como nos códigos fonte, este aplicativo traz no seu conteúdo os termos da "GNU GENERAL PUBLIC LICENSE Version 2, June 1991", órgão que regulamenta a veiculação de softwares de livre distribuição. 


\section{REFERÊNCIAS BIBLIOGRÁFICAS}

ASSOCIAÇÃO BRASILEIRA DE NORMAS TÉCNICAS (1984). NBR 8691 Ações e Segurança nas Estruturas. Rio de Janeiro.

ASSOCIAÇÃO BRASILEIRA DE NORMAS TÉCNICAS (1982). NBR 7190 - Cálculo e Execução de Estruturas de madeira. Rio de Janeiro.

ASSOCIAÇÃO BRASILEIRA DE NORMAS TÉCNICAS (1997). NBR 7190 - Projeto de Estruturas de Madeira. Rio de Janeiro.

ASSOCIAÇÃO BRASILEIRA DE NORMAS TÉCNICAS (1988). NBR 6123 - Forças Devidas ao Vento em Edificações. Rio de Janeiro.

AUTODESK (1993). AutoCad-Reference Manual. Autodesk, Oakland.

AUTODESK (1993). AutoLisp - Reference Manual. Autodesk, Oakland.

BARALDI, L.T. (1998). Critérios de Dimensionamento para Treliças Executadas com Chapas Dentadas de Dentes Estampados. In: ENCONTRO BRASILEIRO EM MADEIRAS E EM ESTRUTURAS DE MADEIRA, VI, Florianópolis, 1998. Anais. Florianópolis. v.2, p.101-112.

BARROS O.J. (1991). Algumas Considerações sobre a Pré-Fabricação das Estruturas de Madeira para Coberturas. São Carlos, USP-EESC-SET-LaMEM .

CALIL C.J. (1996). Treliças de Madeira para Coberturas - Notas de Aula - SET 406 Estruturas de Madeira. São Carlos, Serviço Gráfico EESC USP. 
CALIL C.J. et. al. (1998) - Estruturas de Madeira - Notas de Aula - SET 406 - Estruturas de Madeira. São Carlos, Serviço Gráfico EESC USP.

CANTU, M. (1966). Dominando o Delphi 2. São Paulo, Makron Brooks.

FUSCO P.B. (1995). A Calibração da Nova Norma de Projeto de Estruturas de Madeira. In: ENCONTRO BRASILEIRO EM MADEIRAS E EM ESTRUTURAS DE MADEIRA, V, Belo Horizonte, 1995. Anais. Belo Horizonte. v.2, p.247-264.

FUSCO P.B. (1995). A mudança do Modelo de Segurança nas Normas de Projeto de Estruturas. In: ENCONTRO BRASILEIRO EM MADEIRAS E EM ESTRUTURAS DE MADEIRA, V, Belo Horizonte, 1995. Anais. Belo Horizonte. v.2, p.265-270.

GANE, C. (1983). Análise Estruturada de Sistemas. Rio de janeiro, LTC- Livros Técnicos e Científicos Editora S.A.

GESUALDO F.A.R.;GRECO M. (1998) - Avaliação de Esforços de Flexão em Estruturas do tipo treliçado. In: ENCONTRO BRASILEIRO EM MADEIRAS E EM ESTRUTURAS DE MADEIRA, VI, Florianópolis, 1998. Anais. Florianópolis. v.2, p.93-100.

HUMES, A.F.P. de C. et al. (1984). Noções de Cálculo Numérico. São Paulo, McGraw-Hill do Brasil.

LAHR, F.A.R. (1983). Aspecto Histórico do Emprego de Estruturas de Madeira para Coberturas. In: ENCONTRO BRASILEIRO EM MADEIRAS E EM ESTRUTURAS DE MADEIRA, I, São Carlos, 1983. Anais. São Carlos. v. Telhados, Art.039.

MOLITERnO,A (1981). Caderno de Projetos de Telhados em Estruturas de Madeira. São Paulo, Editora Edgard Blucher Ltda.

MOREIRA, Domício Falcão (1977). Análise Matricial de Estruturas. São Paulo, EDUSP. OZELTON, E.C \& BAIRD, J.A. (1976). Timber Designers Manual. London, Crosby Lockwood Staples.

PARCEL, J.I. \& MOORMAN, R.B.B. (1955). Analisys of Statically Indeterminated Structures. New York, John Wiley \& Sons. 
PARTEL, H. (1988). Automatização do Cálculo Estrutural para Industrialização de Estruturas Treliçadas de Madeira. São Carlos. Relatórios de Iniciação Científica n ${ }^{\circ} 1,2$ e 3. LaMEM - EESC - USP.

SOUZA, J.C.A.O. ; ANTUNES, H.M.C.C. (1995). Introdução à Análise Matricial de Estruturas, 2.ed. São Carlos, Serviço Gráfico EESC USP.

TIMOSHENKO, S. \& YOUNG D.H. (1957). Teoria das Estruturas. Rio de Janeiro, Ao Livro Técnico. Trad. Antonio A Noronha.

YOURDON, E. (1992). Análise Estruturada Moderna. Rio de Janeiro, Editora Campos

WAGNER, S. L. (1996). Delphi 2 em Exemplos. São Paulo, Makron Brooks.

WANG, C.K. (1953). Statically Indeterminated Structures. New York, McGraw-Hill Book. 